\title{
SEISMIC REFRACTION AND ELECTRICAL RESISTIVITY TESTS FOR FRACTURE INDUCED ANISOTROPY IN A MOUNTAIN WATERSHED
}

by

Aída Mendieta

\author{
A thesis \\ submitted in partial fulfillment \\ of the requirements for the degree of \\ Master of Science in Geophysics \\ Boise State University
}

December 2017 
(C) 2017

Aída Mendieta

ALL RIGHTS RESERVED 


\title{
DEFENSE COMMITTEE AND FINAL READING APPROVALS
}

\author{
of the thesis submitted by
}

Aída Mendieta

Thesis Title: Seismic Refraction and Electrical Resistivity Tests for Fracture Induced Anisotropy in a Mountain Watershed

Date of Final Oral Examination: 27 October 2017

The following individuals read and discussed the thesis submitted by student Aída Mendieta, and they evaluated her presentation and response to questions during the final oral examination. They found that the student passed the final oral examination.

John Bradford, Ph.D. Chair, Supervisory Committee

Lee M. Liberty, M.S. Member, Supervisory Committee

James P. McNamara, Ph.D. Member, Supervisory Committee

The final reading approval of the thesis was granted by John Bradford, Ph.D., Chair of the Supervisory Committee. The thesis was approved by the Graduate College. 


\section{DEDICATION}

This thesis is dedicated to my nephews: Gabriel and Julio Mendieta. 


\section{ACKNOWLEDGEMENTS}

As usual, it is impossible to thank everyone who has helped even in the littlest of bits in the completion of this thesis, but I'll try! Beginning with my advisor John Bradford, for all the never ending patience, and continued guidance to help me become a better researcher. Lee Liberty and Jim McNamara for guiding me through this research, and allowing me to ask questions whenever. For the mentoring received from Travis Nielson and Pamela Aishlin, your help was invaluable for this research. I also want to thank Professor Dylan Mikesell for teaching me how to use PRONTO.

Every single person who helped me with the data collection: Travis Nielson, Lucy Gelb, Andy Karlson, Andrew Poley, Joel Góngora, Diego Domenzain, Rebekah Lee, Marlon Ramos, Zongbo Xu, Tom Harper, Hamid Dashti, Nayani Ilangakoon, Becca Garst, Tate Meehan, Andrew Gaze, Tom Van Der Weide, Binbin Mi, Chao Shen, Thomas Otheim, Hugo Ortiz, Nicole Clizzie, James Ford, and Dominic Filiano.

For all the moral support from friends back home: Irving, William, Miguel, and Débora. For all the support given to me by my aunts and uncles, specially: Margarita Carías, Aurelia Poulsen, Francisco Mendieta, and Aída Mendieta. For all the moral support received from home, by my mother, sisters, and nephews: Lorena Tenorio, Aleja Mendieta, Natalia Mendieta, Julio Mendieta and Gabriel Mendieta.

I am grateful for the funding given to me by Fulbright and the Geological Society of America, allowing me to do this research. 


\begin{abstract}
The critical zone $(\mathrm{CZ})$ is the earth's layer where water, air, rock, and life meet. It is the zone with which humans interact most. The National Research council (2001) defines the $\mathrm{CZ}$ as a "heterogeneous, near surface environment in which complex interactions involving rock, soil, water, air, and living organisms regulate the natural habitat and determine the availability of life sustaining resources". The CZ may extend roughly from the top of the vegetation canopy to the deepest part of the rock column where meteoric water circulates - this is often in the $10-30 \mathrm{~m}$ range. The upper $1-2 \mathrm{~m}$ of the $\mathrm{CZ}$, the most weathered portion of the $\mathrm{CZ}$ depth profile, can be reached via soil pits or cores enabling detailed characterization. Weathering is the process in which a parent rock decays into mobile soil, through mechanical breakdown and chemical weakening. The maximum depth at which both, mechanical and chemical processes are present is referred to as weathering depth. Below $2 \mathrm{~m}$, characterizing the $\mathrm{CZ}$ is a challenge because of the expense and logistical challenge of drilling boreholes, particularly in rugged, mountainous terrain. Geophysical methods are increasingly being used to probe deeper into the $\mathrm{CZ}$ and have proven to be a powerful tool. Fully characterizing the deep $\mathrm{CZ}$ is made even more challenging when fractures are present. Fractures may have a preferential orientation according to the local stress field which leads to both geophysical and hydraulic anisotropy. Because fractures can be hydraulically active, understanding fracture induced anisotropy retrieves information on the preferential distribution of water
\end{abstract}


pathways in the subsurface. To test our ability to detect and characterize systems of deep CZ fractures with preferred orientation in a mountain watershed, I conducted a series of multi-azimuthal 2D electrical resistivity tomography and 2D seismic refraction surveys. I utilized the Dry Creek Experimental Watershed (DCEW) as a field laboratory - a previous outcrop study mapped fracture orientations throughout the watershed. I collected data, at three different sites, near or within the DCEW. For the anisotropy and fracture density case, I estimated fracture density as a function of depth at all sites, and determine that the depth at which most fractures close ranges from 13-27 m depth. I found significant P-wave anisotropy throughout the watershed with maximum values of $28 \%$. Additionally, my results indicate that anisotropy continues to much greater depths. I infer that the observed geophysical anisotropy likely correlates with significant hydraulic anisotropy and has an important impact on deep water circulation in the DCEW. Additionally, I show that attempts to characterize this system with single azimuth data and an assumption of isotropy will lead to erroneous results - at my sites the error in estimated fracture density could be as high as 0.24 . I conclude that geophysical investigations in similar terrains need to test for anisotropy and use appropriate models, particularly if the objective is quantitative estimation of hydraulic or other physical properties. General observations of the $\mathrm{CZ}$ were that weathering depth increased with decreasing elevations - this has been observed at other sites and is likely due to increased chemical reactivity at higher temperatures. At the low elevation site I observe a depth to bedrock at approximately $29 \mathrm{~m}$ depth, at the mid-elevation site I observe a depth to bedrock of approximately $23 \mathrm{~m}$ depth, at the high elevation site, I observe a depth to bedrock as little $5 \mathrm{~m}$ depth. I observed a significant increase in weathering depth on 
northwest facing aspects and speculate that this is a combination of lower evaporation rates, slow steady delivery of snow melt waters into the subsurface and the positive feedback of increased vegetation and root enhanced weathering. 


\section{TABLE OF CONTENTS}

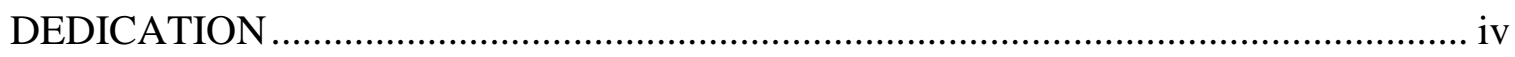

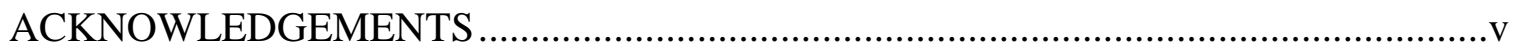

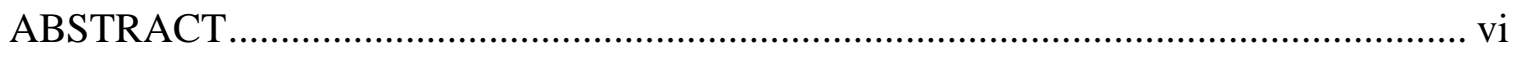

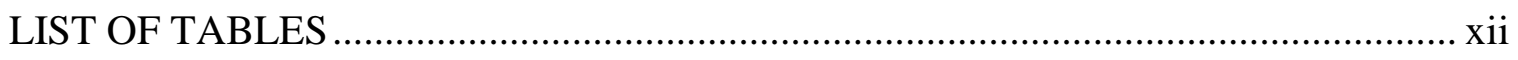

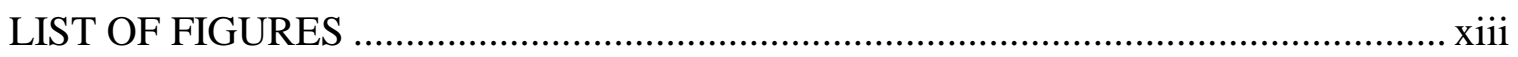

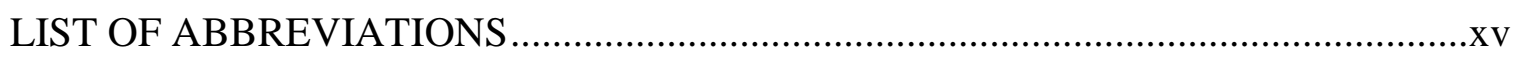

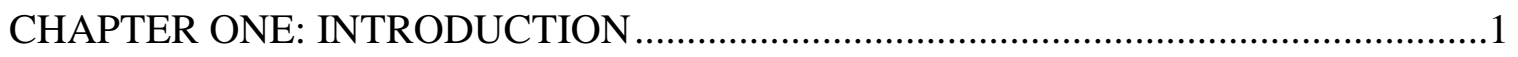

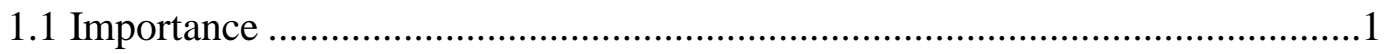

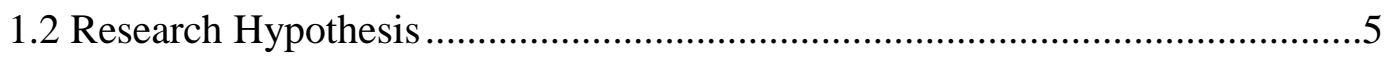

1.3 Description of research sites .................................................................6

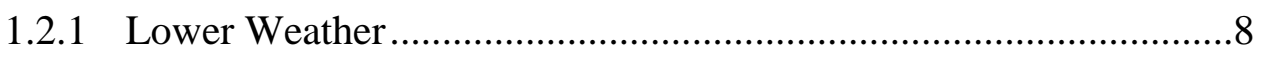

1.2.2 Treeline

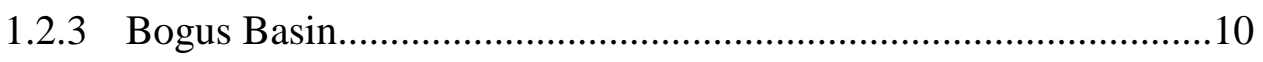

1.4 Development of research .........................................................................10

CHAPTER TWO: SEISMIC REFRACTION ……………........................................12

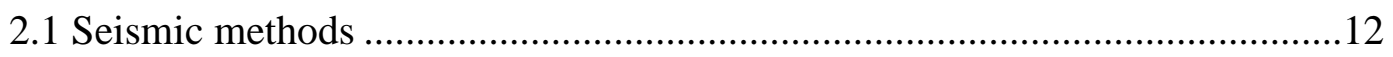

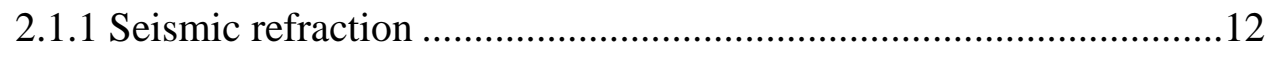

2.1.2 Seismic anisotropy ...................................................................... 12

2.1.3 Fracture density calculation ...........................................................16 
2.1.4 Data collection

2.1.5 Data processing ..........................................................................19

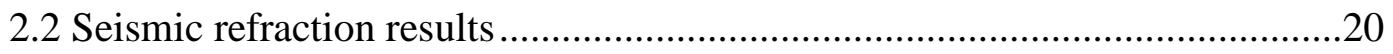

2.2.1 Lower Weather results ..................................................................20

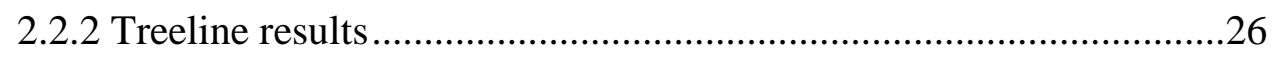

2.2.3 Bogus Basin results.......................................................................

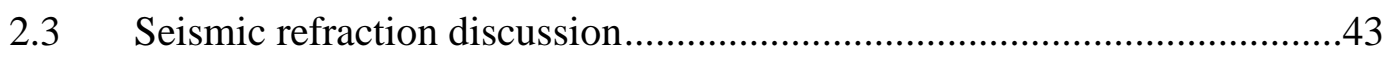

2.4 Seismic refraction conclusions ………………….....................................50

CHAPTER THREE: ELECTRICAL RESISTIVITY TOMOGRAPHY ……..................52

3.1 Electrical resistivity methods ..................................................................52

3.1.1 Electrical resistivity tomography ………………..........................52

3.1.2 Electrical anisotropy ………………………………..................52

3.1.3 Electrical resistivity data collection .................................................53

3.1.4 Electrical resistivity data processing ...............................................55

3.2 Electrical resistivity results ..................................................................56

3.2.1 Lower Weather results ................................................................56

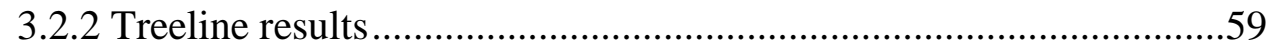

3.3 Electrical resistivity discussion................................................................63

3.4 Electrical resistivity conclusions................................................................63

CHAPTER FOUR: WEATHERING DEPTH .........................................................64

4.1 Weathering depth results..............................................................................64

4.1.1 Weathering depth as a function of elevation.......................................64

4.1.2 Weathering depth per aspect per site ……………………...............65 


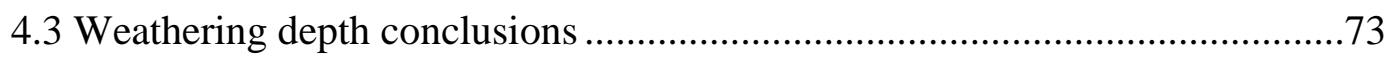

CHAPTER FIVE: CONCLUSIONS AND RECOMMENDATIONS ..........................74

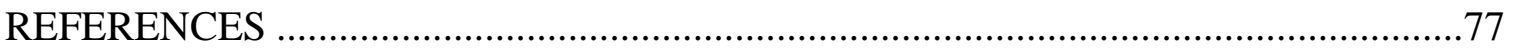

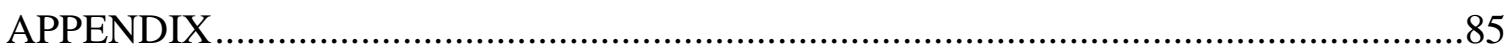




\section{LIST OF TABLES}

Table 1: Correlation between granite weathering states and geophysical parameters.......21

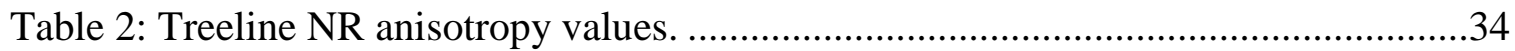

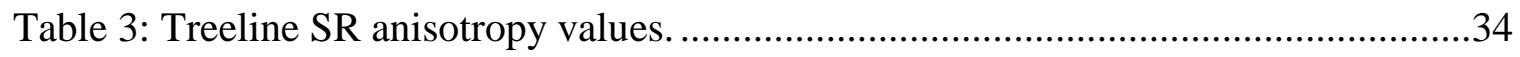

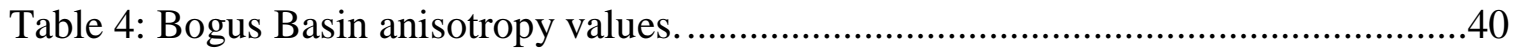

Table 5: Mean depth to bedrock at the Treeline site.....................................................64

Table 6: Mean depth to bedrock at the Bogus Basin site............................................65

Table 7: Weathering layer thicknesses for the Lower weather site.............................66

Table 8: Weathering layer thicknesses for the NR at Treeline. ..................................67

Table 9: Weathering layer thicknesses for the SR at Treeline.....................................68 


\section{LIST OF FIGURES}

Figure 1: $\mathrm{CZ}$ conveyor belt. Different weathering layers within the $\mathrm{CZ}$..........................2

Figure 2: NE-SW transects collected in Treeline, for both Seimics and ERT....................5

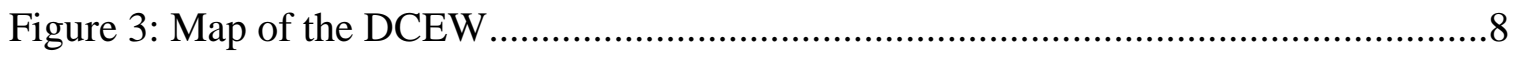

Figure 4: Different types of anisotropy present in the subsurface ................................14

Figure 5: Map of seismic data collection at Lower Weather .......................................17

Figure 6: Map of seismic data collection at Treeline ...................................................18

Figure 7: Map of seismic data collection at Bogus Basin...........................................19

Figure 8: Seismic tomography for Lower Weather.. ...............................................21

Figure 9: Cartoon of lithology near Lower .............................................................22

Figure 10: Fracture density and mean Vp plot at depth, for the Lower Weather.............24

Figure 11: Modelled Vp and mean Vp for each direction at Lower Weather. ................25

Figure 12: Seismic tomography for the NR at Treeline.............................................27

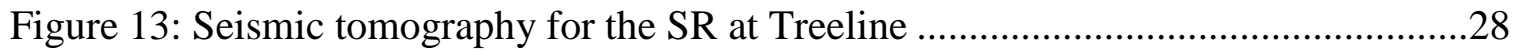

Figure 14: Fracture density and mean Vp plot at depth, for Treeline's NR ....................30

Figure 15: Modelled Vp and mean Vp for each direction at Treeline ...........................31

Figure 16: Fracture density and mean Vp plot at depth, for Treelines SR ......................32

Figure 17: Seismic tomography for the Bogus Basin borehole ....................................36

Figure 18: Seismic tomography for the Bogus Basin surface seismic refraction

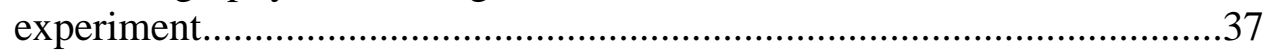

Figure 19: Fracture density and mean Vp plot at depth, for Bogus Basin.......................39 
Figure 20: Traveltimes for the Bogus Basin reverse VSP dataset

Figure 21: Modelled Vp and mean Vp for each direction at Bogus Basin .42

Figure 22: Fracture orientations and geophone locations at Bogus Basin. .42

Figure 23: Fracture density calculations (random vs. azimuthal anisotropy) .46

Figure 24: Histograms of fracture lineament azimuth, for the DCEW and Treeline .48

Figure 25: Map of ERT data collection at the Lower Weather site .54

Figure 26: Map of ER data collection at Treeline......................................................55

Figure 27: Electrical resistivity tomography for the Lower weather site .........................56

Figure 28: Average ER at depth with error bars, at Lower Weather ..............................58

Figure 29: Best fitted ellipse and mean ER, for each direction at Lower Weather. ..........59

Figure 30: Electrical resistivity tomography for Treeline........................................60

Figure 31: Average ER at depth with error bars, at Treeline.......................................61

Figure 32: Best fitted ellipses and mean ER, for each direction at Treeline ...................62

Figure 33: Zoom into forested area at Treeline. ...................................................69

Figure 34: Depth to bedrock and saprolite thickness as a function of elevation. ..............72

Figure 35: Observed apparent, calculated and inverted ER sections for Lower Weather .86

Figure 36: Example of shot-gather and first break picks for Lower Weather .................87

Figure 37: Observed apparent, calculated and inverted ER sections for Treeline............88

Figure 38: Example of shot-gather and first break picks for Treeline..........................89

Figure 39: Example of shot-gather and first break picks for L4, at Bogus Basin.............90 


\section{LIST OF ABBREVIATIONS}

$\begin{array}{ll}\text { CZ } & \text { Critical Zone } \\ \text { DCEW } & \text { Dry Creek Experimental Watershed } \\ \text { ER } & \text { Electrical resistivity } \\ \text { ERT } & \text { Electrical Resistivity Tomography } \\ \text { MASL } & \text { Meters Above Sea Level } \\ \text { NR } & \text { North Ridge } \\ \text { SR } & \text { South Ridge } \\ \text { Vp } & \text { Primary wave velocity } \\ \text { VSP } & \text { Vertical Seismic Profile } \\ \text { WET } & \text { Wavepath eikonal traveltime }\end{array}$




\section{CHAPTER ONE: INTRODUCTION}

\subsection{Importance}

The Critical zone $(\mathrm{CZ})$ can be defined as the portion of earth that extends from the top of trees to a depth that is no longer affected by meteoric fluids (Befus et al., 2011; Riebe et al., 2016). Delineating the upper part of the $\mathrm{CZ}$ is easy, but characterizing the lower part is still a challenge. The top of the trees can be easily identified with the human eye, but the bottom of the CZ lies deep within the subsurface (>10 m depth), and boreholes or geophysical methods are needed to delineate it.

The CZ community is multi-disciplinary, therefore, agreeing on certain terms to refer to elements of the $\mathrm{CZ}$ is important. I will define some terms that could cause confusion between different geoscience disciplines. I will adopt the meaning used in most hydrogeophysics-CZ studies (Anderson et al., 2007; St. Clair et al., 2015; Riebe et al., 2016; Holbrook et al., 2014).

-Soil: mobile soil, part of regolith that moves downslope, disaggregated material.

-Saprolite: fractured and weathered bedrock that has suffered chemical and mechanical processes.

-Regolith: The soil and saprolite layers, also known as mobile and immobile regolith, respectively.

-Fractured bedrock: Unweathered bedrock, fractured, with smaller fracture openings than the saprolite. Altered by mechanical processes, but not chemical. -Intact bedrock: Part of the bedrock that hasn't been affected by meteoric fluids. 
A graphic representation, of the elements mentioned above, is presented in figure 1. The conveyor belt refers to the mechanical and chemical process of uplifting once intact bedrock and converting it into soil, in CZ literature (Anderson et al., 2007).

\section{Figure 1: $\quad C Z$ conveyor belt. Different weathering layers within the $C Z$.}

Several hypotheses on the main processes that control the depth to bedrock in the $\mathrm{CZ}$, for different environments have been proposed. Four of the most predominant hypothesis, in the CZ community, are explained to detail in Riebe et al. (2016). Some of the models describing these hypothesis are:

-The direction of least and most compressive stresses with respect to topographic highs and lows can predict zones of dense subsurface fracturing (St. Clair et al., 2015; Moon et al., 2017).

- The limit of the boundary for unweathered bedrock is given by the highest level of fully saturated fractured bedrock, flowing towards a river channel. The varying of the 
water table level introduces oxidized acids that permit the weathering of bedrock through drying cycles (Rempe and Dietrich, 2014).

- In environments where temperature ranges through the "cracking window" (i.e. $3^{\circ}$ to $-8^{\circ} \mathrm{C}$ ), rock suffers damage by frost cracking, and therefore benefits weathering (Anderson et al., 2013).

- Duration of precipitation controls the residence time of water in the unsaturated zone, rather than the intensity of a precipitation event. As a result of this, thicker soils and weathered bedrock layers are expected to be found in North facing slopes (Langston et al., 2015).

Nielson (2017) did a 2D seismic refraction study at Johnston Draw, a subcatchment within the Reynolds Critical Zone Observatory, located in Southwest Idaho, USA. The underlying material of the sub-catchment is granite. He collected the surveys at different elevations to better understand how aspect asymmetry and depth to bedrock varied according with elevation. Overall Nielson concludes that within Johnston Draw the depth to bedrock increases with decrease of elevation. He suggests this phenomenon is controlled by an interplay between elevation, temperature and precipitation.

Poulos (2016) did a series of depth to bedrock measurements using blind penetration tests and augers to assess properties of the soil throughout the DCEW. He concluded that soil layers were thicker on north-facing slopes at low and mid-elevations. However, this asymmetry reduces with elevation increase at the DCEW.

Fractures can have a significant effect on the deep architecture of the critical zone (CZ). According to Riebe et al. (2016), fractures are a high hydraulic conductivity pathway allowing transport of meteoric fluids into the deep unweathered parts of the CZ. 
St. Clair et al. (2015) showed that the use of both electrical resistivity (ER) and seismic measurements can reveal highly fractured zones and, in some cases, these can be correlated with the regional stress field. Most geophysical studies in mountainous watersheds ignore fracture induced anisotropy.

Geophysical methods help us better understand fracture induced azimuthal anisotropy, specifically, 2D seismic refraction, and ER methods (Yeboah-Forson and Whitman, 2014; Busby, 2000; Zhu et al., 2012; Holbrook et al., 2014; Befus et al., 2011; Babcock et al., 2015; Greenhalgh et al., 2009; Matias, 2002; Li and Uren, 1997). Fracture presence introduces seismic azimuthal anisotropy (Tsvankin and Grechka, 2011; Lynn and Michelena, 2011; Burns et al., 2007; Crampin, 1985), and electrical azimuthal anisotropy (Berryman and Hoversten, 2013; Greenhalgh et al., 2010; Yeboah-Forson and Whitman, 2014; Taylor and Fleming, 1989). If hydraulic anisotropy exists in the subsurface, but is not taken into account, geophysical measurements can be interpreted incorrectly. Anisotropy should be considered when performing geophysical surveys where there is potential for anisotropic media so that appropriate models can be utilized. Multi-azimuthal surveys can significantly increase field time and expense, however applying isotropic models in anisotropic media will lead to erroneous results.

Most CZ-hydrogeophysics surveys are collected using only a single azimuth (Olona et al., 2010; Befus et al., 2011; Holbrook et al., 2014; Yamakawa et al., 2012; Yamakawa et al., 2010). The results might vary dramatically depending on the direction of the survey with respect to the fracture orientation. I will attempt to quantify the difference between geophysical results collected at different azimuths in a mountain watershed with fractured bedrock. 


\subsection{Research Hypothesis}

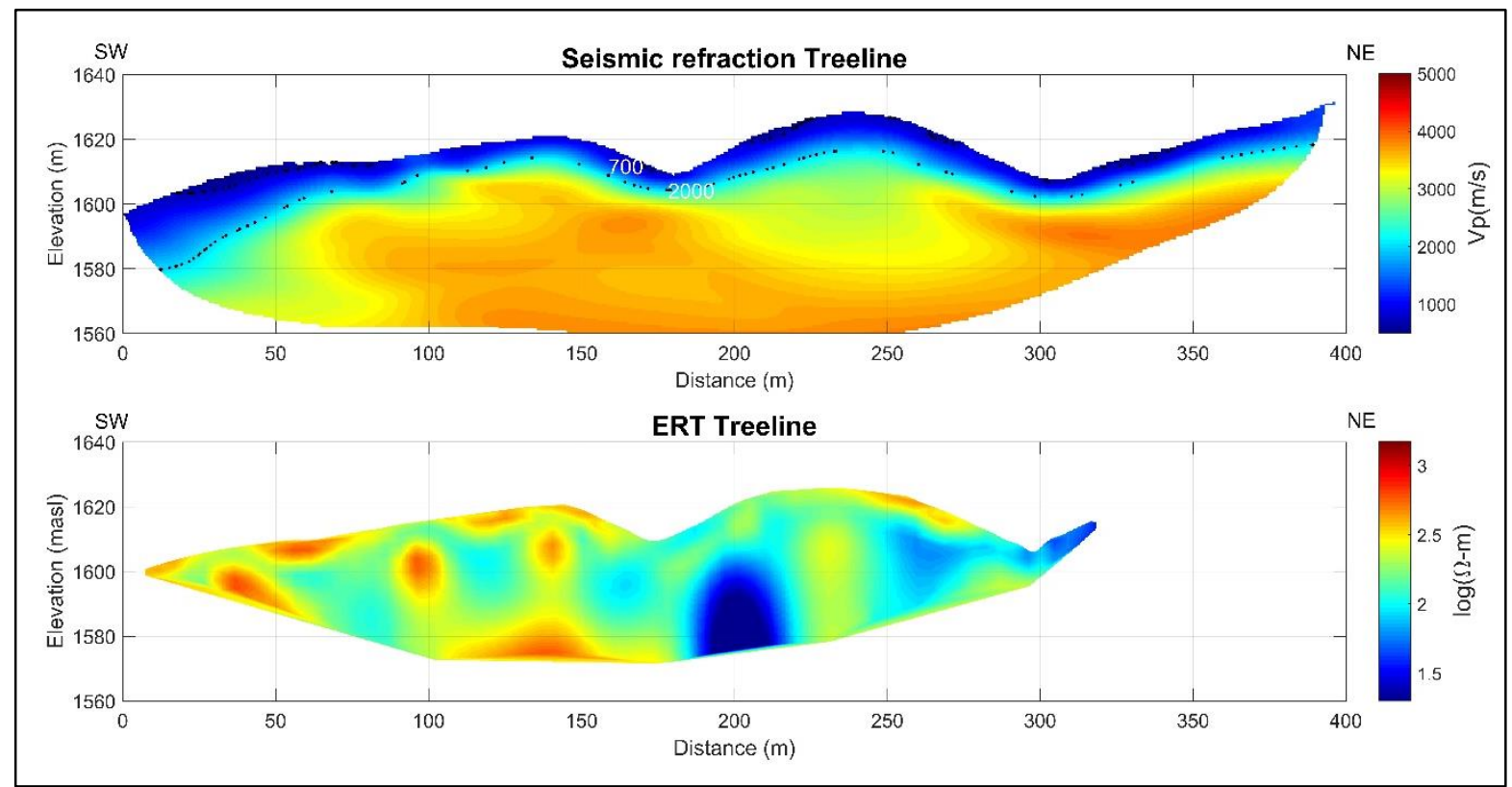

Figure 2: NE-SW transects collected in Treeline, for both Seimics and ERT. These were the first ones collected chronologically. ERT was collected in Fall 2014, and seismic in Fall 2015.

In Fall 2014 an Electric resistivity tomography (ERT) profile was collected at Treeline for the class of electric and electromagnetic methods of 2014, at Boise State University. In Fall 2015 a seismic refraction survey was collected at Treeline for a class project in the seismic methods class at Boise State University. When analyzing both results (figure 2), I observed a decrease in Vp below the top of the North Ridge (NR), accompanied with low ER, below the top of the NR. I don't observe a decrease of Vp below the ridge top of the South Ridge (SR), and the decrease in ER is not as predominant below the SR. Based on these observations, I hypothesized the existence of a fracture system with a ridge parallel preferential orientation, allowing deep weathering below the North ridge-top, at Treeline. At the SR, I hypothesized a weaker fracture system, or lack of fractures. 
To test my hypothesis I used multi-azimuth Vp and ERT measurements to test for fracture induced anisotropy. Since fracture systems are complex and highly heterogeneous, I decided to test the hypothesis at 3 different sites within or near the DCEW, located at different elevations.

\subsection{Description of research sites}

The city of Boise depends on mountain block recharge to move water from the mountains to the valley aquifers, either by subsurface inflow or by streams (Acker, 2008). The subsurface inflow process is poorly understood because there is little information on the hydraulic properties, at depth, in the Dry Creek Experimental watershed (DCEW).

The DCEW is located in Southwest Idaho, USA (see figure 3), it was created to better understand hydrologic processes in a semi-arid environment, and it's located approximately $16 \mathrm{~km}$ northeast of Boise, Idaho. The dominant rock unit in the DCEW is granite. Vegetation varies with elevation at the DCEW. Lower elevations are dominated by grass and shrublands; mid-elevations have a variety of grass, shrublands, and forest communities; and high elevations are characterized by ponderosa pine and Douglas-fir forest communities with patches of lodgepole pine and aspen (Williams, 2005).

A few studies have been carried out, to try to account for the bedrock infiltration portion of the water balance at the DCEW. These studies have either modeled how much water goes to bedrock infiltration (Kormos et al., 2015), used a chloride mass balance approach (Aishlin and McNamara, 2011), or used satellite imagery to delineate fractures (Acker, 2008). So far, no study has been carried to better understand the characteristics of fractured bedrock at depth and at varying azimuths. Aishlin and McNamara (2011) estimated that as much as $44 \%$ of annual precipitation goes to bedrock infiltration at the 
DCEW. Kormos et al. (2015) found that $34 \%$ of precipitation at Treeline, a subcatchment within the DCEW, goes to bedrock infiltration.

It is known that a substantial amount of water flows vertically from the soil into the bedrock, presumable through a fracture system, but this is not well characterized or understood (Gates et al., 1994). The conceptual hydrologic model for the DCEW accounts for soil-bedrock water flow directed towards stream channels and infiltration of precipitation through sandy soil to bedrock (Aishlin and McNamara, 2011). However, in reality, the system is more complex because fractures in crystalline rocks (Illman, 2006) create highly variable hydraulic properties (Acker, 2008). The DCEW is located in the Idaho batholith, a granitic intrusion with fracture presence (Acker, 2008). 


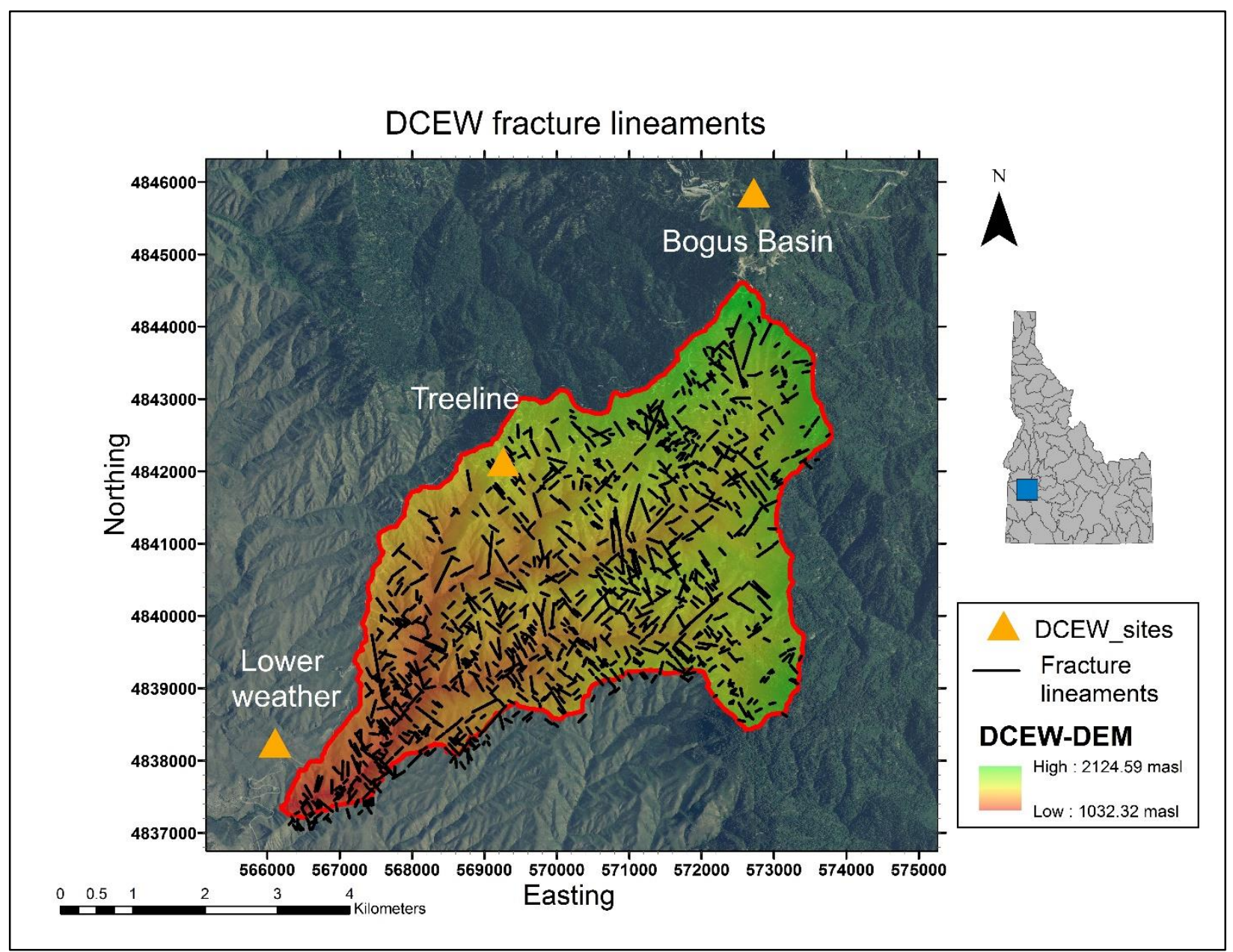

Figure 3: Map of the DCEW, with a digital elevation model, surveyed sites, and fracture lineaments defined by Acker (2008).

I selected three locations to collect data at. The criteria I used to select these sites was: difference in elevation, vegetation, and rain and/or snow dominated recharge system. I also wanted to preserve the same ridge aspect among all of my research sites, as much as possible. To better preserve other characteristics, like geology and climate, I chose all my sites to be located within, or near the DCEW.

\subsubsection{Lower Weather}

Lower Weather is located at an elevation of around 1140 masl, near the DCEW ( 400 m). This site is characterized by grasses, forbs, and shrubs with few trees outside of the immediate riparian zone. This site is rain dominated (Parham, 
2015). The least and most steep slopes of the surveyed profiles were $11^{\circ}$, and $34^{\circ}$ respectively.

\subsubsection{Treeline}

Treeline is a small catchment of approximately 1.5 hectares, located within the DCEW. Treeline lies in the rain-snow transition zone. The average elevation for the catchment is 1622 masl, the average slope is $21^{\circ}$. Vegetation is characteristic of a transition zone between grasslands and forests due to change in elevation (Kormos et al., 2014).

There are two predominant ridges that conform the Treeline sub catchment. For convenience, I've named these two ridges: North ridge (NR) and South ridge (SR), and correspond to the north-most and south-most ridges, respectively (see figure 6).

In the NR surveyed profiles, the steepest and least steep slopes were $39^{\circ}$ and $26^{\circ}$, respectively. In the SR surveyed profiles, the steepest and least steep slopes were $31^{\circ}$ and $17^{\circ}$, respectively.

One of the advantages of studying Treeline is the amount of hydrologic and meteorological data being collected at the site: soil moisture, soil temperature, wind direction and speed, air temperature, etc. This is the reason why Treeline has been subject of several hydrologic, and geophysical studies, in the past. Among the most relevant to my study are:

A series of snow studies done by Kormos et al. (2014; 2015) suggest that the snowpack remains for longer periods of time in Northern facing aspects, and that northeast facing slopes contribute more to the total soil drainage for the water 
year. Anderson et al. (2014) suggest that forested sites retain more snow than nonforested areas, throughout the DCEW. Williams (2005) did soil analysis at Treeline, and determined that soil depth ranges from 0.3-1.2 m. Finally, Miller et al. (2008) performed a 2D time-lapse electrical resistivity tomography (ERT) at Treeline. He attributes a change in time of ER to the intersection of two sets of fractures, in the SR, near the ridge-bottom.

\subsubsection{Bogus Basin}

The highest elevation site is located within the Bogus Basin ski resort at an elevation of 1940 masl. This site is conifer dominated, and snow dominated. This site is not located inside the DCEW boundaries, but it's located near the DCEW (Parham, 2015). This surveyed site is in an almost flat surface.

Gates et al. (1994) completed a fracture trace analysis, from aerial photos and outcrops, and borehole tests at Bogus Basin. They determined the existence of three major sets of fractures with orientations $\mathrm{N} 70^{\circ} \mathrm{W}, \mathrm{N} 20^{\circ} \mathrm{W}$, and $\mathrm{N} 20^{\circ} \mathrm{E}$. Bogus Basin counts with 3 boreholes. The borehole in which I collected data has a total depth of $152 \mathrm{~m}$, and the drilled material is mostly granodiorite.

\subsection{Development of research}

For readability purposes, I will divide my thesis into four additional chapters. Chapter 2 will be focus on the seismic results related to anisotropy. Chapter 3 will focus on ER results. In Chapter 4 I will discuss some ancillary observations related to weathering depth. Finally I will close the thesis with conclusions and recommendations for future research.

My research objectives are: 
- Better understand fracture density and orientation at the DCEW.

- Link electric and seismic azimuthal anisotropy to hydraulic azimuthal anisotropy.

- Validate the use of both, electric and seismic methods, to characterize fractured, granitic experimental watersheds with steep topography. 


\section{CHAPTER TWO: SEISMIC REFRACTION}

\subsection{Seismic methods}

\section{$\underline{\text { 2.1.1 Seismic refraction }}$}

A seismic refraction survey consists in deploying a line of seismic receivers (i.e. geophones) on the ground, and shooting a seismic source into the receivers, usually at multiple locations. The method of seismic refraction works when you have two layers of different rock materials in the subsurface, and the upper layer has a smaller Vp (overburden) than the lower layer (refractor). When the incident angle of a seismic wave is the critical angle, the seismic wave travels through the interface with the Vp of the lower layer, and then is refracted back to the surface. We measure the time it takes for the primary wave to travel from the seismic source to every receiver in the profile. With these travel times and inversion methods we are able to model a seismic tomogram of the probed subsurface. These velocity models help us better determine the presence of structures or anomalies in the subsurface.

\subsubsection{Seismic anisotropy}

According to Lynn and Michelena (2011), the general definition of anisotropy is "the value measured (e.g. Vp) depends upon the direction in which you make the measurement".

We can define at least three types of seismic anisotropy (see figure 4). Layer anisotropy that has a vertical axis of symmetry, and is known as VTI. Azimuthal anisotropy happens in the presence of unequal horizontal stress and/or micro- or macro-fractures, and has a 
horizontal axis of symmetry, known as HTI. When fractures or dipping layers are present in the subsurface, we can determine a tilted axis of symmetry, known as TTI. The third case of anisotropy corresponds to orthotropic (orthorhombic) media, and arises when you have a combination of flat-layers, and vertical fractures or dipping layers or dipping fractures.

The type of anisotropy we are interested in is azimuthal anisotropy, because vertical fractures create a horizontal axis of symmetry. 


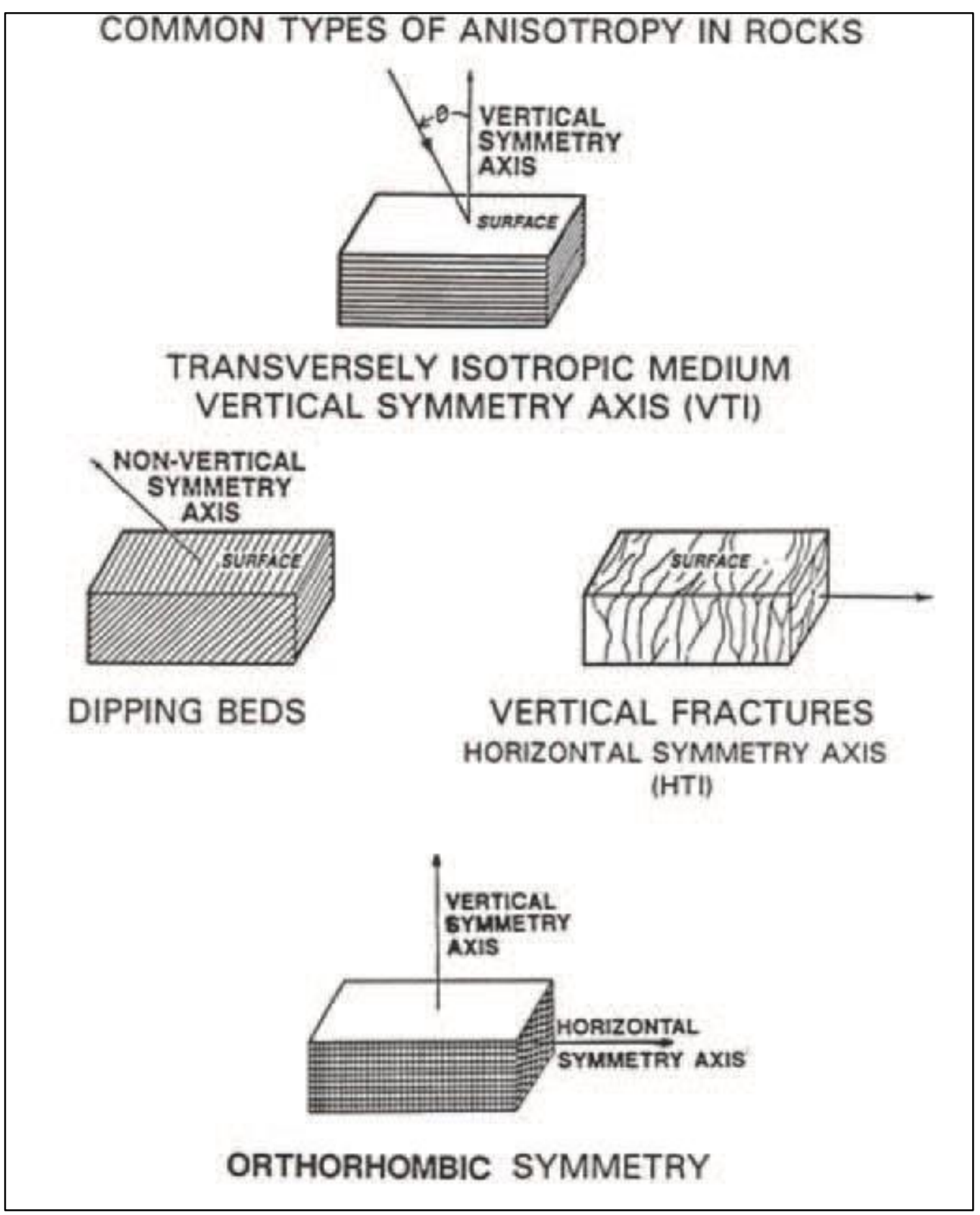

Figure 4: Different types of anisotropy present in the subsurface (taken from Lynn and Michelena, 2011).

According to Crampin et al. (1980) the simplified equations that govern seismic velocity affected by one set of fractures are:

- Dry cracks: 


$$
V_{p}=V_{b} /\left(1+\frac{8}{3} \varepsilon\left\{\frac{8}{7}\left(c^{2}-c^{4}\right)+\left[\left(1+2 c^{2}\right)^{2}\right]\right\}\right)^{1 / 2}
$$

- Saturated cracks:

$$
V_{p}=V_{b} /\left(1+\frac{64}{21} \varepsilon\left(c^{2}-c^{4}\right)\right)^{1 / 2}
$$

Where: $\varepsilon=N r^{3} / V$ is the crack density of $\mathrm{N}$ cracks of radius $\mathrm{r}$ in a volume $\mathrm{V}$, $c=\cos \theta$, and $\theta$ is the angle of incidence relative to the crack orientation, where $\varepsilon \ll 1$. $V_{b}$ is the $\mathrm{Vp}$ of the background material, in our case we assumed a value of the velocity of fresh granite of $V_{b}=3500 \mathrm{~m} / \mathrm{s}$, taken from Olona et al. (2010).

These set of equations are valid for thin, penny-shaped, oriented cracks. The modeling is suitable for a system of planar cracks (parallel) or bi-planar cracks (two sets of intersecting parallel cracks).

Hydraulic relations (Watanabe and Higuchi, 2015) allow us to calculate porosity $(\phi)$ from fracture density, with:

$$
\phi=\frac{4}{3} \pi \varepsilon \beta
$$

Where $\beta$ represents fracture aperture.

When two sets of fractures are present in a media, the simplified equations that govern the seismic velocity, according to Crampin et al. (1980) are:

- Dry cracks:

$$
V_{p}=V_{b} R_{P}^{D}\left(\varepsilon_{1} ; \cos \theta\right) R_{P}^{D}\left(\varepsilon_{2} ; \cos (\theta-\alpha)\right),
$$

Where: 
$=1 /\left\{1+\frac{8}{3} \varepsilon_{1}\left[\frac{8}{7}\left((\cos \theta)^{2}-(\cos \theta)^{4}\right)+\frac{\left(1+2(\cos \theta)^{2}\right)^{2}}{4}\right]\right\}^{1 / 2}$

- Saturated cracks:

$$
V_{p}=V_{b} R_{P}^{S}\left(\varepsilon_{1} ; \cos \theta\right) R_{P}^{S}\left(\varepsilon_{2} ; \cos (\theta-\alpha)\right),
$$

Where:

$$
R_{P}^{S}\left(\varepsilon_{1} ; \cos \theta\right)=1 /\left\{1+\frac{64}{21} \varepsilon_{2}\left[(\cos \theta)^{2}-(\cos \theta)^{4}\right]\right\}^{1 / 2}
$$

Also, $\varepsilon_{1}$ and $\varepsilon_{2}$ represent fracture density for the first, and second set of fractures, respectively, $\theta$ is the angle of incidence relative to the crack plane normal, and $\alpha$, is the angle between the two sets of fractures.

\section{$\underline{\text { 2.1.3 Fracture density calculation }}$}

From Crampin et al. (1980, eqns. 1-7), I inverted for the best fracture density, minimizing the error. I used the search method of Lagarias (or fminsearch from Matlab's library) to minimize the error function. I constrained the fracture density values to vary only within one and zero. The error function I minimized is:

$$
\text { error }=\sqrt[2]{\frac{1}{n} \sum\left[\left(d_{\text {obs }}-d_{\text {calc }}(\varepsilon)\right)^{2}{ }_{\text {azimuth } 1}+\cdots+\left(d_{\text {obs }}-d_{\text {calc }}(\varepsilon)\right)^{2}{ }_{\text {azimuthN }}\right]}
$$

Where $n$ is the number of azimuths under minimization. 


\subsubsection{Data collection}

I collected all seismic profiles using 24-channel Geometrics Geodes. I deployed lines using a range of $62-83$ channels. Receiver spacing was $5 \mathrm{~m}$, and sources were separated $20 \mathrm{~m}$ apart. I used $10 \mathrm{~Hz}$, vertical component geophones.

Lower Weather seismic profiles (figure 5) were collected in early September 2016. I collected a profile parallel to the ridge and one ridge perpendicular.

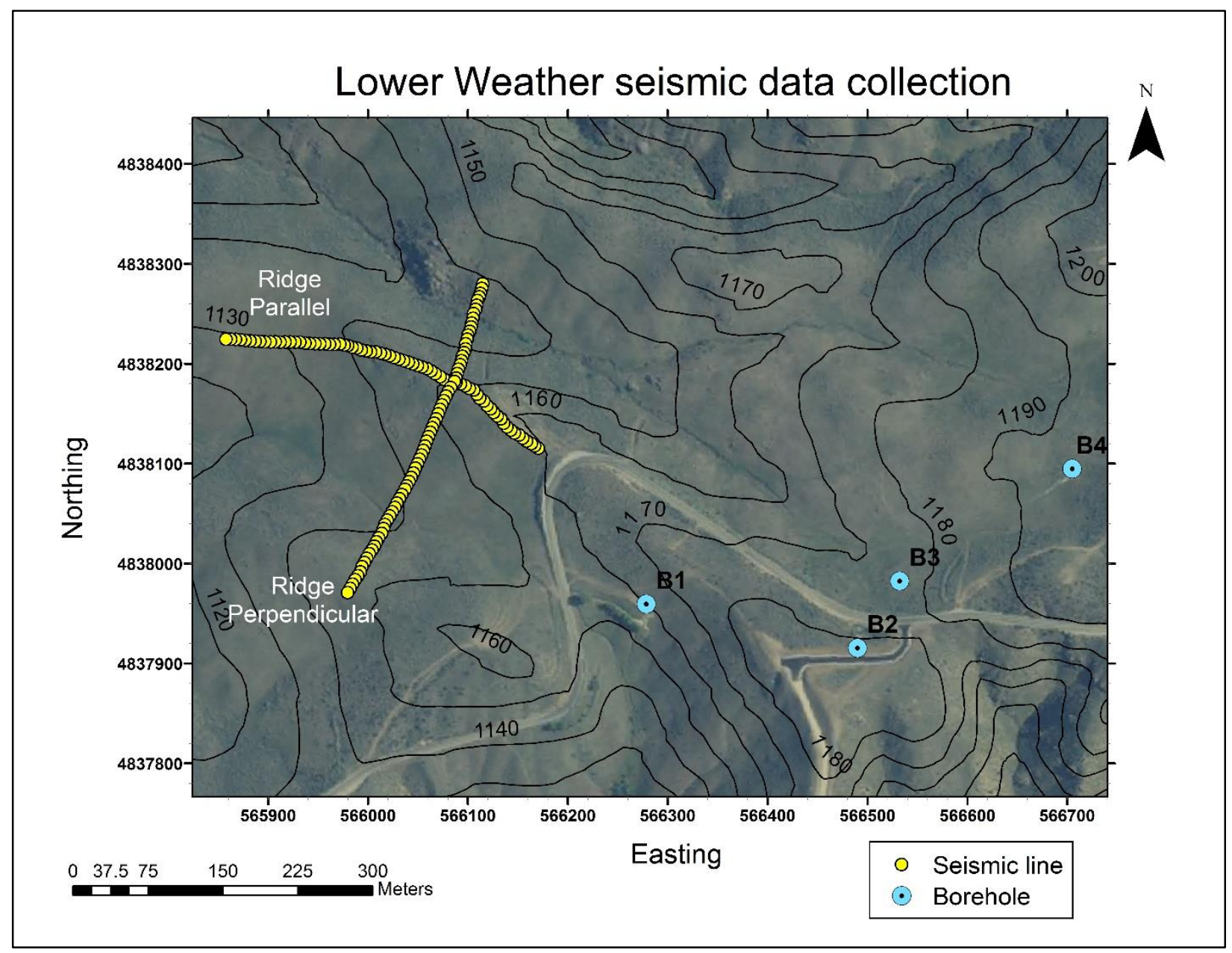

Figure 5: $\quad$ Map of seismic data collection at Lower Weather.

The first Treeline seismic profile, was collected during Fall 2015, one was collected in Spring 2016, and 7 lines were collected during Fall 2016. At Treeline I collected data in a wagon-wheel pattern, in both the NR and SR (see figure 6). 


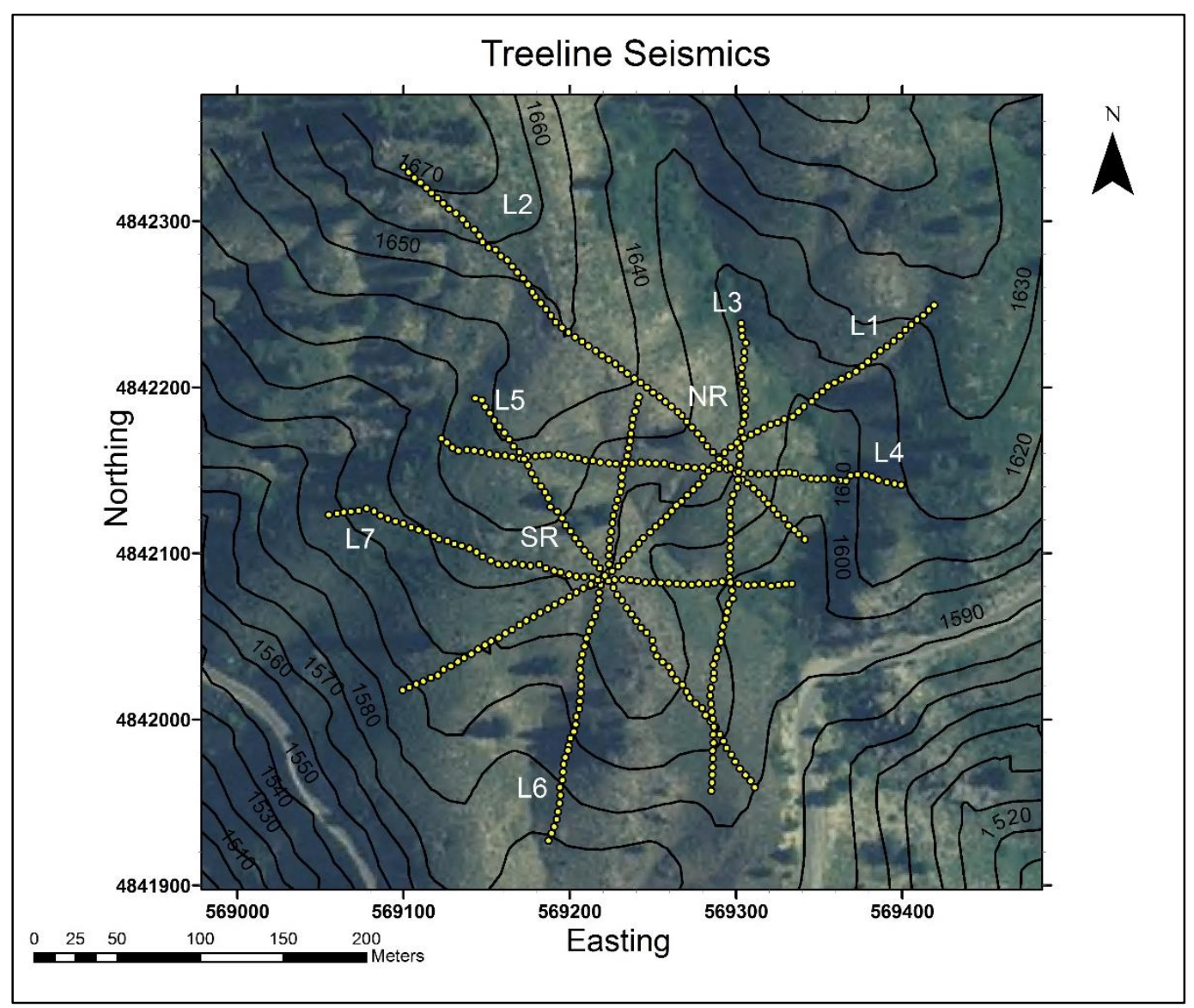

Figure 6: $\quad$ Map of seismic data collection at Treeline.

Four reverse vertical seismic profiles (VSP), at four different azimuths, were collected at the end of Fall 2016, at Bogus Basin. These survey lines were centered at the top of the borehole, see figure 7. These surveys consisted in locating a seismic source (i.e. sparker) down a borehole, to $89 \mathrm{~m}$ depth, and moving the source up the borehole with a $1 \mathrm{~m}$ vertical spacing between shot locations. At the surface, I planted 48 vertical $10 \mathrm{~Hz}$ geophones with a separation of $1 \mathrm{~m}$ and centered on the borehole. The experiment was repeated four times with the receiver lines at four different azimuths (Figure 7). To better constrain our anisotropy problem, I also performed a deviation test in the borehole, and shot seismic sources at certain receivers in the surface. 


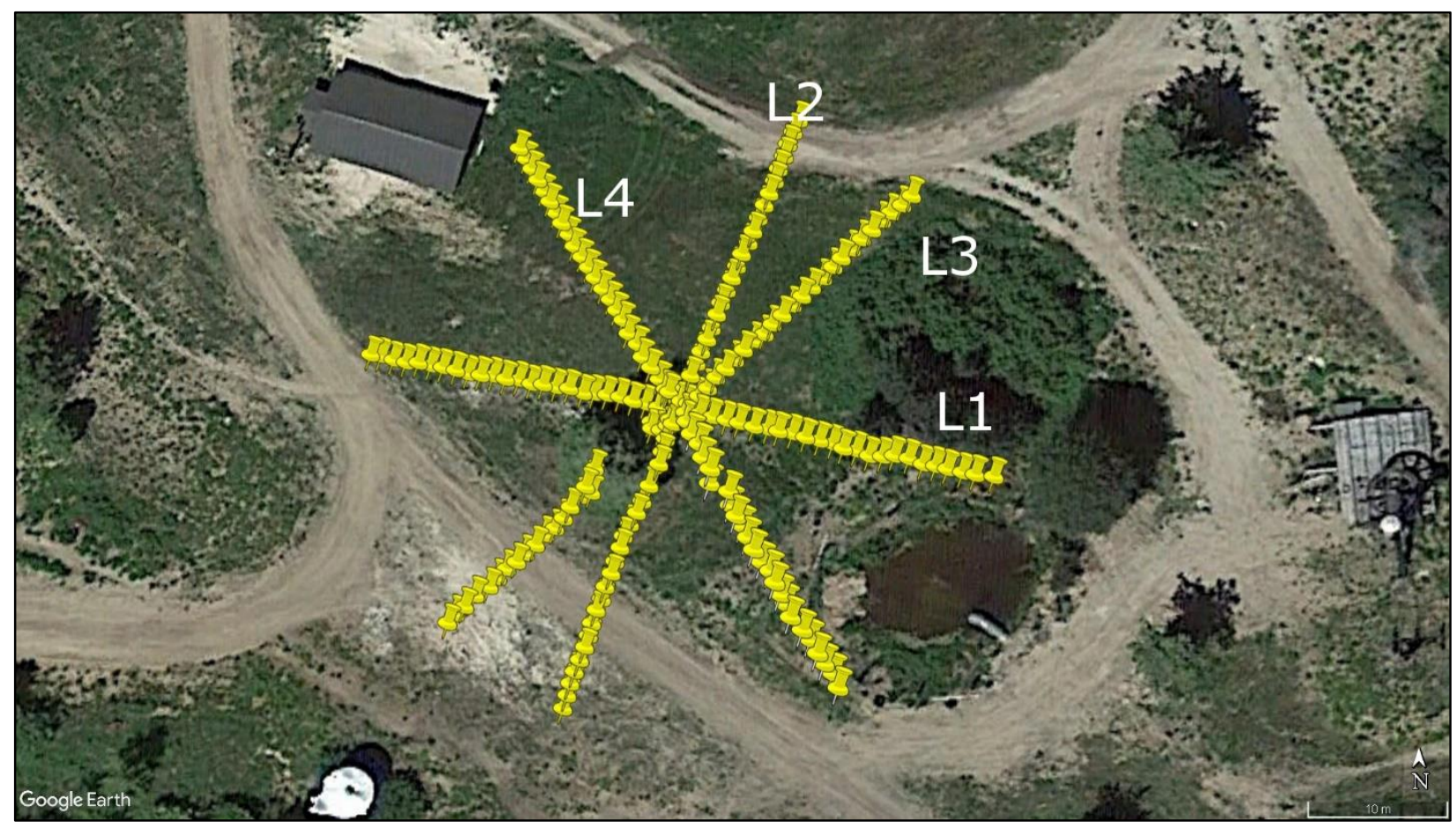

Figure 7: Map of seismic data collection at Bogus Basin.

\subsubsection{Data processing}

For most of my seismic refraction surveys, I picked first arrivals using the software Geotomo. To remove high frequency noise from the data, I applied a filter from 0-5-100-150 Hz. I used the commercial software Rayfract to invert for the velocity section. Rayfract uses a wavepath eikonal traveltime (WET) inversion method. WET inversions compute wavepaths by using finite-difference solutions to the eikonal equation. WET partially accounts for the band limited effects of the source wavelet and diffraction effects, by allowing the wavepath width to decrease as the peak Ricker source frequency increases. In other words, when the source wavelet period increases, a bigger region of the model is allowed to contribute scattered energy to the measured travel times. This bigger region is obtained due to the increase in an enlarged wavepath. Velocities are calculated by back-projecting phase residuals in wavepaths related to source-receiver pairs (Schuster and Quintus-Bosz, 1993). 
For the reverse VSP experiment, I picked the first time arrivals with the software ProMax. Due to low frequency noise present in the data, I used a bandpass filter from 70100-250-300 Hz. I used the open source code PRONTO to invert each 2D line, individually. PRONTO employs a nonlinear inversion procedure, where it calculates first arrival traveltimes, for every source location, to all points in the gridded area. It generates a raypath between all source-receiver pairs and checks results to existing slowness model. Finally, it updates the slowness model iteratively (Aldridge and Oldenburg, 1993).

To use the inversion software PRONTO, I obtained the 2D sections by projecting the $\mathrm{x}, \mathrm{y}$, and $\mathrm{z}$ coordinates, from the sources and receivers to a $2 \mathrm{D}$ plane, in the receiver line orientation. I chose the regularization parameters from a checkerboard test, based on my data collection geometry. For the starting velocity models, I used the WET inverted sections (from Rayfract) from the surface sources; for the deeper depths, I calculated interval velocities. I did not invert for all the depth sources, since the deeper recorded shots had too much noise in them, so I cut them out of the inversion. The inverted sections were consistent with the lithology log, obtained from the driller's log (see figure 17).

\subsection{Seismic refraction results}

\subsubsection{Lower Weather results}

\subsubsection{Tomograms}

Figure 8 shows the $2 \mathrm{D}$ inversion results for the seismic refraction surveys at Lower Weather. We observe there is a dramatic difference in Vp values, at the crossing points, between the ridge parallel and perpendicular directions. The intact bedrock appears to be deeper in the perpendicular direction than in the parallel direction. I 
interpret $3500 \mathrm{~m} / \mathrm{s}$ to correspond to intact granite (see table 1), based on the study done by Olona et al. (2010). They performed a seismic refraction and an ER survey, as well as a laboratory analysis on granite samples from boreholes. Additionally, they determined correlations between Vp and ER values to weathering states for granite. These results are shown in table 1.

Table 1: Correlation between granite weathering states and geophysical parameters Vp, and ER, by Olona et al. (2010).

\begin{tabular}{|l|l|l|}
\hline Description & $\mathrm{Vp}(\mathrm{m} / \mathrm{s})$ & ER $(\Omega-\mathrm{m})$ \\
\hline Disaggregated materials & $<700$ & $66-800$ \\
\hline Saprolite & $700-2000$ & \\
\hline Fractured bedrock & $2000-3500$ & \multirow{2}{*}{$800-3125$} \\
\hline Fresh bedrock & $>3500$ & \\
\hline
\end{tabular}

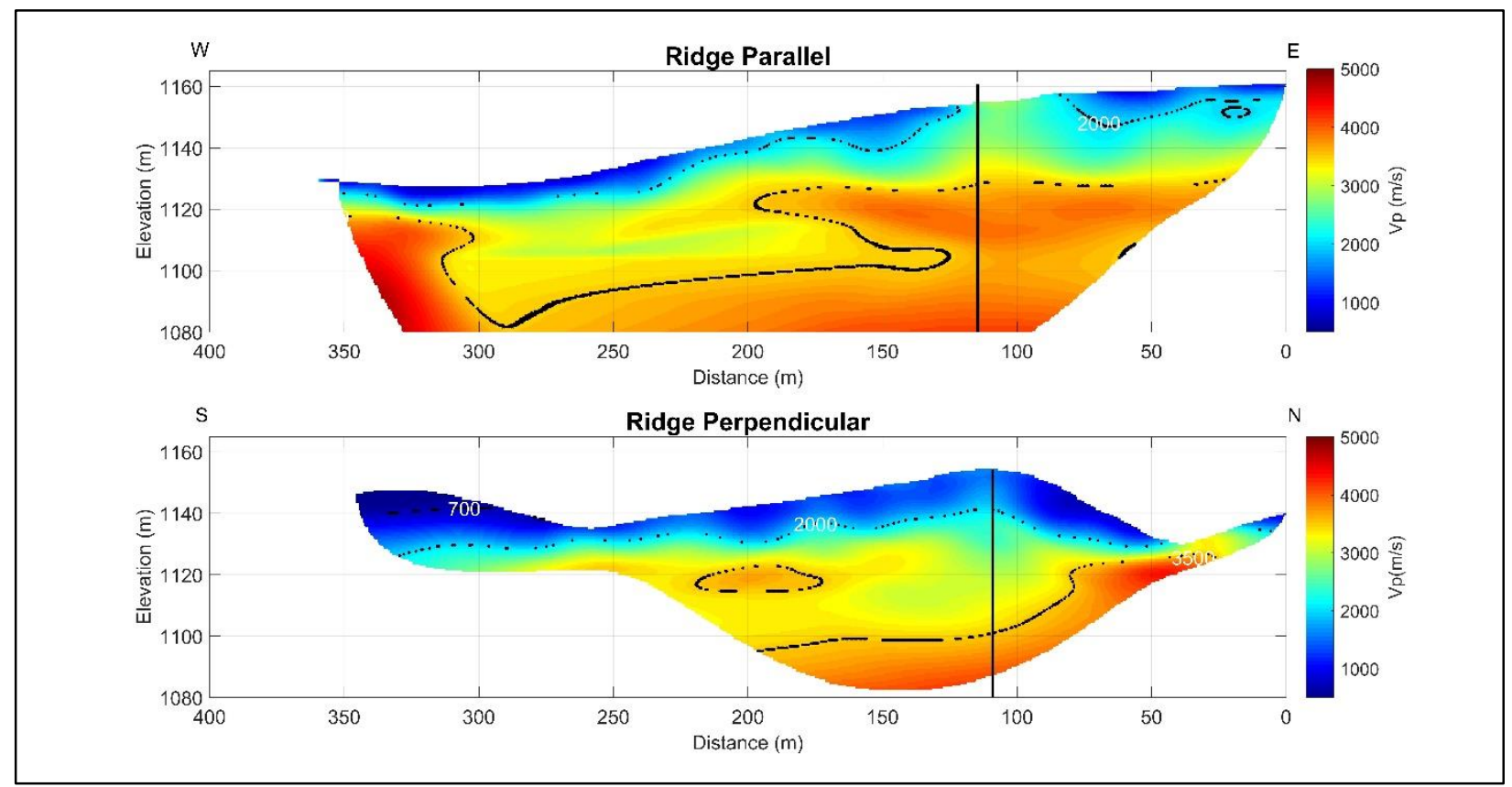

Figure 8: Seismic tomography for Lower Weather. Black lines represent the crossing point between both surveys. Contour lines represent different states of weathering in granite, as seen in table 1. 
From lithologic logs (obtained from the Idaho department of water resources website; https://www.idwr.idaho.gov/) we observe soils and clays at the surface near Lower Weather. At deeper depths, we observe a combination of solid and fractured granite (figure 9).

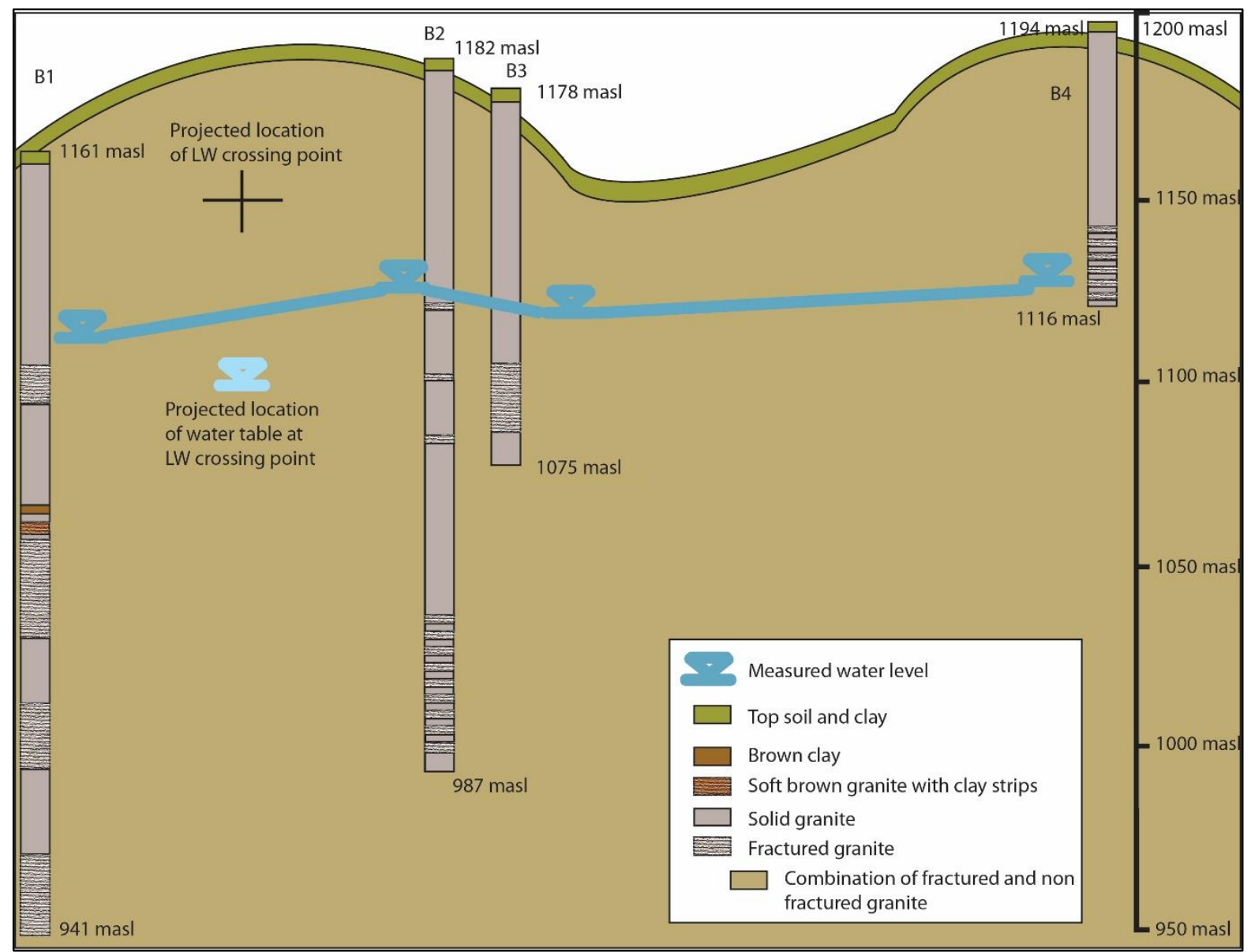

Figure 9: Cartoon of lithology near Lower Weather. Lithologic logs were taken from the Idaho department of water resources website (https://www.idwr.idaho.gov/).

The water table appears to be at around $50 \mathrm{~m}$ depth, near Lower Weather. A $5 \mathrm{~m}$ layer of soil and clays appears to be at the top of all profiles.

I additionally present an example of the first break picks for Lower Weather in the Appendix (figure 36).

2.2.1.2 Crossing point and fracture density 
To compare data collected at different azimuths, I took a $20 \mathrm{~m}$ section centered at the crossing point, for every azimuth, then I calculated an average at depth.

Figure 10 represents $\mathrm{Vp}$ values averaged at depth and fracture density, for Lower Weather. The Vp values are highly suggestive of anisotropy at this site. Ridge perpendicular corresponds to the slow direction and ridge parallel to the fast direction. These results strongly suggest the existence of a dominant set of fractures running ridge parallel, however it does not disqualify the possible existence of another set of fractures. I don't have enough azimuthal coverage to rule out another set of fractures.

These results match my hypothesis that fractures run ridge parallel. At around 55 $\mathrm{m}$ depth, I observe both directions converge in Vp values. From the fracture density calculations, I observe that most fractures close around $25 \mathrm{~m}$ depth. I continue observing Vp anisotropy at deeper depths than that of the fracture "closure". This is an indicator that the fracture system continues to greater depths, even though the majority of fractures are "closed". From the lithologic logs (figure 9) I confirm that fracture systems do continue at deeper depths (> $30 \mathrm{~m}$ depth) than that of fracture "closure".

It is important to acknowledge that the fracture density model and therefore “closing" of fractures calculation is velocity dependent. The velocity I chose for fracture closure is $3500 \mathrm{~m} / \mathrm{s}$ (from Olona et al., 2010). This assumption could be wrong. Calculated fracture density values are the result of a model, and like all models, it is just an approximation of reality, subject to errors.

I made an assumption of dry fractures. I believe this assumption is valid. Based on the lithologic logs (figure 9), we know that during Spring the water level lies greater than $50 \mathrm{~m}$ depth across most of the survey. With the acquisition geometry, the maximum 
depth I imaged was approximately $50 \mathrm{~m}$. Therefore, I made the assumption that most of my velocity profile lies above the water table.

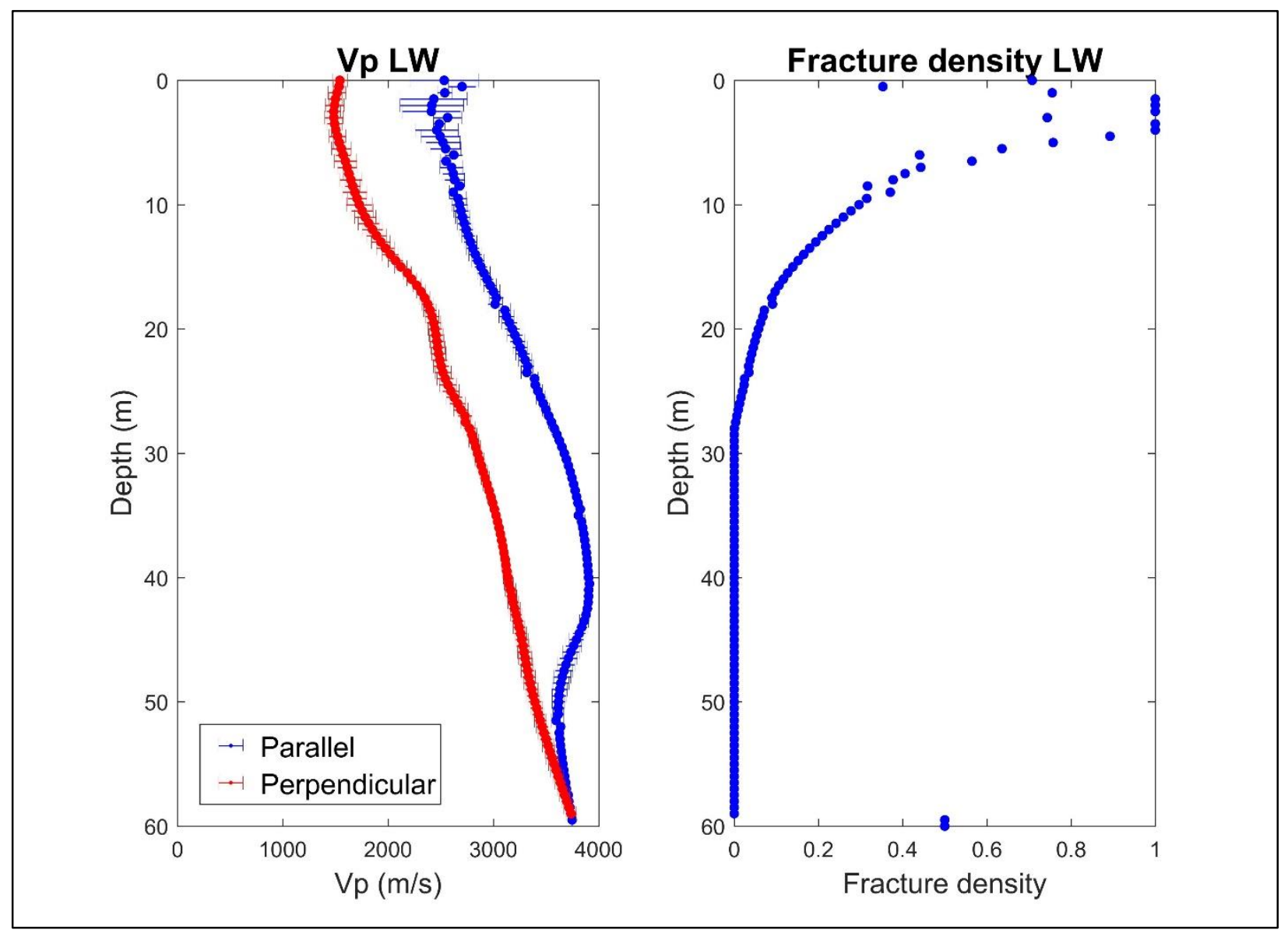

Figure 10: Plot on the left is the fracture density at depth, for Lower Weather. Plot on the right represents the average $V p$ value at depth with error bars, for the Lower weather site. The blue line is the parallel direction, and the red line is the perpendicular direction. Plot on the left is the fracture density at depth, for the Lower weather site. (Note: the error bars represent the standard deviation of $\mathrm{Vp}$ at depth).

\subsubsection{Preferential orientation and percentage change}

The preferential direction for fractures, should match the direction of fast Vp. I plotted a mean Vp, per azimuth, in figure 11 (shown in red). I calculated the mean Vp from 5-25 m depth, from figure 10. I modelled $\mathrm{Vp}$ (in blue) from the calculated fracture density (figure 10), for all azimuths. I assumed the fracture orientation was aligned 
perpendicular to the observed fast direction. For Lower Weather, results suggest the existence of a set of fractures running ridge parallel (figure 11). However, since I only collected data at two azimuths I cannot rule out the existence of another set of fractures oriented differently.

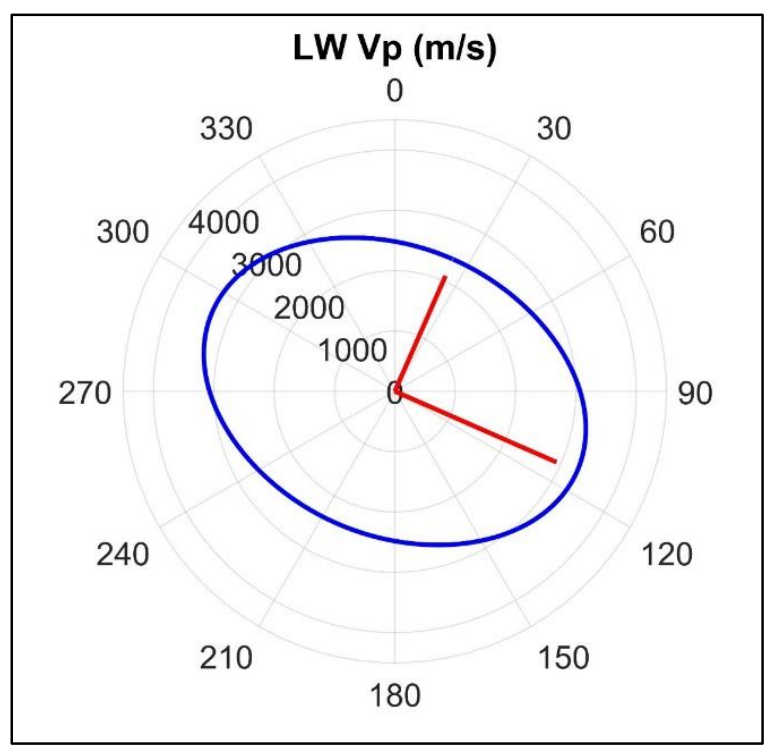

Figure 11: Modelled Vp (blue, from eqns. 1-8), and the mean Vp, for each direction (red), at Lower Weather (Note: $0^{\circ}$ is $\mathrm{N}$ ).

One of the main elements that must be taken into account with the used methodology, is error. All measurements in the physical realm are subject to error. How large should the change in Vp be so we can confirm anisotropy? Meaning, a small change in the characterized physical values, is not enough evidence of anisotropy, but a large change is clear evidence of anisotropy.

I calculated seismic anisotropy values with:

$$
\text { anisotropy }=100 \times\left(\frac{V_{\text {fast }}-V_{\text {slow }}}{V_{\text {fast }}}\right)
$$


For Lower Weather the anisotropy value is $28.56 \%$. Thomsen (1986) mentions that changes smaller than $20 \%$ are in the weak-to-moderate anisotropy range. Therefore, a percentage change of almost $30 \%$ is highly suggestive of anisotropy.

\subsubsection{Treeline results}

\subsubsection{Tomograms}

Figures 12-13 show the 2D inversion results for the seismic refraction surveys at Treeline. The survey lines have been numbered for reference. In general, we observe the "bow-tie" effect described by St. Clair et al. (2015). Below ridge tops there is a decrease in $\mathrm{Vp}$, and at ridge bottoms the thickness of soil, saprolite, and fractured bedrock are thinner. 


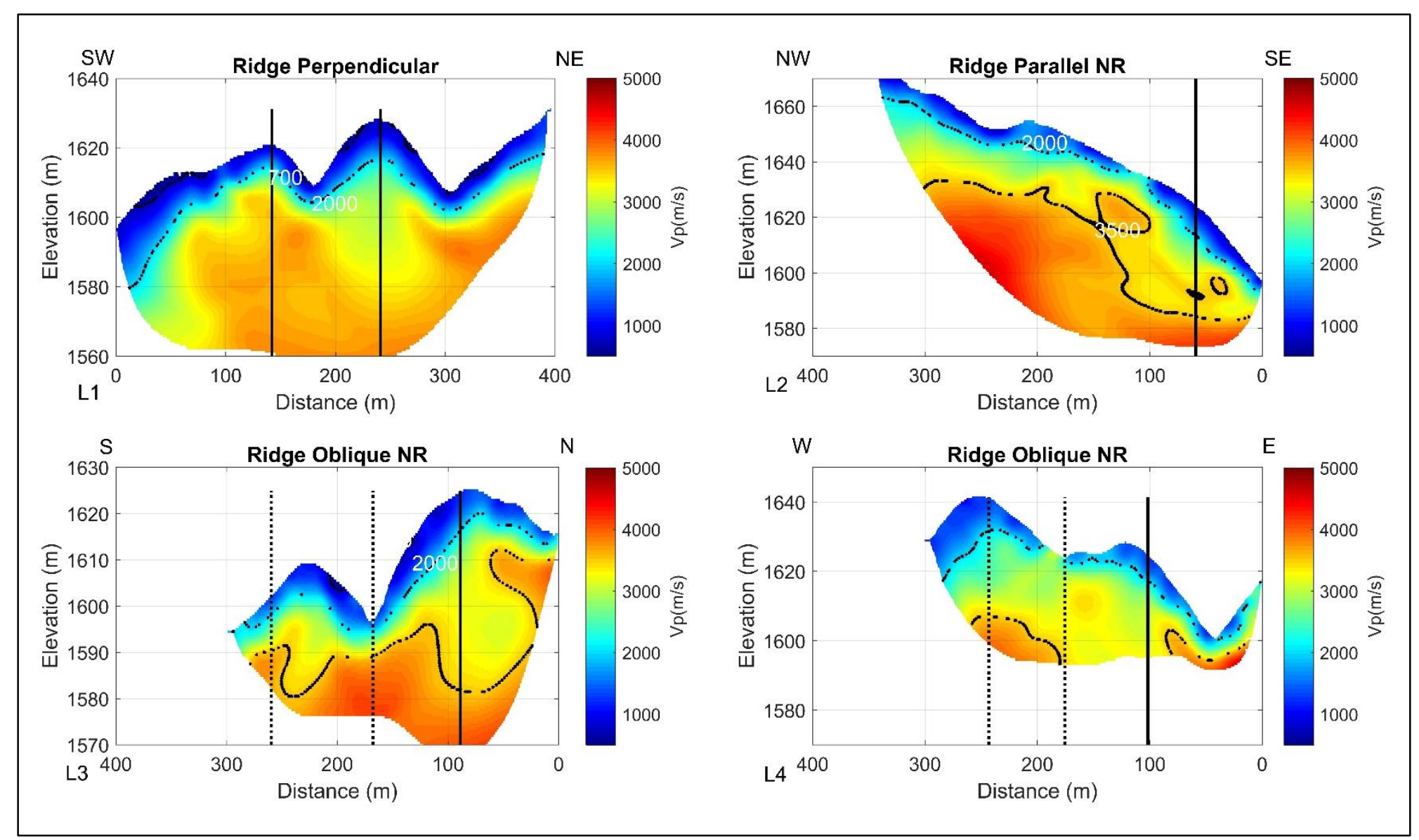

Figure 12: Seismic tomography for the NR at Treeline. Black lines represent the crossing point between both surveys (bold lines are the main crossing points, and the dotted lines represent other crossing points). Contour lines represent different states of weathering in granite, as presented in table 1. 


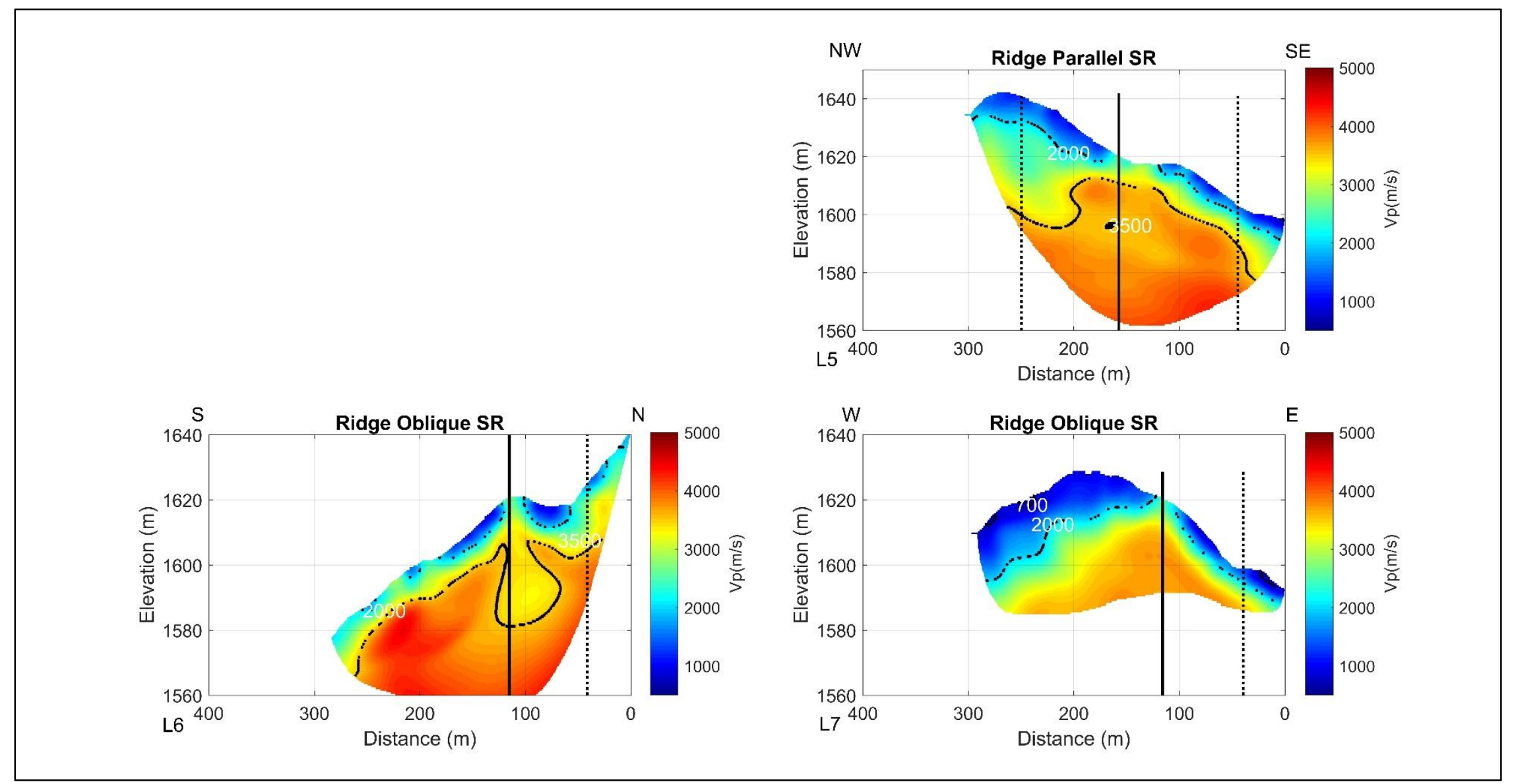

Figure 13: Seismic tomography for the SR at Treeline. Black lines represent the crossing point between both surveys (bold lines are the main crossing points, and the dotted lines represent other crossing points). Contour lines represent different states of weathering in granite, as seen in table 1.

I additionally present an example of the first break picks for Treeline in the Appendix (figure 37). 


\subsubsection{Crossing points and fracture density}

Figure 14 represents Vp values averaged at depth and fracture density, for the NR at Treeline. At shallow depths, no obvious slow or fast direction appears. At deeper depths, there is still no clear behavior of fast velocity, but the ridge perpendicular direction is the slowest.

From figure 15, we can see that our results are consistent with at least two sets of fractures N-S, and E-W trending. However, I don't have enough azimuthal coverage to resolve the exact orientation of fractures.

Because my data agrees with the existence of two set of fractures I decided to use Crampin et al. (1980) set of equations for two set of fractures. To calculate fracture density I assumed the preferential orientation of fractures to be ridge parallel and perpendicular, based on the work of Acker (2008, figure 3).

The calculations of fracture density for the NR (figure 14) suggest that the set of ridge parallel running fractures are more dominant than the ridge perpendicular running fractures. The ridge perpendicular set of fractures appear to close at $25 \mathrm{~m}$ depth. The fracture density decreases with depth significantly after $15 \mathrm{~m}$ depth, for the ridge parallel set of fractures. However, I am not able to probe deep enough to obtain the depth at which most fractures are closed, for the ridge parallel set of fractures. 


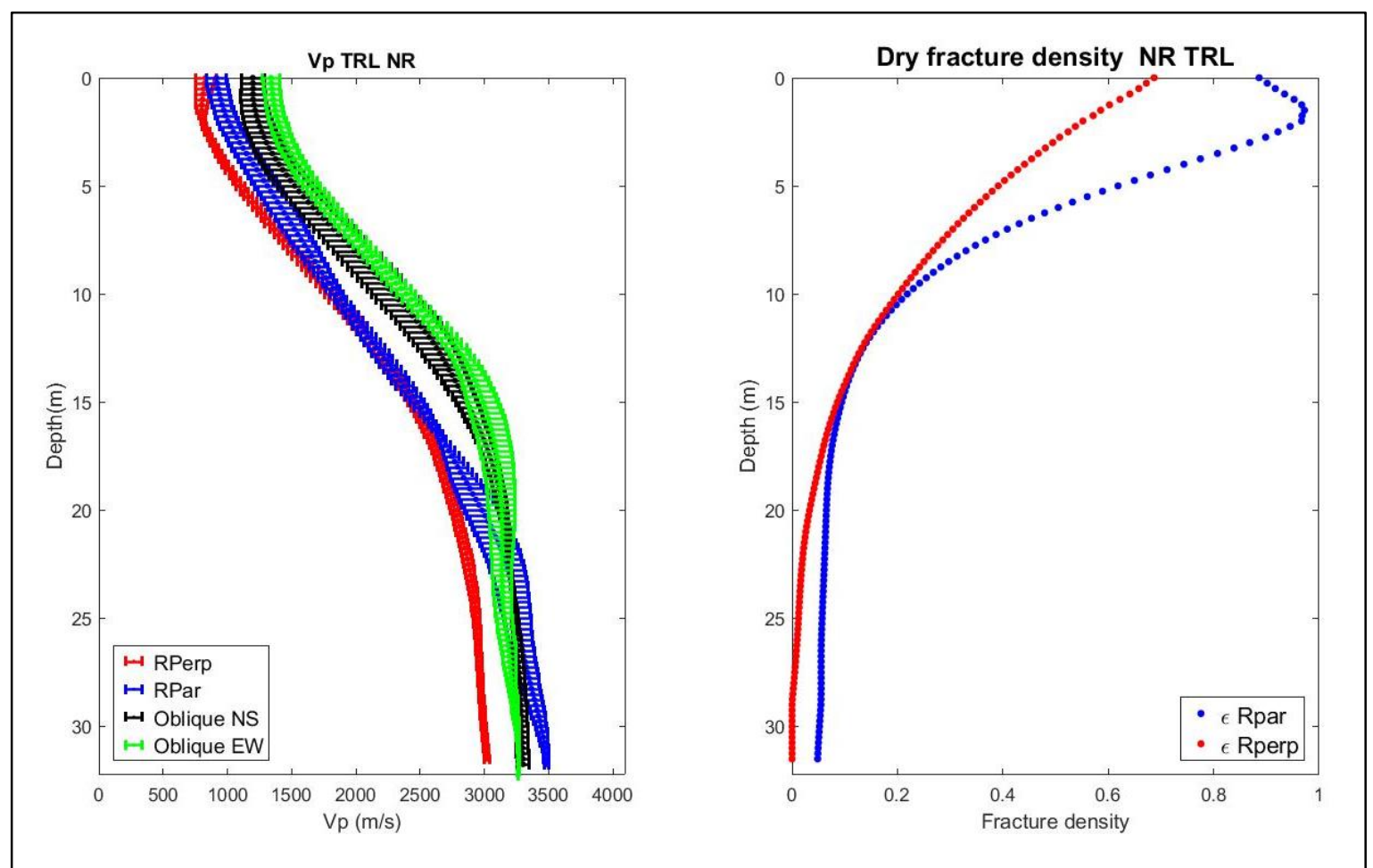

Figure 14: Plot on the left represents the average $V p$ value at depth with error bars, for the NR at Treeline. The blue line is the parallel direction, the red line is the perpendicular direction, the black line is the $\mathrm{N}-\mathrm{S}$ direction, and the green line is the E-W direction. Plot on the left is the fracture density at depth, for Treeline.Blue line represents fracture density for the ridge parallel set of fractures, and the red line represents fracture density for the ridge perpendicular set of fractures. (Note: the error bars represent the standard deviation of $\mathrm{Vp}$ at depth). 


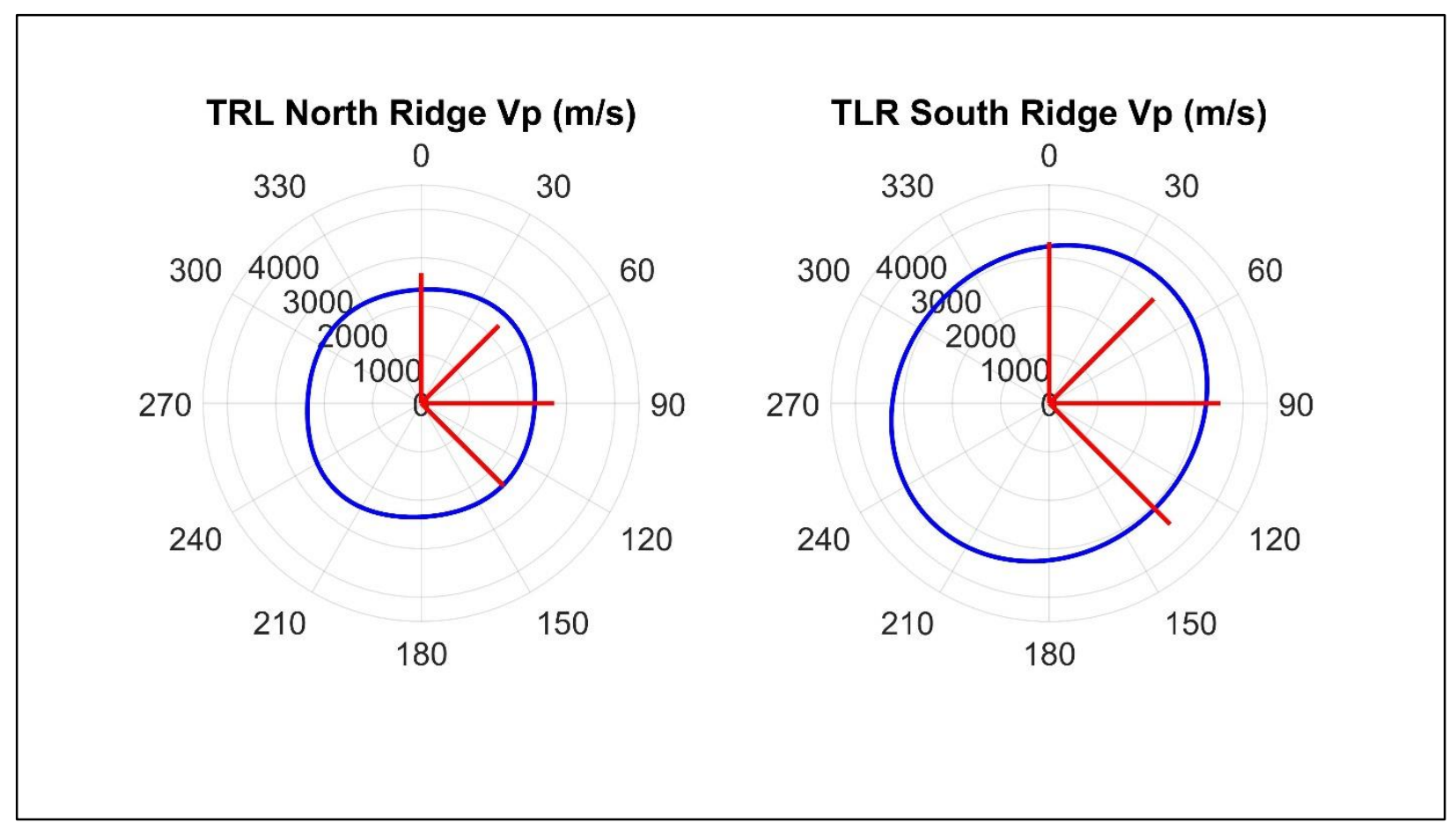

Figure 15: Modelled Vp (blue, from eqns. 1-8), and the mean $\mathrm{Vp}$, for each direction (red), Treeline (Note: $0^{\circ}$ is $\mathrm{N}$ ).

Figure 16 represents Vp values averaged at depth, and fracture density, for the SR at Treeline. At shallow depths ridge perpendicular seems to be the slowest direction, at around $15 \mathrm{~m}$ depth all directions converge. At $15 \mathrm{~m}$ depth both sets of fractures close. Unlike the NR, the fracture density in the ridge perpendicular direction is negligible. The predominant set of fractures is oriented ridge parallel; this would explain the fact that ridge perpendicular displays the slow velocity direction. 


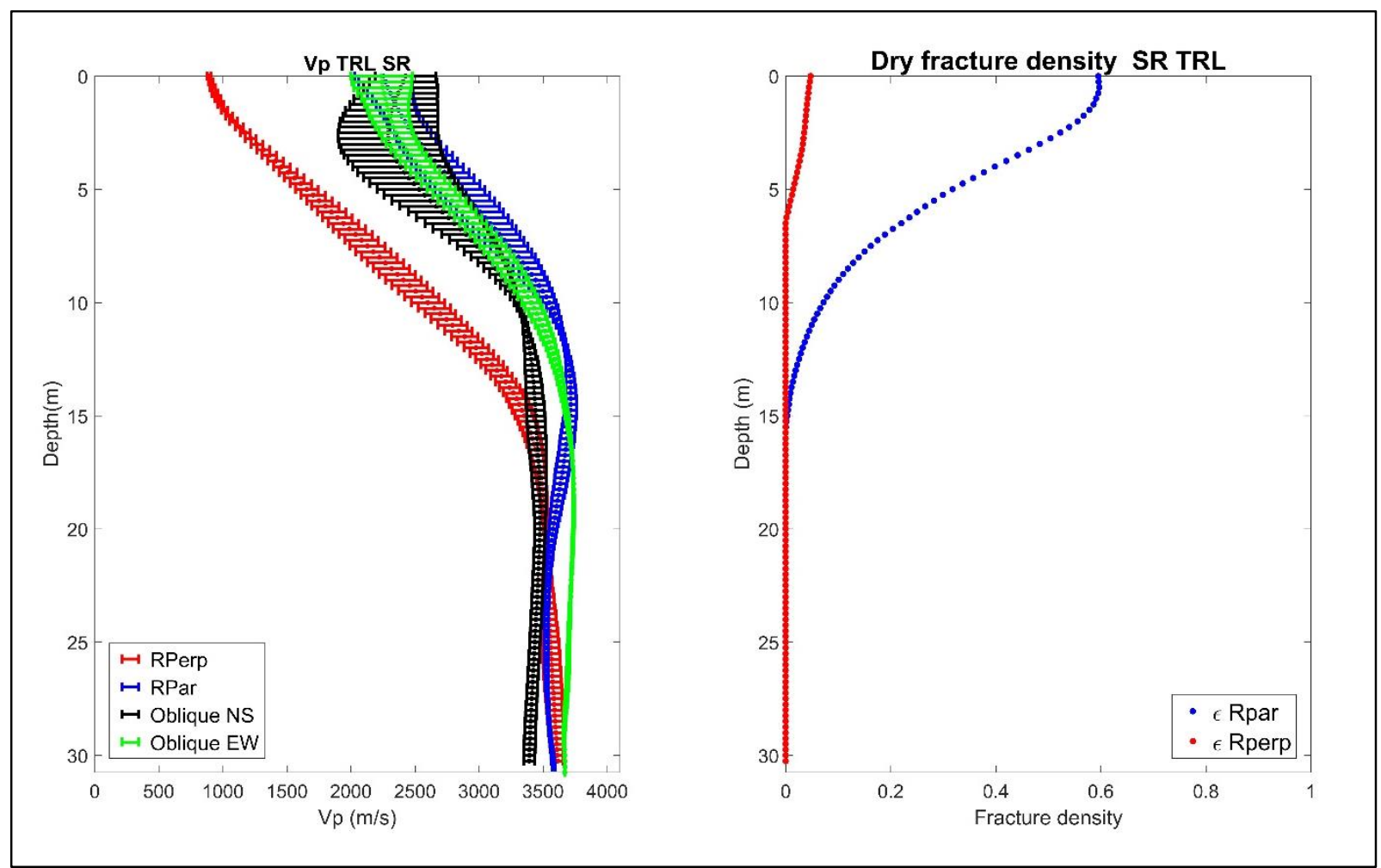

Figure 16: Plot on the left represents the average Vp value at depth with error bars, for the SR at Treeline. The blue line is the parallel direction, the red line is the perpendicular direction, the black line is the $\mathrm{N}-\mathrm{S}$ direction, and the green line is the E-W direction. Plot on the left is the fracture density at depth, for Treeline. Blue line represents fracture density for the ridge parallel set of fractures, and the red line represents fracture density for the ridge perpendicular set of fractures. (Note: the error bars represent the standard deviation of $V p$ at depth).

The $\mathrm{N}$ and $\mathrm{S}$ ridges do not have a similar behavior. According to St. Clair et al. (2015), fracture density is dependent on both regional and topographic stress. Regional stress is the same in both ridges. The only striking difference between ridges is that NR has a steeper topography, than SR. Another, perhaps significant, difference is that NR is much longer and the survey profile is much further from the up -elevation ridge termination. These differences may lead to differences in the local stress and therefore influence the fracture behavior. 


\subsubsection{Preferential orientation and percentage change}

The preferential direction for fractures, should match the direction of fast $\mathrm{Vp}$. Treeline's situation is more complicated than Lower Weather's (figures 11 and 15).

The major axis of the modelled Vp should roughly point to the direction of the dominant set of fractures. For the SR, the direction of the Vp major axis point to the NESW direction. However, I cannot confirm with certainty a preferential fracture orientation with my azimuthal density.

I plotted a mean Vp per azimuth, in figure 15 (in red). I calculated the mean Vp from 5-25 m depth, of figures 14 and 16. I modelled Vp (in blue) from the calculated fracture density (figures 14 and 16), for all azimuths.

From the modelled Treeline Vp polar plots (figure 15), we are able to see that in fact there are faster and slower velocities, however I cannot determine a preferential orientation for fractures. I don't have enough azimuthal coverage.

I have to take into account the error in the measurements, if I want to discuss anisotropy. For low anisotropy values, I could not prove with high certainty the existence of fracture induced anisotropy. I have more certainty of fracture induced anisotropy when obtaining high anisotropy values. I calculated seismic anisotropy at Treeline, from orientation to orientation, shown in tables 2-3. Yellow indicates the highest anisotropy values, and pink the lowest. 
Table 2: $\quad$ Treeline NR anisotropy values.

\begin{tabular}{|l|l|l|l|}
\cline { 2 - 4 } \multicolumn{1}{|l|}{} & \multicolumn{2}{l}{ Vp } \\
\cline { 2 - 4 } & SE-NW & NS & EW \\
\hline NE-SW & 5.68 & 15.54 & 17.41 \\
\hline SE-NW & & 10.45 & 12.44 \\
\hline NS & & & 2.21 \\
\hline
\end{tabular}

\section{Table 3: $\quad$ Treeline SR anisotropy values.}

\begin{tabular}{|l|l|l|l|}
\hline \multirow{2}{*}{} & \multicolumn{2}{|l|}{ Vp } \\
\cline { 2 - 4 } & SE-NW & NS & EW \\
\hline NE-SW & 13.62 & 8.34 & 13.74 \\
\hline SE-NW & & 5.75 & 0.14 \\
\hline NS & & & 5.89 \\
\hline
\end{tabular}

For Treeline, NR displays the highest anisotropy values between the N-S and NESW direction, and between the E-W and NE-SW directions.

This suggests anisotropy presence in the NR, but resolving the fracture preferential orientation is not possible with only four azimuths. The directions that display the highest anisotropy value in the SR, is the NE-SW, with respect to the SE-NW and E-W directions. The anisotropy value in the SR is lower than in the NR, but it is still suggestive of anisotropy. 


\subsubsection{Bogus Basin results}

\subsubsection{Tomograms}

Figure 17 shows the tomography sections for the reverse VSP's done at Bogus Basin. One of the benefits of conducting surveys in a borehole is the access to a lithology $\log$. Pictured in figure 17 is an approximate lithology log. I originally, shot seismic sources to depths of $89 \mathrm{~m}$, but only used sources shallower than $57 \mathrm{~m}$ depth due to the poor quality of the data at lower depths. 


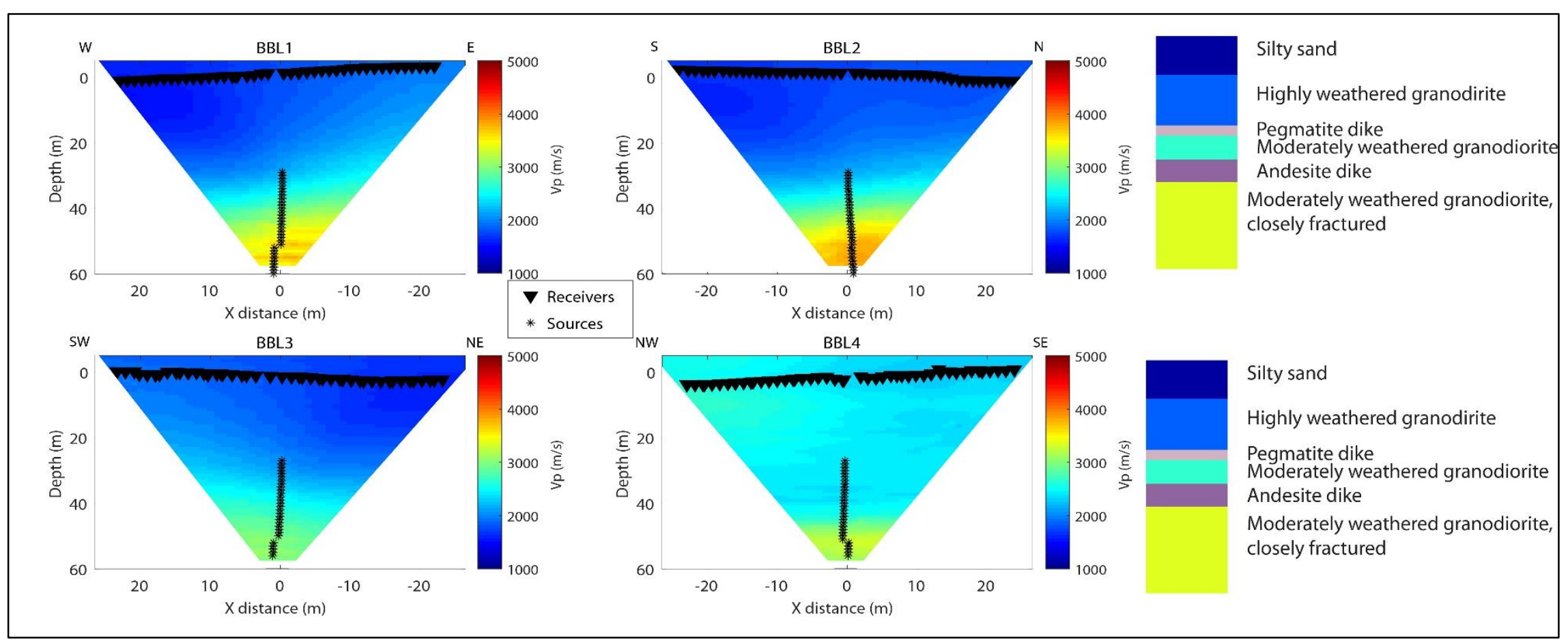

Figure 17: Seismic tomography for the Bogus Basin borehole (on the left), and lithology log from the borehole (on the right). Lithology was taken from drilling report (Kleinfelder, 1993).

I additionally present an example of the first break picks for Bogus Basin in the Appendix (figure 39). 
In all sections we observe a sudden increase of $\mathrm{Vp}$ at around $35 \mathrm{~m}$ depth, which roughly corresponds to the depth at which the "moderately weathered granodiorite, closely fractured" section begins. In the shallower area we are able to observe that the L4 direction is the fast direction. With the data collection geometry I am not able to resolve the soil portion of the weathering layers, at Bogus Basin. In lines L1, L2, and L3 I am able to observe a decrease of $\mathrm{Vp}$, in the West, South, and Northeast upper portions of the tomography sections.

I obtained seismic refraction tomograms from the sources I shot at the surface, at Bogus Basin (see figure 18). I inverted these sections using Rayfract. We observe a decrease in $\mathrm{Vp}$ in the $\mathrm{W}-\mathrm{S}$ direction.
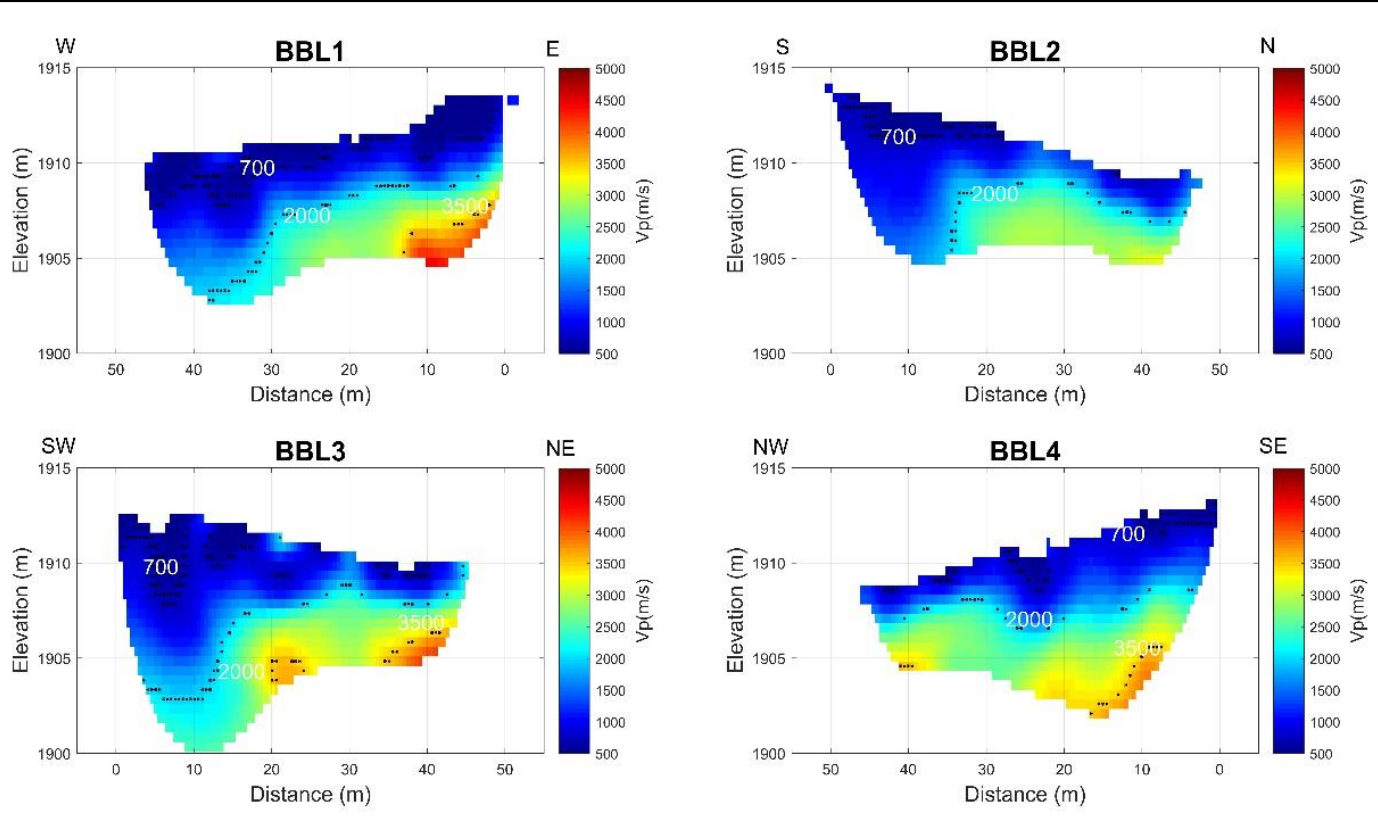

Figure 18: Seismic tomography for the Bogus Basin surface seismic refraction experiment.

Both seismic methods are models, and an approximation of reality, and both methods contain errors. Both methods have also different sensitivities, and resolution. 
The surface seismic has better power in resolving the near surface portion of the Bogus Basin site. The reverse VSP dataset better resolves the overall velocity structure at depth. The reverse VSP ray paths are closer to vertical and it may be harder to identify azimuthal anisotropy, with such a data collection geometry.

\subsubsection{Crossing point and fracture density}

Figure 19 shows Vp values averaged at depth and fracture density for Bogus Basin. In general, L3 appears to be the slowest direction, at most depths. At lower depths L1, and L2 have the fastest velocities. In the shallowest section L4 displays the fastest velocity.

From the fracture analysis done by Gates et al. (1994) at Bogus Basin, I assumed that the direction of the main sets of fractures were in the $\mathrm{N}$ and $\mathrm{E} 20^{\circ} \mathrm{S}$ directions. I used Crampin et al. (1980) equations to solve for fracture density for each set of fractures. The predominant set of fractures results to be north oriented. Both sets of fractures "close" at around $45 \mathrm{~m}$ depth, using the reverse VSP dataset (figure 19). 


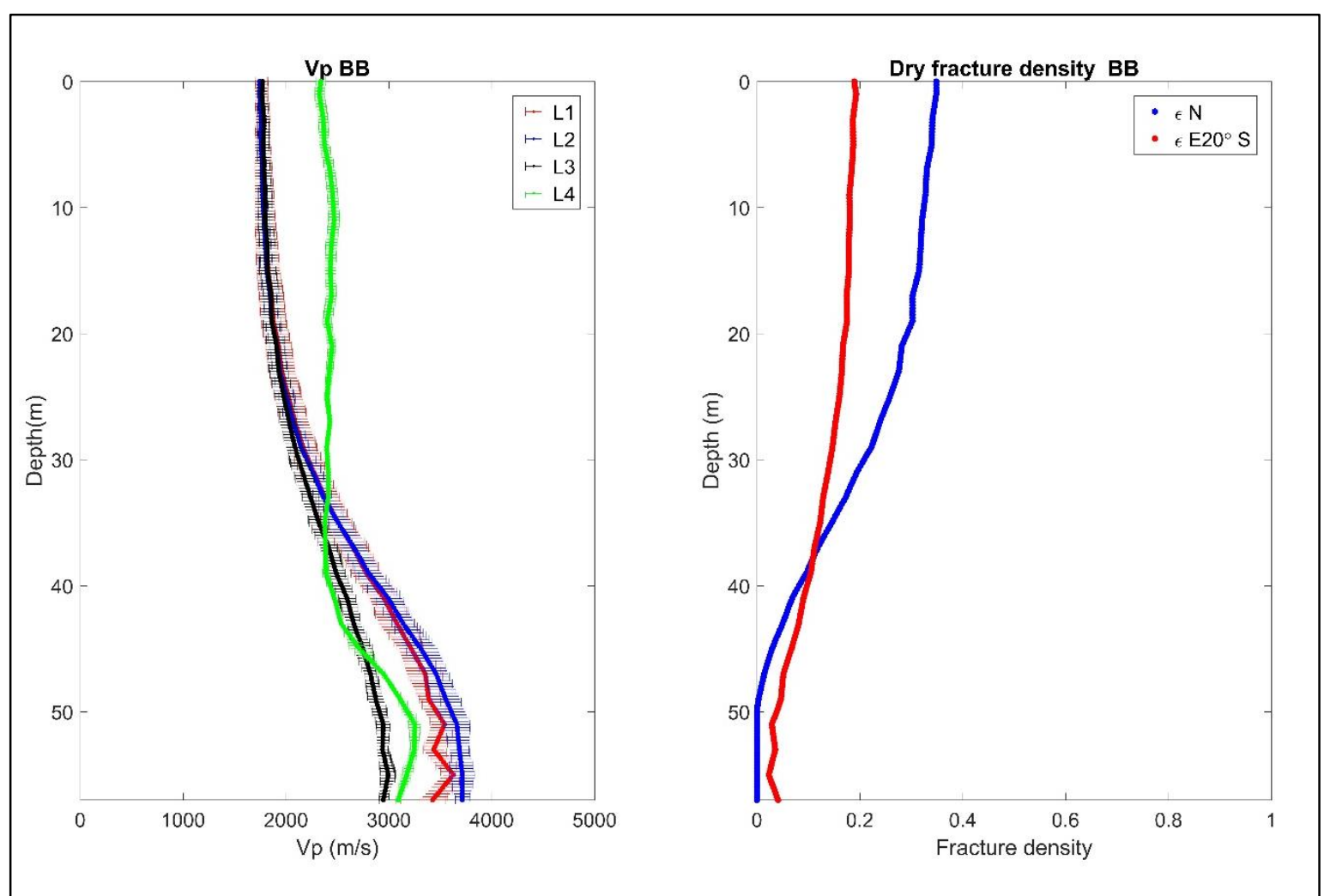

Figure 19: Plot on the left represents the average $V p$ value at depth, for Bogus Basin. Plot on the left is the fracture density at depth, for Bogus Basin. Blue line represents fracture density for the N-S set of fractures, and the red line represents fracture density for the N-S set of fractures, and the red line represents fracture density for the $\mathrm{E20}^{\circ} \mathrm{S}$ set of fractures. (Note: the error bars represent the standard deviation of $\mathrm{Vp}$ at depth).

\subsubsection{Preferential orientation and percentage change}

For Bogus Basin (figure 19) the slow Vp direction appears to be in the NE

direction. Again, I cannot resolve completely preferential fracture orientations, solely based on my results, since I do not have enough azimuthal coverage.

In order to gauge fracture induced anisotropy, I calculated Vp percentage change at Bogus Basin. If there's large changes in Vp values I will be able to state, with more confidence, the existence of fracture induced anisotropy. 
I calculated velocity averages per line over depths of 20-50 m. I calculated percentage change in $\mathrm{Vp}$ values from orientation to orientation, and are shown in table 4. Yellow indicates the highest anisotropy values, and pink the lowest.

Table 4: $\quad$ Bogus Basin anisotropy values.

\begin{tabular}{|l|l|l|l|}
\hline & \multicolumn{3}{|l|}{ Vp } \\
\cline { 2 - 4 } & L2 & L3 & L4 \\
\hline L1 & 0.98 & 9.01 & 2.38 \\
\hline L2 & & 9.90 & 3.33 \\
\hline L3 & & & 6.79 \\
\hline
\end{tabular}

For Bogus Basin (table 4), we see little to no anisotropy between directions.

For the Bogus Basin site, to avoid inversion artifacts I decided to plot first arrival travel times (figure 20), per azimuth. I only used picked travel times from 29-45 m depth, due to the verticality of the well in that section $(>0.5 \mathrm{~m}$ deviation from the top of the borehole). I only used travel times from geophones 5 and 44 of each line, due to their symmetry, and the completeness of picks in that particular section. Bogus Basin velocity inversion shows no clear anisotropy, however plotting the travel times from 29-45 m depth allows us to better observe anisotropy, within first arrival travel times. 


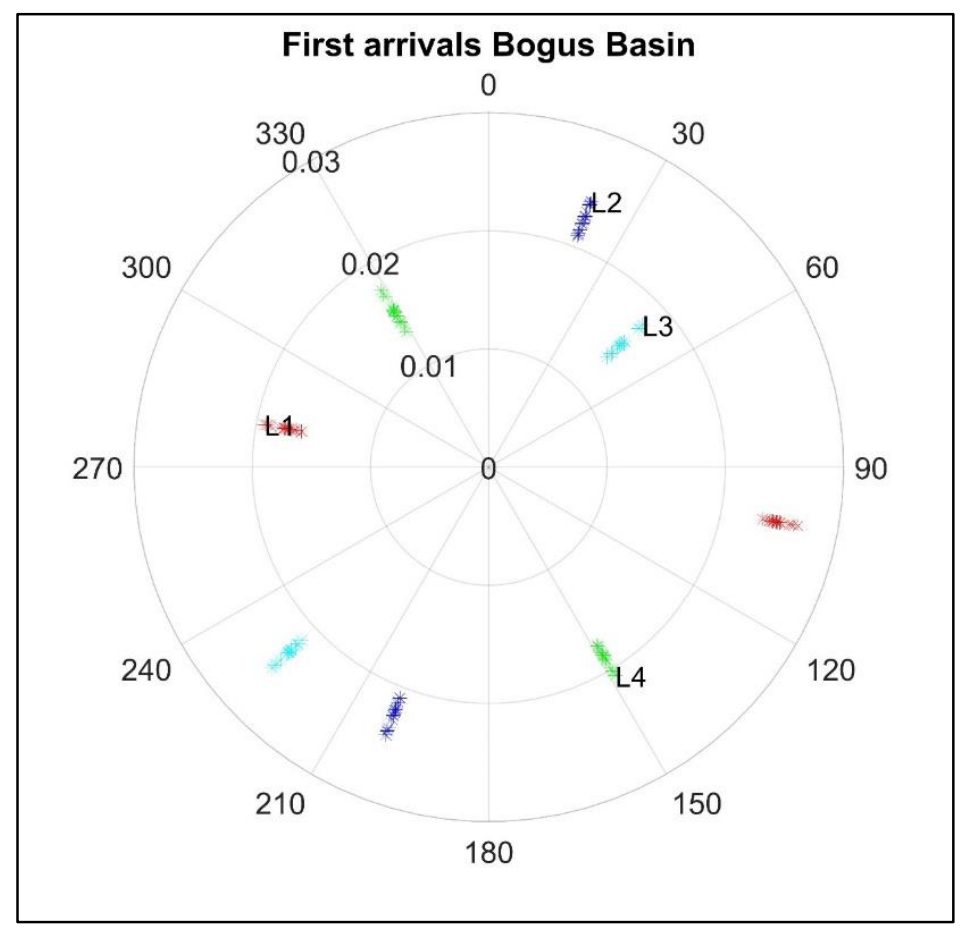

Figure 20: Traveltimes (blue, cyan,red, and green), for the Bogus Basin reverse VSP dataset (Note: $0^{\circ}$ is $\mathbf{N}$ ).

The preferential direction of fractures (see figure 22), should match the direction of fast $\mathrm{Vp}$ (see figure 21). Three out of the 4 lines in which I surveyed at Bogus Basin, match almost exactly the direction in literature (Gates et al., 1994) of possible fractures at Bogus Basin; this was not actually intended. Seismic profiles were deployed in those exact locations for logistic reasons (avoiding trees, or other structures).

I calculated a mean $\mathrm{Vp}$, from the tomography sections, in 20 by $30 \mathrm{~m}$ regions, from depths $20-50 \mathrm{~m}$. The fast velocities correlate well with the direction of the previously measured fracture sets. From mean Vp's and mean fracture densities, I modelled Vp at all azimuths, using Crampin et al. (1980) equations for two sets of fractures. 


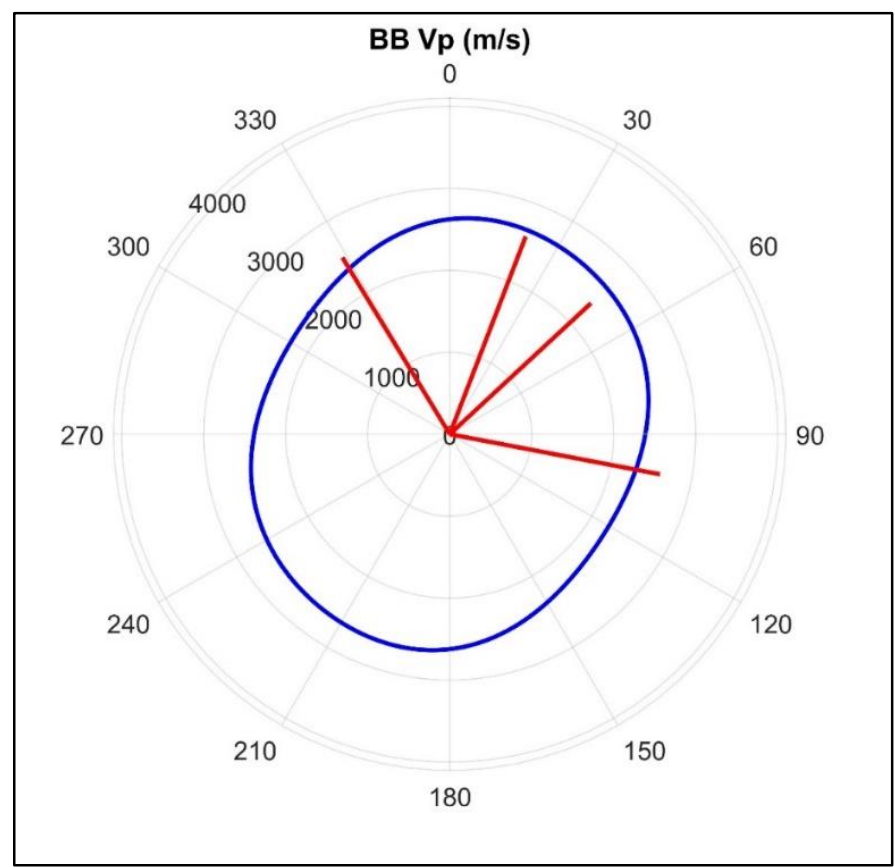

Figure 21: Modelled Vp (blue, from eqns. 1-6), and the mean Vp, for each direction (red), calculated for the depth range of 20-50 m, at Bogus Basin. (Note: $0^{\circ}$ is $\mathbf{N}$ ).

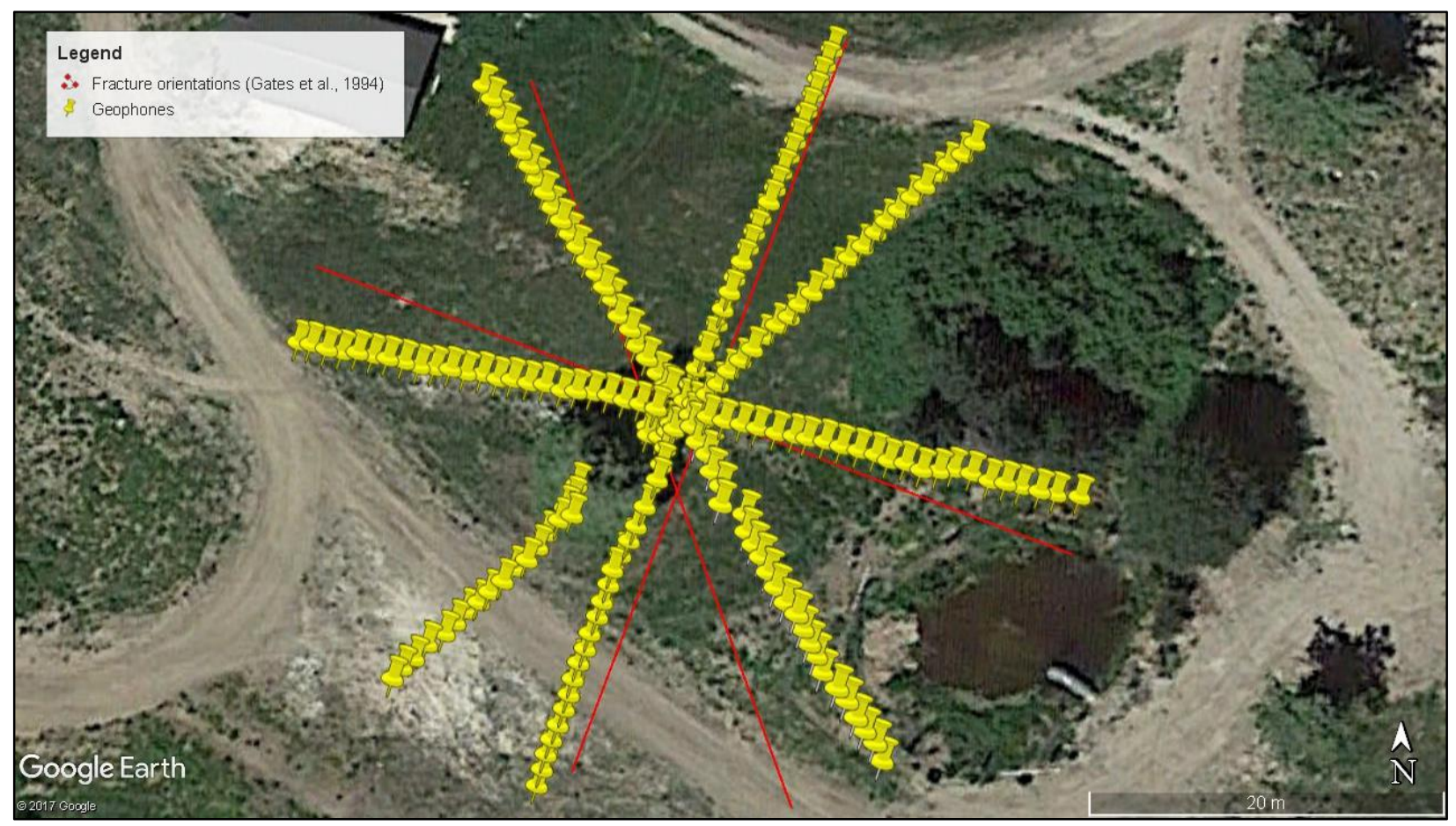

Figure 22: Fracture orientations according to Gates et al. (1994), and geophone locations at Bogus Basin. 


\subsection{Seismic refraction discussion}

In hydrogeophysical studies, geophysical methods are used in the hopes of obtaining a better understanding of hydraulic parameters such as fracture density, porosity, hydraulic conductivity, etc (Knight and Endres, 2005). In order to obtain the best possible hydrologic parameters, one has to begin with a good geophysical data collection strategy to avoid obtaining misleading results in the hydrologic parameters. Of course, even with a good geophysical data collection strategy, there are other possible sources of error or uncertainty in the survey area (e.g. choosing an incorrect petrophysical model, artifacts in the inversion of the geophysical parameters, etc.). However, planning for a good survey is always the first step into obtaining a hydrologic model closer to the true model. In my case, I surveyed in a known fractured area, therefore we expected anisotropy in the geophysical parameters. From the seismic anisotropy measurements (tables 2-4) I identify that the location that portrays the highest Vp azimuthal anisotropy is Lower Weather.

In order to understand how much error might be introduced by assuming an isotropic medium and collecting measurements in only one direction. I calculated fracture density for each azimuth. I made the assumption that the medium contained multiple sets of fractures in random orientations. This would be a valid assumption in a mountain watershed underlain by fractured bedrock.

I used a model of randomly oriented vertical fractures to calculate fracture density, described in detail in Berryman (2007):

$$
\varepsilon=\frac{-15}{2} \frac{G_{0}}{E_{0}} \epsilon \frac{1+v_{0}}{5+v_{0}}
$$


Where: $G_{0}, E_{0}$, and $v_{0}$ are the background's material shear modulus, Young's modulus, and Poisson's ratio, respectively. $\epsilon$ is the Vp Thomsen anisotropy parameter, and depends on the measured $\mathrm{Vp}$ and the $\mathrm{Vp}$ of the background material.

In order to derive equation 10 from Berryman (2007), I assumed a noninteraction approximation from Berryman and Grechka (2006).

I used equation 10, to calculate fracture density using each survey's Vp values. I calculated the Lamé parameters using a Young modulus of 52, and a Poisson ratio of 0.31 , for the background material (obtained from Olona et al., 2010). I assumed dry fractures and a background Vp of $3500 \mathrm{~m} / \mathrm{s}$. From the lithologic logs near Lower Weather (figure 9) we see that the water table near Lower Weather is roughly at around $50 \mathrm{~m}$ depth. I collected both seismic profiles at Lower Weather at the end of summer, basically in the driest conditions. Therefore, assuming dry fractures for this analysis is valid.

Figure 23 shows the fracture density calculated using equation 10, with the ridge parallel survey (red), and the ridge perpendicular survey (blue). For comparison, the minimized root mean square error (rmse) fracture density (eqn.8) using both surveys appears in black.

Deciding to solely deploy a 2D survey, the obtained results would greatly vary depending on the azimuth on which the survey was collected. From figure 23 we can observe that the "parallel-random" line shows that most fractures close at around 27 m depth. The "perpendicular-random" line shows that most fractures close at around $53 \mathrm{~m}$ depth, and the minimized rmse line shows that most fractures close at around 28 
$m$ depth. Hydraulically, there is a big difference between having possibly active hydraulic fractures closing at around $27 \mathrm{~m}$, than at $52 \mathrm{~m}$ depth.

I must mention again that the "closure depth" is velocity dependent. I chose $3500 \mathrm{~m} / \mathrm{s}$ for closure (from Olona et al., 2010). Such an assumption could be wrong. Apparent fracture density values also change for every case, the rmse minimized case has the widest range of values (from 0 to 1), both "parallel-random" and "perpendicular-random" have a very linear behavior on the decrease of fracture density with depth. For these reasons, when surveying in suspected fractured areas, fracture induced hydraulic anisotropy must be taken into account to make good hydrologic interpretations. 


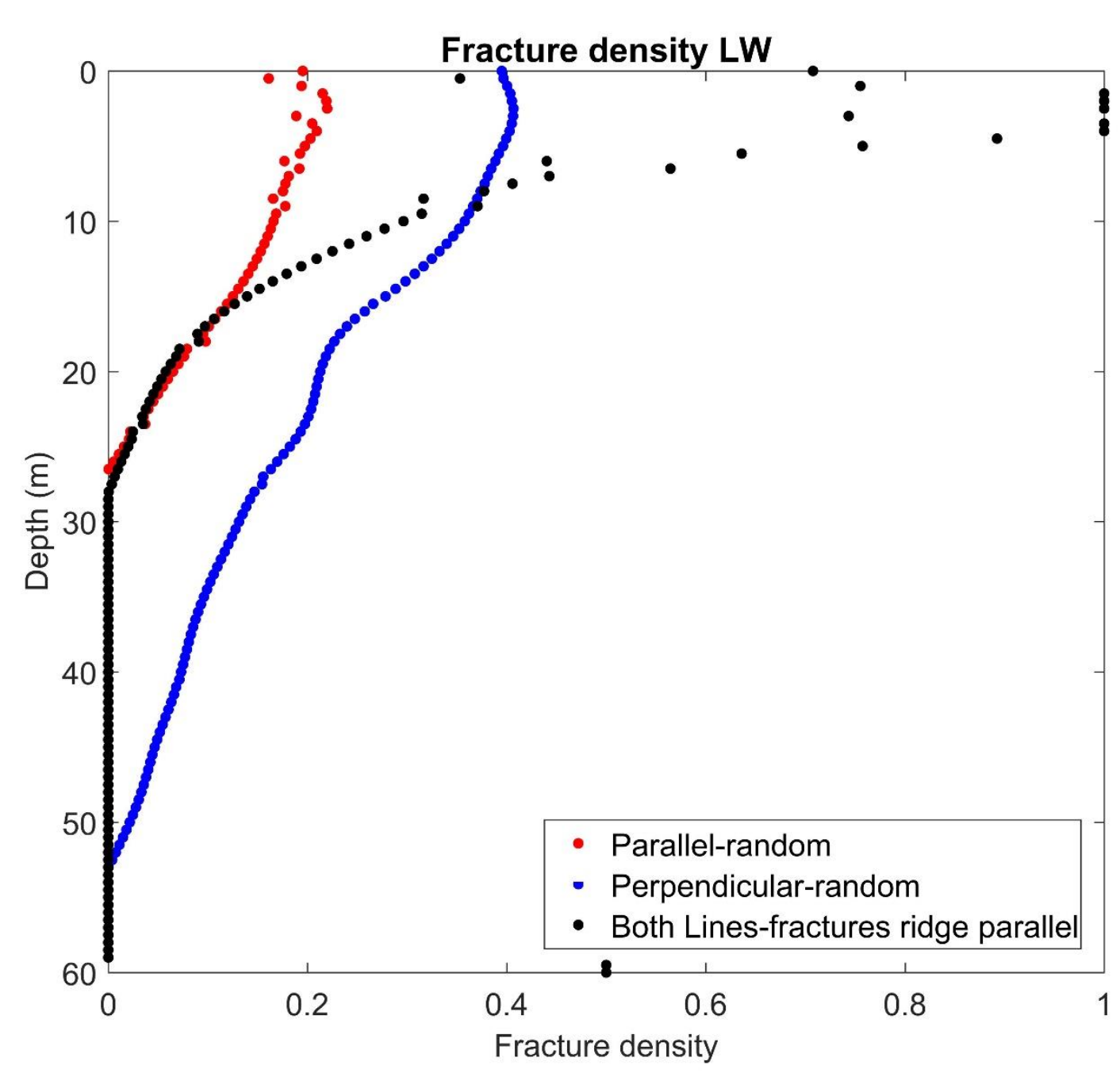

Figure 23: Fracture density calculated with a randomly oriented set of fractures using the ridge-parallel survey (red), and the ridge-perpendicular survey (blue), both at Lower Weather. The black line represents the minimized fracture density depth profile obtained by using a model with one set of fractures and taking into account the angle between suspected set of fractures and survey orientation.

Often times, CZ geophysicists deploy seismic surveys in order to obtain

measurements of depth to bedrock. If I decided to use only one of my profiles to calculate depth to bedrock, I would get completely different results. I use a velocity contour of $3500 \mathrm{~m} / \mathrm{s}$ (table 1) as a rough gauge of bedrock. Using the ridge parallel profile I would obtain a depth to bedrock at $27 \mathrm{~m}$ depth. Using the ridge perpendicular profile I would obtain a depth to bedrock at $53 \mathrm{~m}$ depth. Due to the anisotropy in the subsurface, we 
obtain such a difference in our results. For fractured mountain watersheds, we should be using 2D seismic profiles at different azimuths or even better, a full 3D seismic deployment. These systems are too complex to be interpreted solely using one $2 \mathrm{D}$ profile in one single orientation.

My research hypothesis was: "there is a fracture system with a ridge parallel preferential orientation, allowing deep weathering below the North Treeline ridge top". When analyzing the results from figures 10,14 , and 16 it appears that there is a striking difference between Treeline ridges. In the NR, both sets of fractures appear to have an effect in the $\mathrm{Vp}$ values we obtained. However, for the SR, the ridge perpendicular set of fractures appears to have little to no effect on the Vp values. In the SR there is an obvious slow velocity direction, and also a depth in which all directions sort of converge; this depth is roughly the same depth at which fractures appear to close. In the NR, we can infer there is a fast velocity direction, it is hard to determine a depth at which all or most fractures converge.

Upon reviewing figure 15, we observe a clear slow and a fast direction. We observe a fast, then a slow velocity at $0^{\circ}$ and $45^{\circ}$ respectively, from figure $15 \mathrm{NR}$ seismic plot. We observe the fastest direction at $90^{\circ}$, them a slow velocity at $135^{\circ}$, from figure 15 NR seismic plot. These results match a model of two sets of orthogonal fractures. However, we need more azimuthal coverage in order to validate the existence of two sets of fractures.

A similar behavior is displayed in the SR. Changes in Vp values aren't as dramatic as in the NR. For both ridges, it is necessary to do a full 3D survey or collect data at more azimuths if we want to better determine the orientation of all fracture sets. 
For control, I created histograms of fracture lineaments for the DCEW (figure 3) and Treeline, based on the careful mapping study given by Acker (2008). From the histograms (figure 24), I can determine roughly two main fracture orientations, in the DCEW. One fracture orientation is in the NE direction $\left(\mathrm{N} 45^{\circ} \mathrm{E}\right)$, and the other orientation appears to be in the $\mathrm{SE}$ direction $\left(\mathrm{S} 45^{\circ} \mathrm{E}\right)$. At Treeline, one dominant fracture orientation is evident at around $150^{\circ}$ from $\mathrm{N}$. There are more fractures at other orientations in Treeline, but they range azimuths from $0^{\circ}$ to $45^{\circ}$, and $68^{\circ}$ from the north. From both histograms we observe that there's a wide range in which fractures are present in the DCEW, and Treeline. With my surveys, I was only able to measure Vp and ER at four or two azimuths. I need better azimuthal coverage to be able to fully characterize the fracture azimuthal variance.

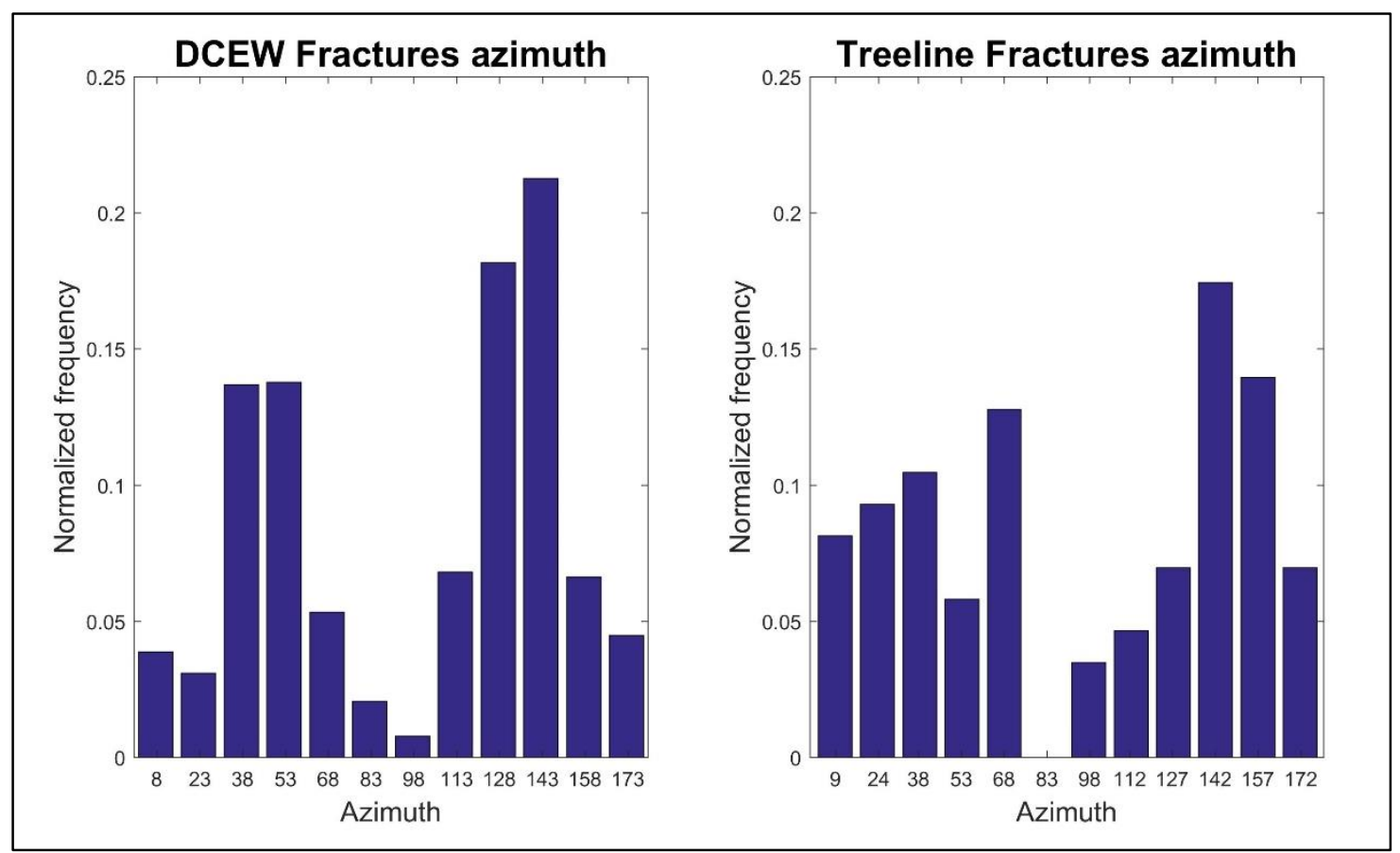

Figure 24: Histograms of fracture lineament azimuth, for the DCEW and Treeline. 
Locating a seismic source in the center of a circle of geophones is a method that has been used in the past, for example, for shear wave propagation in anisotropic media (Sondergeld and Rai, 1992). At different azimuths it is possible to see a change in shear wave polarization, according to the material fabric.

For CZ purposes, other research groups (Steven Holbrook) have tackled the characterization of fracture orientation by using the circle method for $\mathrm{P}$-wave propagation (Novitsky et al., 2016). Early arrival times correspond to the fracture orientation. This method has a great advantage in the sense that the azimuthal coverage of geophones can be high, without significantly increasing the physical labor in data collection. With a denser azimuthal coverage it may be possible to resolve fracture orientation more effectively in the case of multiple fracture sets. One of the down sides of this method is that rough topography complicates the analysis, e.g. simple traveltime differences, as interpreted by St. Clair et al. (2015) can be caused either by topography or by velocity variation. Another problem is that we do not get much depth information with this approach. We do not, at present, have a way to invert these data for velocity in the presence of rough topography. Propagating a seismic wave into the saprolite or fractured bedrock layer might be too hard for places with rough topography, in specific the absence of long enough planar surfaces. Another element to look out for, while using this method, is the existence of a possible dipping refractor below the surface, if there is, a correction must be taken into account. The wagon-wheel method I used has the downside that the azimuthal coverage is significantly lower, and increasing the azimuthal coverage implies a significant increase in physical labor, by graduate students. A positive aspect of the wagon-wheel method is that the 2D lines can extend for longer distances, as long as the 
lines are maintained straight throughout the survey. This allows for deeper probing into the subsurface. When topography is too rough and no geophones circles can be deployed, the wagon-wheel array should be used. However, the best approach would be full 3D seismic acquisition. There is currently software available for such inversions (e.g. Geotomo). However, the field labor for collecting such data was beyond the resources available for this project. It is still to be researched if the fracture orientation is preserved from the fractured bedrock, all the way up to the saprolite. If this were to be the case, $\mathrm{Vp}$ azimuthal variation due to fractures could be measured first with the circle method. To characterize the deeper parts of the CZ, 2D seismic surveys could be deployed, at specific azimuths.

\subsection{Seismic refraction conclusions}

My results suggest the presence of anisotropy at the surveyed sites. Lower Weather displayed the highest anisotropy, up to almost 30\%. We also determined anisotropy at Treeline. Bogus Basin showed little to no anisotropy. Geophysical surveys done at a mountain watershed underlain by fractured bedrock should take into account the possibility of anisotropic medium. Therefore, data collection should be planned accordingly. One single azimuth (e.g. a single 2D profile) is not sufficient to properly characterize the fractured subsurface.

The "closure" of fractures is velocity dependent. The velocity I chose for fracture closure is $3500 \mathrm{~m} / \mathrm{s}$, based on Olona et al. (2010). I admit this assumption could be wrong. However, I am able to determine a major difference on calculating fracture “closure" depth, using individual surveys at Lower Weather. Using solely the ridge parallel profile we observe a depth of closure of around $27 \mathrm{~m}$ depth. On the other hand, 
using the ridge perpendicular direction we observe depth of fracture closure of around 50 $m$ depth. From this, we learn that several azimuths or better, a full 3D survey must be collected in order to better characterize the "depth of fracture closure" in anisotropic media.

One of our research objectives was to understand fracture orientation. However, I recognize that to fully characterize fracture orientations we need more azimuthal coverage. 


\section{CHAPTER THREE: ELECTRICAL RESISTIVITY TOMOGRAPHY}

\subsection{Electrical resistivity methods}

\section{$\underline{\text { 3.1.1 Electrical resistivity tomography }}$}

An ordinary electrical resistivity survey consists in injecting electrical current into the subsurface and measuring the electric potential. Any array of electrodes used to inject current or measure potential can be set to study variations of electrical resistivity with depth, lateral, and azimuthal variations in resistivity (Keller and Frischknecht, 1966). As the spacing between electrodes increases, the depth probed also increases. The measured electric potential depends on the material in which the survey is being conducted, because different materials have different electrical resistivity values. Through the electric potential measurements we are able to create a model of electrical resistivity of the subsurface. The electrical resistivity model helps us better determine the presence of structures or anomalies in the subsurface.

\subsubsection{Electrical anisotropy}

Electrical anisotropy is present when electrical resistivity varies depending on the direction in which it is measured (Greenhalgh et al., 2010). Anisotropy can take place on a macro scale when different isotropic layers behave as a single anisotropic system; fractures can cause this effect. Resistivity values are usually larger (up to ten times) when measured perpendicular to the direction of fractures ( $\rho_{t}$ known as transverse resistivity) in contrast with the parallel values ( $\rho_{l}$ known as longitudinal resistivity, Yeboah-Forson and Whitman, 2014). 
Keller and Frischknecht (1966) defined two elements to characterize electrical anisotropy in the subsurface, mean resistivity $\rho_{m}=\sqrt{\rho_{t} \rho_{l}}$, and coefficient of anisotropy $\lambda=\sqrt{\rho_{t} / \rho_{l}}$. When trying to detect electrical anisotropy using static ER measurements two strategies are mainly used: ER lines deployed at varying azimuths (Taylor and Fleming, 1989; Zhu et al., 2012; Busby, 2000), or square array techniques developed by Habberjam (Habberjam and Watkins, 1967; Habberjam, 1971; Matias, 2002). Some studies have resulted on measurements of electrical anisotropy coefficients (Yeboah-Forson and Whitman, 2014; Busby, 2000; Zhu et al., 2012). It has been suggested that most cases of anisotropy reported in the literature have been most likely misinterpretations (Greenhalgh, 2008). Characterization of anisotropic media, using ER methods is a research field that still needs advancements, in both the theoretical, and applied portions. I can use a modified version of Archie's law (Morey et al., 1984), to obtain a relation between the measured DC conductivity $\left(\sigma_{D C}\right)$, porosity $(\phi)$, and water conductivity $\left(\sigma_{W}\right)$ :

$$
\sigma_{D C}=\sigma_{W} \phi^{r}
$$

Babcock et al. (2015) used the above relation for fully saturated sea ice cracks. I assume I can use the same relation for fully saturated fractures, even though it hasn't been empirically verified. I use the same values as Morey et al. (1984) for the $r$ exponent, with $r=1.75$ if the profile is fracture parallel or $r=1.55$ if the profile is fracture perpendicular.

\subsubsection{Electrical resistivity data collection}

I collected all ERT profiles using the Syscal Pro instrument, by IRIS instruments. The setup for all of my ERT data collection was: 72 channels, using both Wenner and dipole-dipole arrays, with an electrode spacing of $5 \mathrm{~m}$. 
For both the ERT profiles at Lower Weather, I deployed two orthogonal profiles, one ridge parallel and one ridge perpendicular (figure 25). Both ER profiles were collected at the end of Spring 2017.

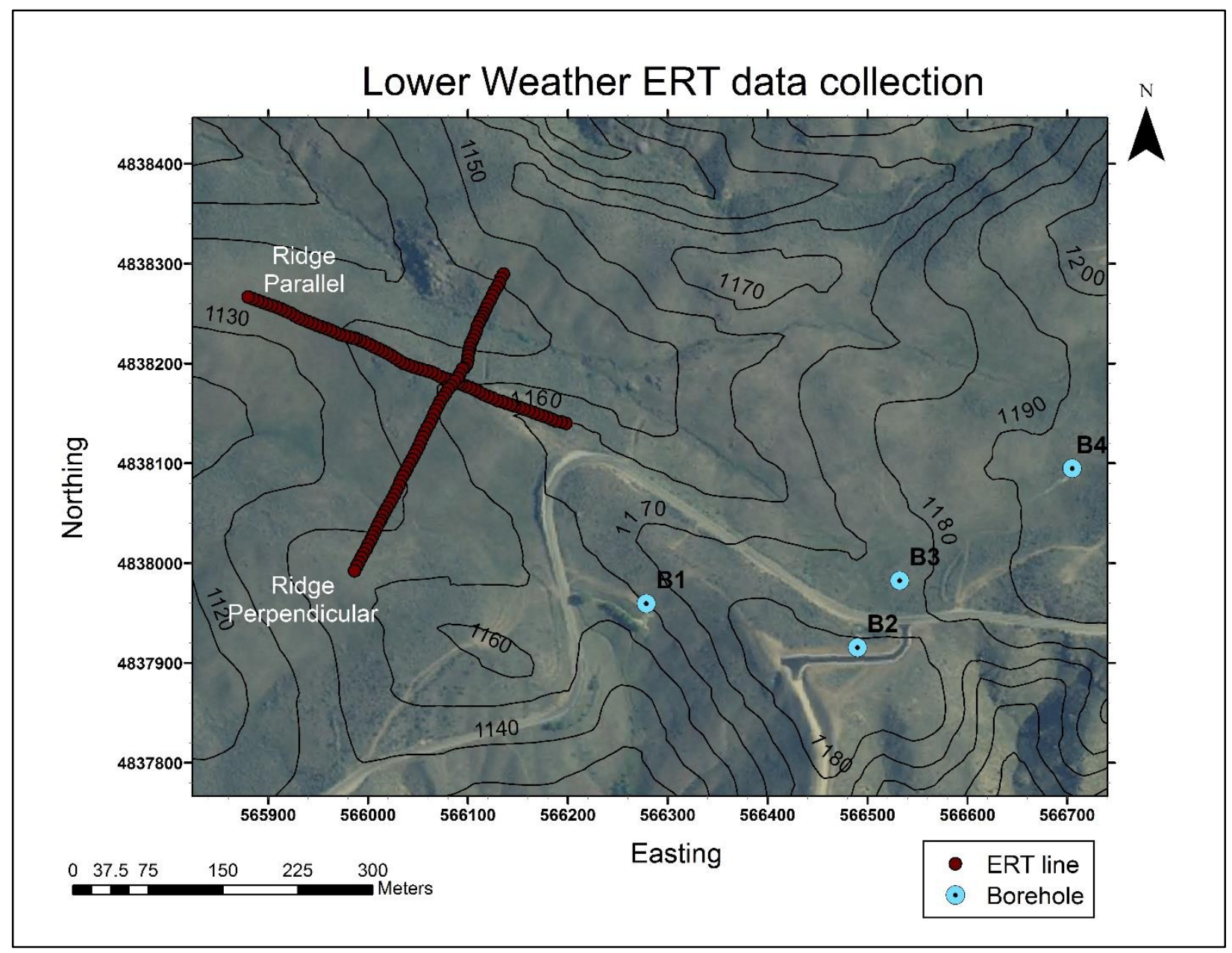

Figure 25: Map of ERT data collection at the Lower Weather site.

For the Treeline ERT data collection I collected data at three different azimuths, at each ridge (see figure 26). The profile crossing both ridges (L1) was collected in the Fall 2014, by the electrical and electromagnetic methods class of 2014, of the Department of Geosciences, at Boise State University. The remaining four profiles were collected in the Fall of 2016. 


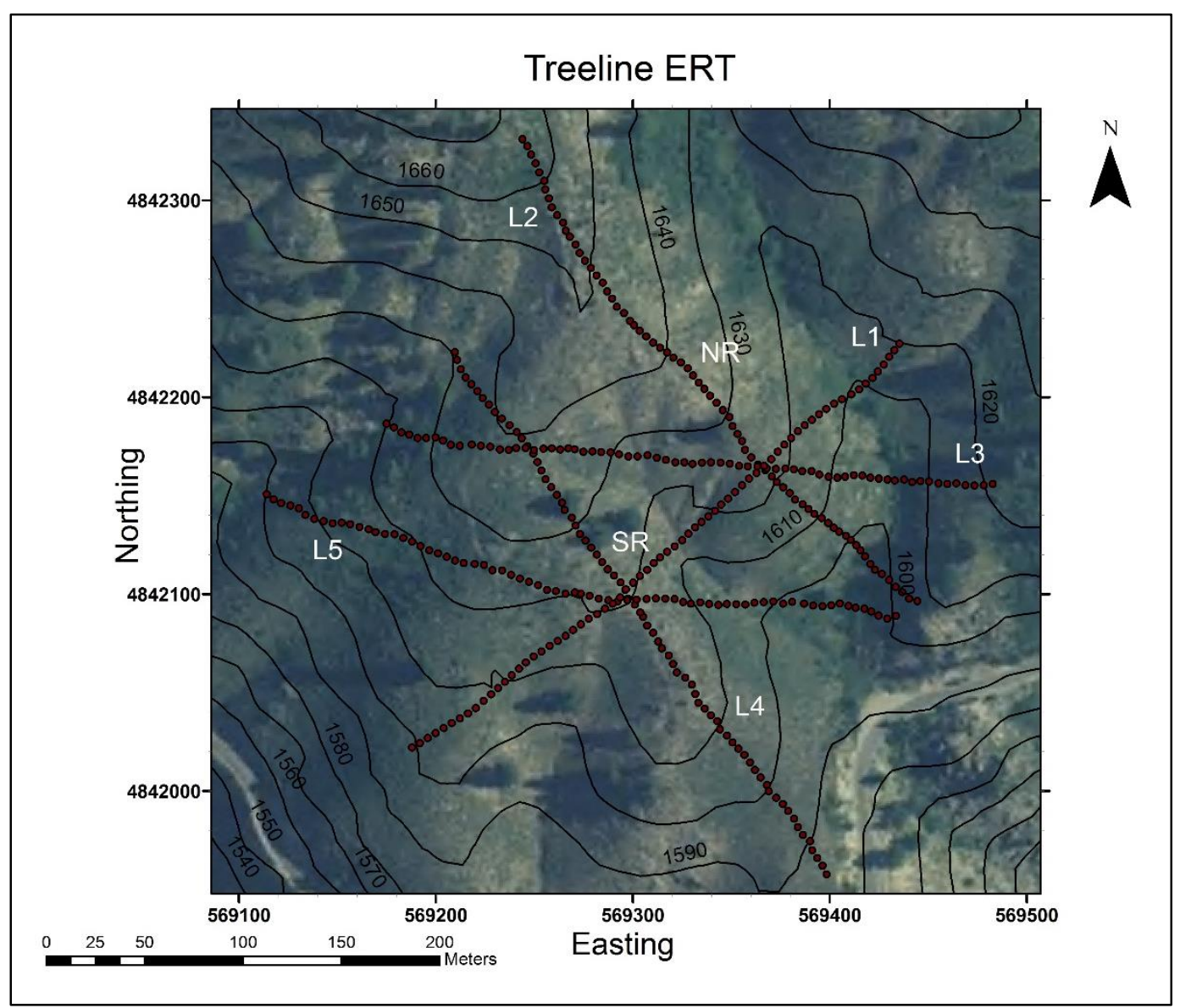

\section{Figure 26: $\quad$ Map of ER data collection at Treeline.}

\subsubsection{Electrical resistivity data processing}

I used the commercial software RES2DInv to invert the data. The inversion method I used was a finite difference, smoothed least-squares scheme, I included the errors in the measurement to improve the inversion results. I removed bad data points with standard deviations above 35\%. According to Loke et al. (2003), one of the most commonly used methods to invert ERT data is the least-squared optimization method, with a smoothness-constraint or L2 norm. This method minimizes the sum of squares of the spatial changes in the model resistivity and the data misfit. It yields better results when the changes in the subsurface are smooth (Barker, 1996). Although, when clear, sharp boundaries exist, this method tends to smear them out. 


\subsection{Electrical resistivity results}

\subsubsection{Lower Weather results}

\subsubsection{Tomograms}

Figure 27 shows the 2D ERT inversion results for Lower Weather. We observe ER heterogeneity in both directions, ridge parallel and ridge perpendicular. The sections are both laterally and vertically heterogeneous, making it difficult to interpret in terms of a simple weathering model.

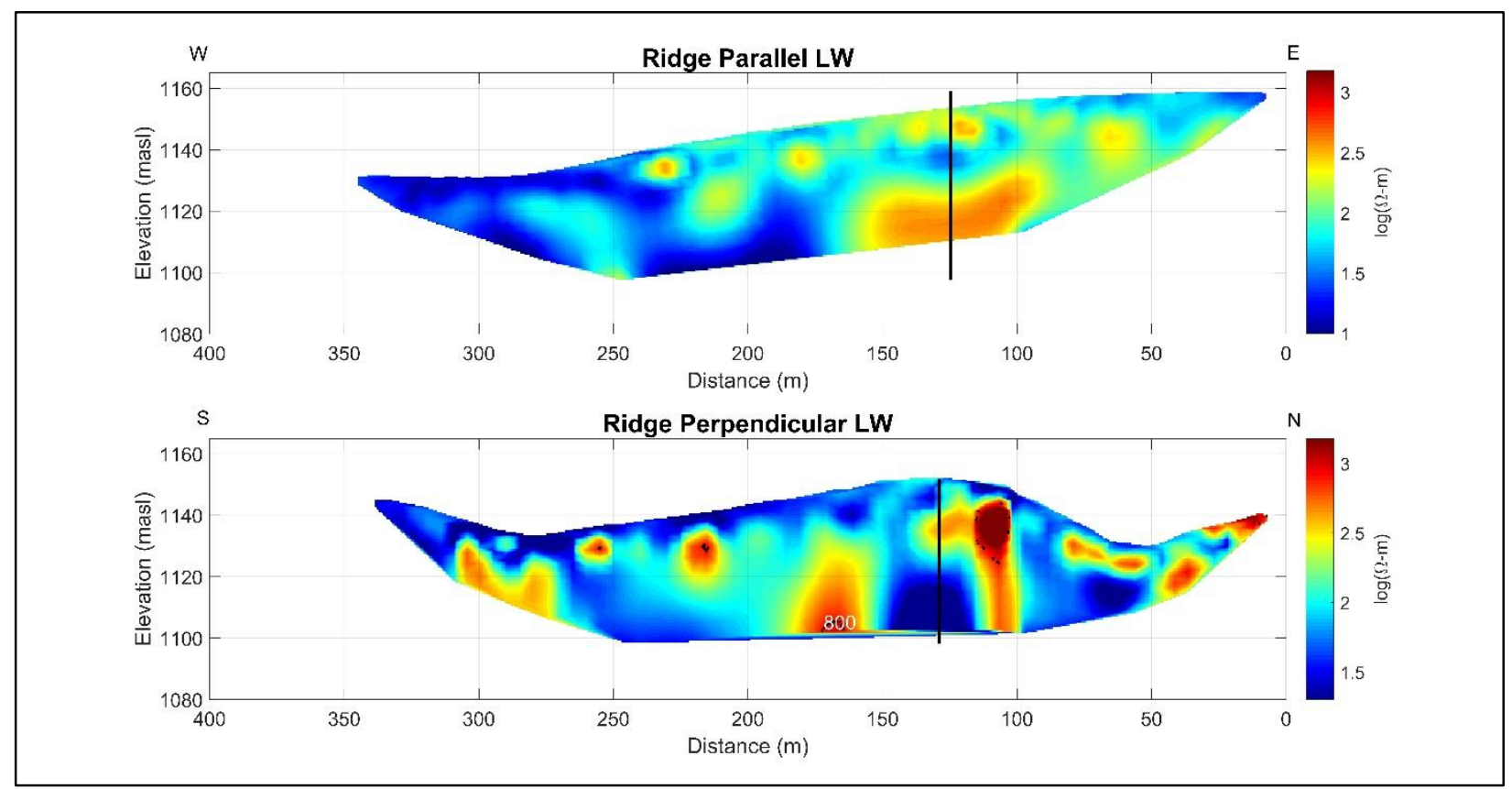

Figure 27: Electrical resistivity tomography for the Lower weather site. Black lines represent the crossing point between both surveys. Contoured sections display a higher ER, distinctive of fresh granite (see table 1).

I additionally present ER pseudo-sections for Lower Weather in the Appendix (figure 35).

Electrical characterization of fractured systems is by itself a complicated task, if the system includes clays, this task becomes more challenging. We see from the lithologic logs (figure 9) that clays are found at the very top of the depth profile, near 
Lower Weather. We also see clays at depth in one of the wells near Lower Weather. Clays have low ER when wet and high ER when dry. The inversion models I used are highly regularized, in order to get a stable solution. These high regularizations might interfere in the correct resolution of fractures in the subsurface, and yield smoothed models. I believe my Lower Weather ERT profiles are hard to interpret, because we have an especially complex system in the subsurface.

\subsubsection{Crossing points}

To compare data collected at different azimuths, I took a $20 \mathrm{~m}$ section centered at the crossing point, for every azimuth, then I calculated an average resistivity as a function of depth. Figure 28 represents the averaged section, at the crossing point in Lower Weather. Due to the presence of many heterogeneities in the ERT profiles, interpreting such results for electrical anisotropy purposes is impossible. 


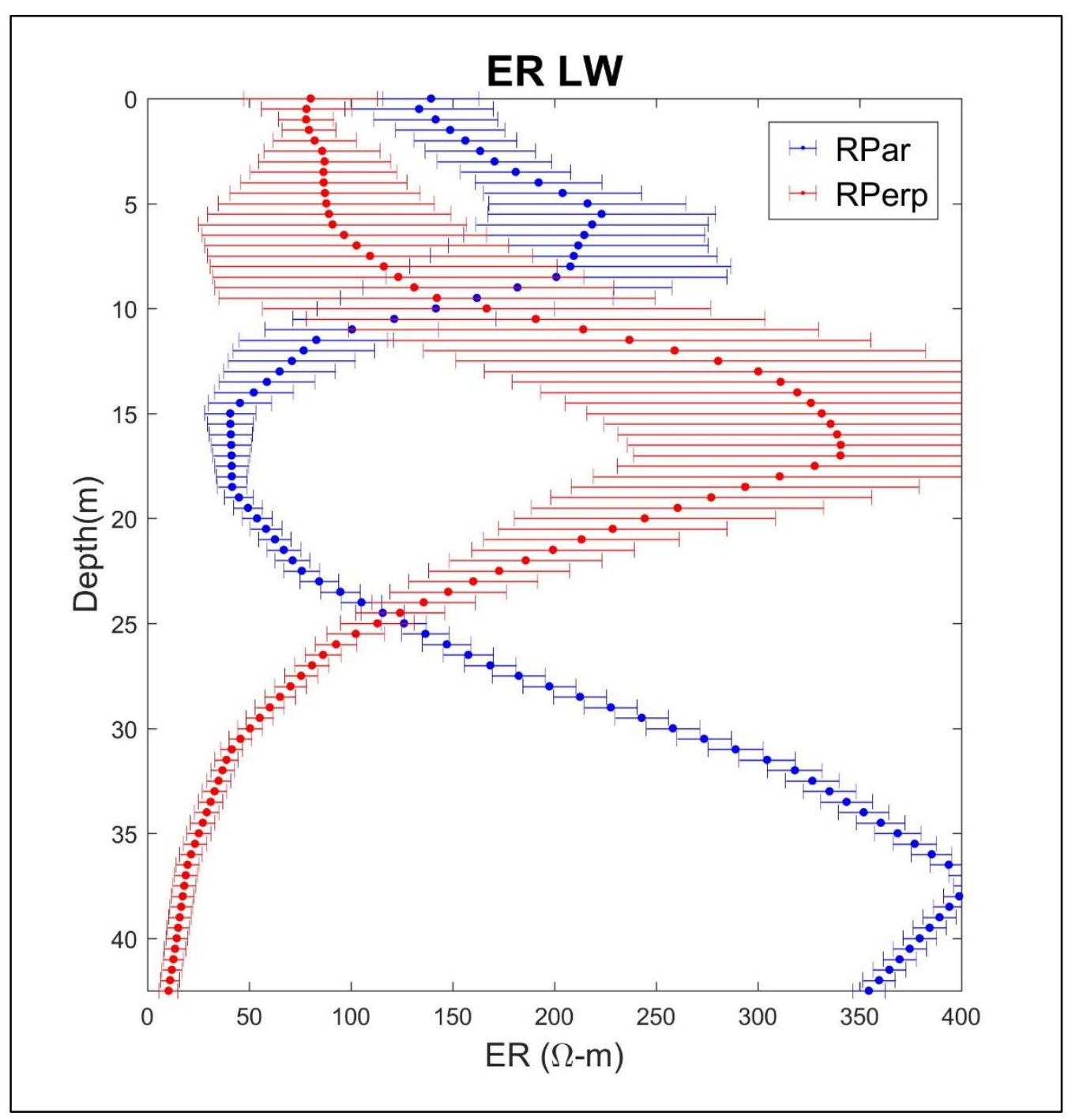

Figure 28: Average ER at depth with error bars, at Lower Weather. The blue line represents the parallel direction, and the red line represents the perpendicular direction. (Note: the error bars represent the standard deviation of ER at depth).

Based solely on the ER results I am unable to prove ER anisotropy at Lower Weather. The uncertainty and heterogeneity is too high to make any firm conclusions.

\subsubsection{Preferential orientation}

The preferential direction for fractures, should match the direction of low ER. I plotted a mean ER per azimuth, in figure 29 (shown in red). I calculated the mean ER from 5-25 $\mathrm{m}$ depth, from figure 28. I fitted an ellipse to the mean ER values. We observe from figures 11 and 29 that the direction of low ER matches the direction of the fast Vp. 
This observation agrees, qualitatively, with what is expected for ER values. However, I must recognize that our ER results for Lower Weather are too heterogeneous and too uncertain to make firm conclusions on anisotropy matters.

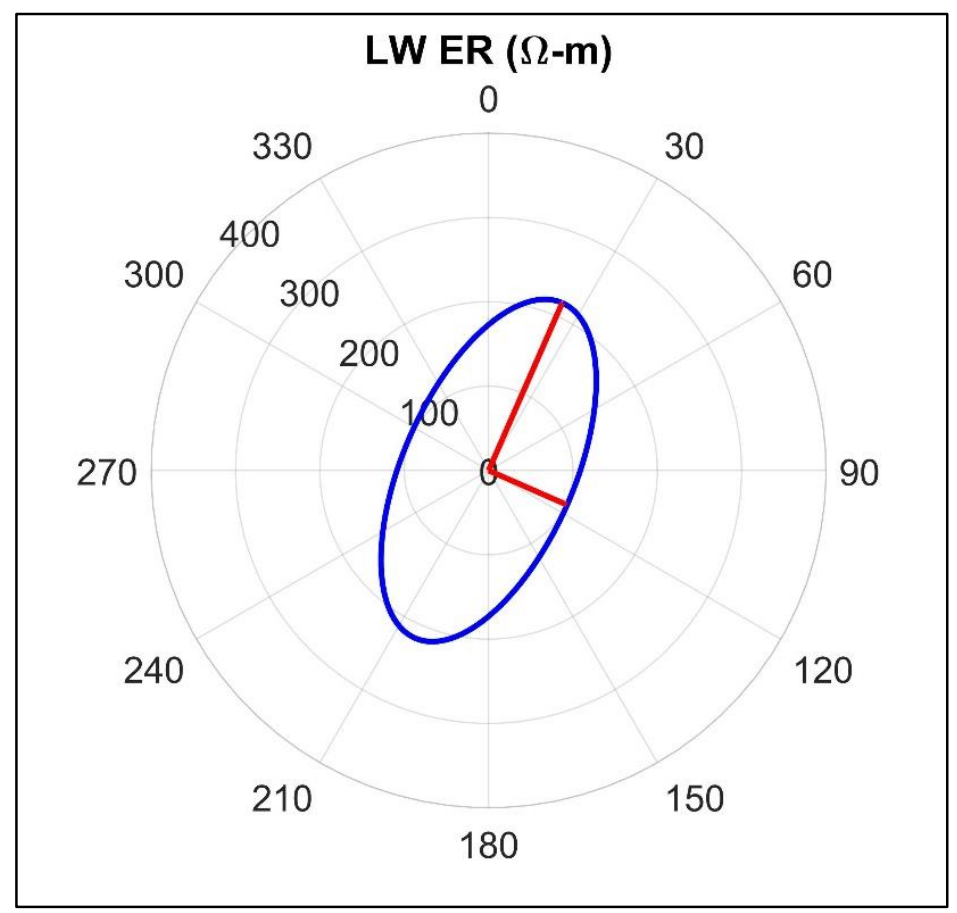

Figure 29: Best fitted ellipse (blue) and the mean ER, for each direction (red). (Note: $0^{\circ}$ is $\mathbf{N}$ ).

\subsubsection{Treeline results}

\subsubsection{Tomograms}

Figure 30 shows the $2 \mathrm{D}$ inversion results for the Treeline ERT surveys. We observe more ER heterogeneity in the NR than in the SR. Interpretation of 2D ERT results, for weathering purposes, is difficult solely using this method. Major high ER resistivity anomalies are observed, mainly in the NR such anomalies are also present in the seismic results (see figures 12-13). The utilization of 2D ERT for granite weathering states is best when complemented with another geophysical method. 


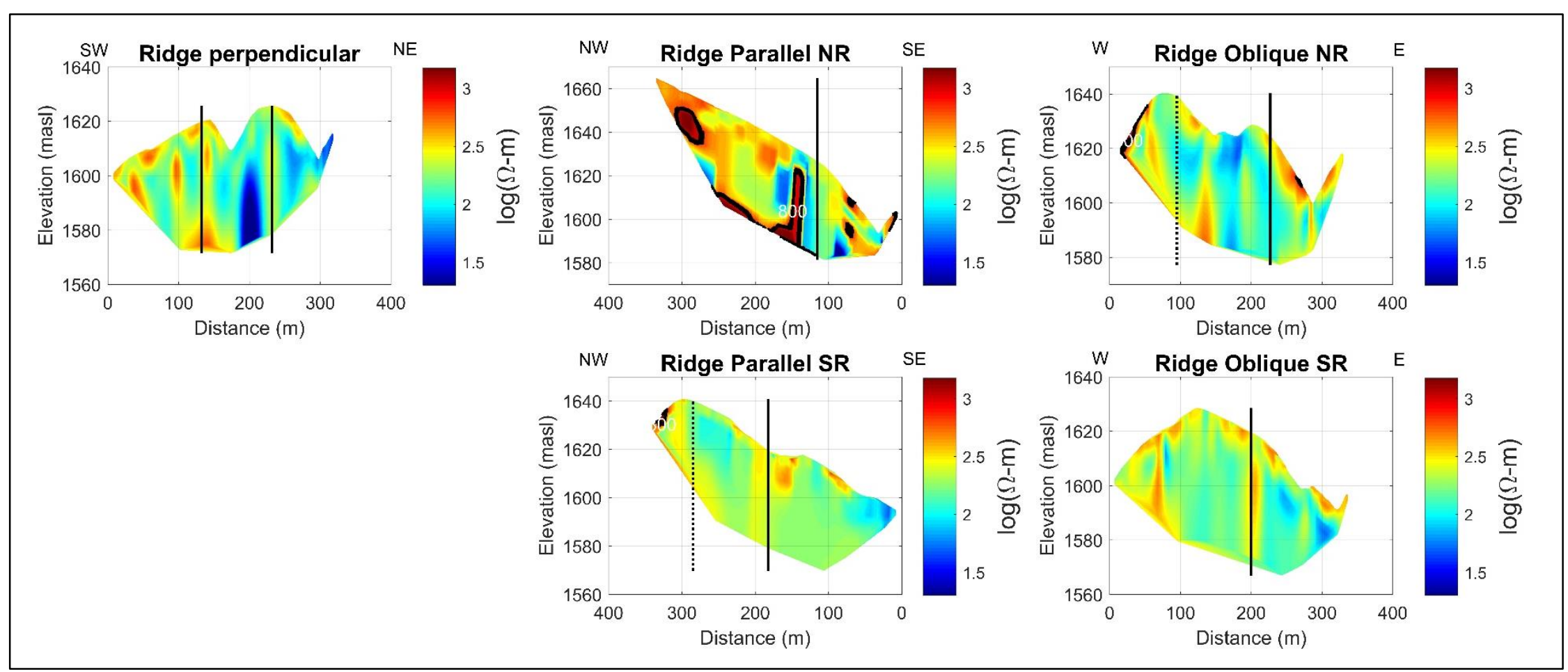

Figure 30: Electrical resistivity tomography for Treeline. Black lines represent the crossing point between both surveys (bold lines are the main crossing points, and the dotted lines represent other crossing points). Contoured sections display a higher resistivity, representative of fresh granite (see table 1).

I additionally present ER pseudo-sections for Treeline in the Appendix (figure 37). 


\subsubsection{Crossing points}

Figure 31 represents the averaged sections at depth for the main Treeline crossings. There isn't a clear anisotropic behavior of ER as a function of depth. The ridge parallel has the highest ER, and the ridge perpendicular has the lowest ER, in both ridges, as shown in the plots below. At lower depths this behavior changes that is why I can't affirm with high certainty the existence of ER anisotropy at Treeline based on these results only. ER is generally higher and more homogeneous in the SR. This is consistent with less fracturing in the SR than in the NR.
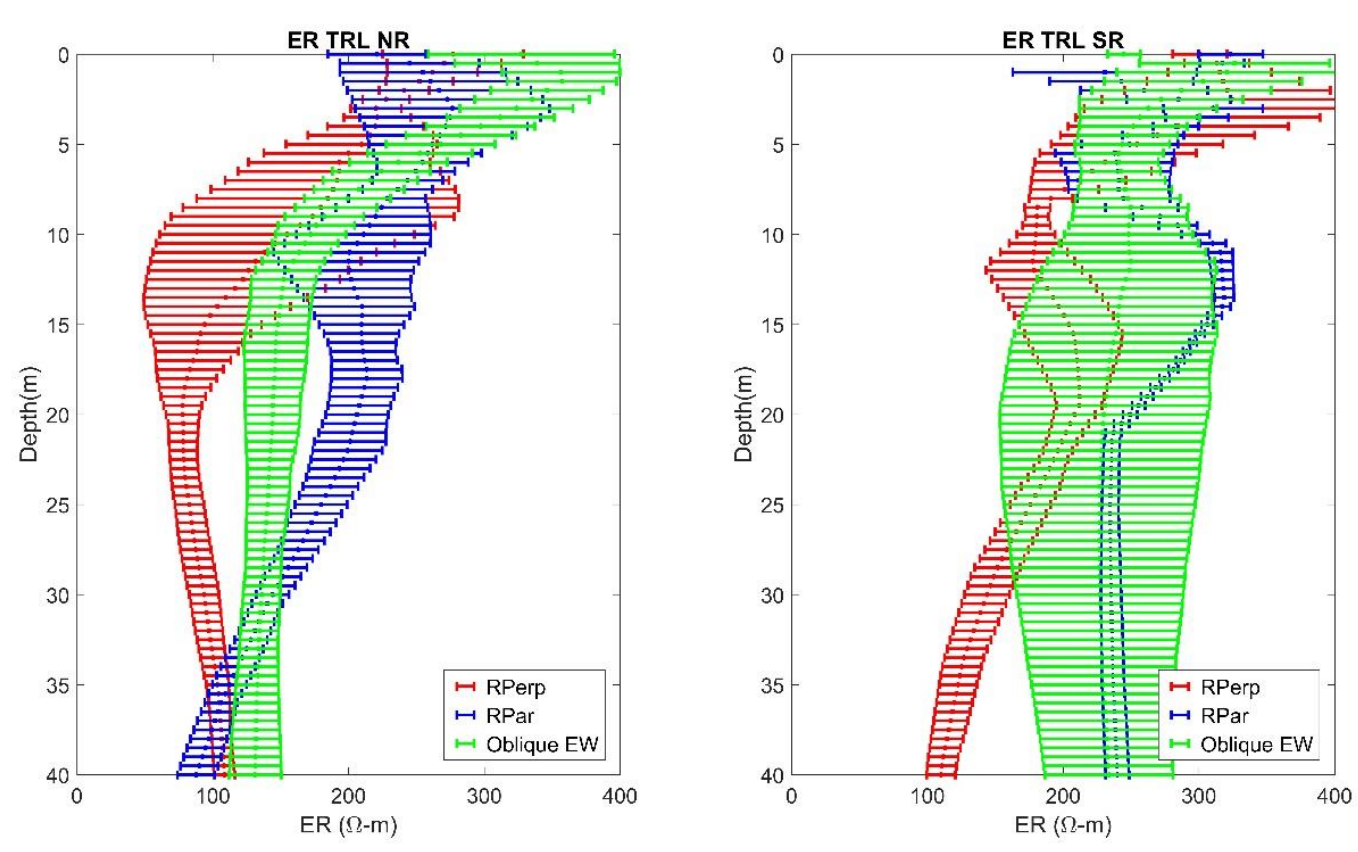

Figure 31: Average ER at depth with error bars, at the Treeline site. The blue line represents the parallel direction, the red line represents the perpendicular direction, and the green line represents the E-W direction. (Note: the error bars represent the standard deviation of ER at depth).

Based solely on the ER results I am unable to prove ER anisotropy at Treeline.

The uncertainty is too high to make any firm conclusions. 


\subsubsection{Preferential orientation}

The preferential direction of fractures should match the direction of low ER.

I plotted a mean ER per azimuth, in figure 32 (in red). I calculated the mean ER

from 5-25 $\mathrm{m}$ depth of figure 31 . I fitted an ellipse (in blue) from the mean ER values, for all azimuths.

The fitted ER ellipses for the NR and SR are roughly tilted in the same direction; meaning, both have the smallest ER in the NE-SW direction.

The minor axis of the fitted ellipse should roughly point to the direction of the dominant set of fractures. For the SR, the direction of the ER minor axis point to the NESW direction, which roughly coincides with the direction of the fast Vp direction (figures 15 and 32). However, I cannot confirm with certainty a preferential fracture orientation with the small range of azimuthal coverage in the survey.

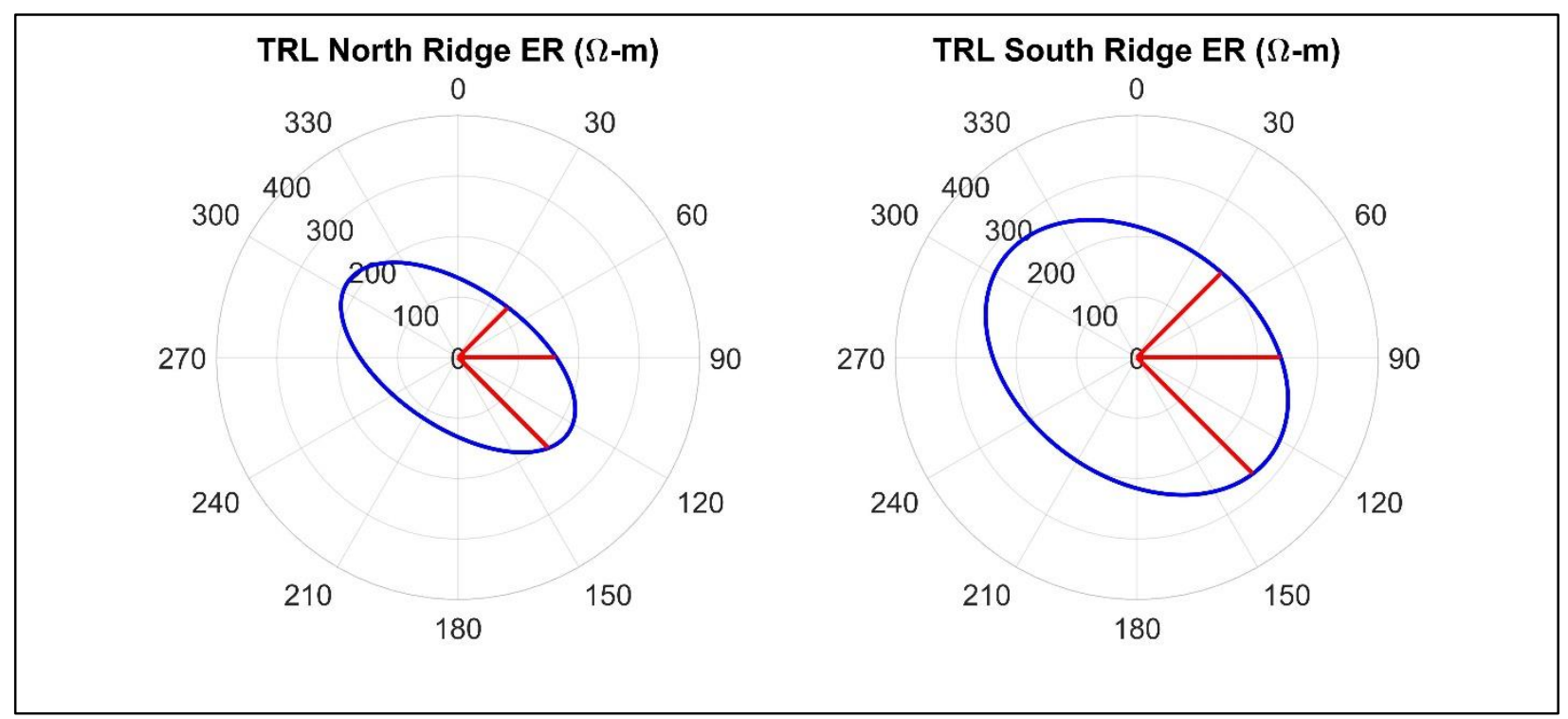

Figure 32: $\quad$ Best fitted ellipses (blue) and mean ER, for each direction (red). (Note: $\mathbf{0}^{\circ}$ is $\left.\mathbf{N}\right)$. 


\subsection{Electrical resistivity discussion}

I wasn't able to resolve preferential fracture orientation with ER measurements. I also wasn't able to determine the different weathered layers of the $\mathrm{CZ}$, at any of the sites I collected data. Roubinet and Irving (2014) suggest that the current numerical modeling tools are not well suited for the complexity of fractured media. Current numerical methods consider heterogeneities to be of a particular grid size. Fractures vary in size and aperture, and within a given volume in the subsurface. Current methods "blur-out" these fracture caused heterogeneities, so we are not able to resolve them. However, efforts are being done currently to improve the modeling of electrical conduction through fractured media (Roubinet et al., 2016; Caballero-Sanz et al., 2017).

\subsection{Electrical resistivity conclusions}

My ER results are too uncertain and heterogeneous to make clear statements on electrical anisotropy. Solely using 2D ERT methods to characterize fractured media is not suggested. At least not with the current inversion methodology available. These fractured systems are too complex to be fully characterized using a 2D approach. However, new methodologies or 3D surveys could help us better resolve fractures. 


\section{CHAPTER FOUR: WEATHERING DEPTH}

\subsection{Weathering depth results}

\subsubsection{Weathering depth as a function of elevation}

I used the seismic refraction results to calculate depth to bedrock at all sites. I used a $3500 \mathrm{~m} / \mathrm{s}$ contour (table 1) as a rough gauge to calculate depth to bedrock in all 2D surface seismic refraction profiles (tables 5-6). Using a single velocity value to calculate weathering depth in an anisotropic system is incorrect. It is important to mention that these measurements are the mean and lateral variability along a single seismic profile. Correct characterization would require full 3D data, anisotropic inversion, and an anisotropic petrophysical model. I use this single velocity value more as a qualitative measure to get a rough estimate of relative variation as a function of site elevation and aspect.

At Lower Weather, in the ridge parallel profile (figure 8) I measured a depth to bedrock of $30 \pm 10 \mathrm{~m}$. For the ridge perpendicular profile, I measured a depth to bedrock of $28 \pm 16 \mathrm{~m}$. The mean depth to bedrock at Lower weather is $29 \pm 16 \mathrm{~m}$.

Table 5: $\quad$ Mean depth to bedrock at the Treeline site.

\begin{tabular}{|l|l|l|}
\hline $\begin{array}{l}\text { TREELINE } \\
\text { PROFILE }\end{array}$ & Mean Depth to bedrock (m) & Standard deviation (m) \\
\hline L1 & 29 & 14 \\
\hline L2 & 28 & 8 \\
\hline L3 & 20 & 11 \\
\hline
\end{tabular}




\begin{tabular}{|l|l|l|}
\hline L4 & 24 & 10 \\
\hline L5 & 20 & 12 \\
\hline L6 & 16 & 9 \\
\hline L7 & 21 & 10 \\
\hline
\end{tabular}

Overall the average depth to bedrock at Treeline is $23 \pm 12 \mathrm{~m}$. From table 5, we see that overall the seismic profiles collected in the SR (L5, L6, and L7) show a shallower bedrock. This agrees with less fracturing in the SR than in the NR.

Overall the average depth to bedrock at Bogus Basin is $5 \pm 2 \mathrm{~m}$ (see table 6). I decided to calculate the depth to bedrock using the surface seismic at Bogus Basin, instead of the reverse VSP data, to be consistent within the seismic method used to calculate depth to bedrock in the rest of the locations.

Table 6: Mean depth to bedrock at the Bogus Basin site.

\begin{tabular}{|l|l|l|}
\hline $\begin{array}{l}\text { BOGUS BASIN } \\
\text { PROFILE }\end{array}$ & Mean Depth to bedrock (m) & Standard deviation (m) \\
\hline BBL1 & 4 & 1 \\
\hline BBL2 & 5 & 1 \\
\hline BBL3 & 6 & 3 \\
\hline BBL4 & 6 & 1 \\
\hline
\end{tabular}

\subsubsection{Weathering depth per aspect per site}

I calculated the weathering layer thicknesses as a function of aspect at Lower Weather (Table 7). I assumed mobile soil to be within the $0-700 \mathrm{~m} / \mathrm{s}$ Vp values, saprolite to be within $700-2000 \mathrm{~m} / \mathrm{s}$, and fractured granite to be within $2000-3500 \mathrm{~m} / \mathrm{s}$, according to Olona et al. (2010, see table 1). I am aware that the results given below (tables 7-9) are 
mere approximations, because these data are taken from an inverse model; therefore these are subject to smoothing of boundaries due to regularizations.

In Lower Weather, due to the relatively course $5 \mathrm{~m}$ geophone spacing, I was unable to resolve the mobile soil layer.

Table 7: Weathering layer thicknesses for the Lower weather site. (Note: the \pm indicates standard deviation per aspect, not error).

\begin{tabular}{|c|c|c|c|}
\hline Layer & Aspect & Thickness (m) & Average $(\mathrm{m})$ \\
\hline \multirow{3}{*}{$\begin{array}{l}0-700 \mathrm{~m} / \mathrm{s} \\
\text { (Mobile soil?) }\end{array}$} & W & 0 & \multirow{3}{*}{0} \\
\hline & $\mathrm{N}$ & 0 & \\
\hline & $S$ & 0 & \\
\hline \multirow{3}{*}{$\begin{array}{l}700-2000 \mathrm{~m} / \mathrm{s} \\
\text { (Saprolite?) }\end{array}$} & $\mathrm{W}$ & $5.99 \pm 2.49$ & \multirow{3}{*}{8.12} \\
\hline & $\mathrm{N}$ & $9.91 \pm 5.42$ & \\
\hline & S & $8.47 \pm 2.96$ & \\
\hline \multirow{3}{*}{$\begin{array}{l}2000-3500 \mathrm{~m} / \mathrm{s} \\
\text { (Fractured granite?) }\end{array}$} & W & $32.99 \pm 5.58$ & \multirow{3}{*}{24.5} \\
\hline & $\mathrm{N}$ & $15.19 \pm 12.34$ & \\
\hline & $S$ & $25.33 \pm 9.23$ & \\
\hline
\end{tabular}

At Lower Weather, the West aspect has the least thick saprolite layer $(5.99 \pm 2.49$ $\mathrm{m})$, but the thickest fractured granite layer $(32.99 \pm 5.58 \mathrm{~m})$. On the contrary, the North aspect has the thickest saprolite layer $(9.91 \pm 5.42 \mathrm{~m})$, but the least thick fractured bedrock layer $(15.19 \pm 12.34 \mathrm{~m})$. 
Table 8: Weathering layer thicknesses for the NR at Treeline. (Note: the \pm indicates standard deviation per aspect, not error).

\begin{tabular}{|c|c|c|c|}
\hline Layer & Aspect & Thickness (m) & Average (m) \\
\hline \multirow{4}{*}{$\begin{array}{l}0-700 \mathrm{~m} / \mathrm{s} \\
\text { (Mobile soil?) }\end{array}$} & $\mathrm{E}$ & $0.05 \pm 0.22$ & \multirow{4}{*}{0.10} \\
\hline & SW & $0.24 \pm 0.57$ & \\
\hline & SE & 0 & \\
\hline & $\mathrm{S}$ & 0 & \\
\hline \multirow{4}{*}{$\begin{array}{l}700-2000 \mathrm{~m} / \mathrm{s} \\
\text { (Saprolite?) }\end{array}$} & $\mathrm{E}$ & $5.64 \pm 2.79$ & \multirow{4}{*}{7.06} \\
\hline & SW & $6.02 \pm 3.67$ & \\
\hline & SE & $8.13 \pm 2.67$ & \\
\hline & $\mathrm{S}$ & $8.43 \pm 2.61$ & \\
\hline \multirow{4}{*}{$\begin{array}{l}2000-3500 \mathrm{~m} / \mathrm{s} \\
\text { (Fractured granite?) }\end{array}$} & $\mathrm{E}$ & $19.85 \pm 12.60$ & \multirow{4}{*}{20.12} \\
\hline & SW & $29.11 \pm 7.95$ & \\
\hline & SE & $16.70 \pm 7.05$ & \\
\hline & $\mathrm{S}$ & $14.83 \pm 10.11$ & \\
\hline
\end{tabular}


Table 9: Weathering layer thicknesses for the SR at Treeline. (Note: the \pm indicates standard deviation per aspect, not error).

\begin{tabular}{|c|c|c|c|}
\hline Layer & Aspect & Thickness (m) & Average $(\mathrm{m})$ \\
\hline \multirow{3}{*}{$\begin{array}{l}0-700 \mathrm{~m} / \mathrm{s} \\
\text { (Mobile soil?) }\end{array}$} & E & $0.02 \pm 0.13$ & \multirow{3}{*}{0.06} \\
\hline & NW & $0.16 \pm 0.45$ & \\
\hline & $\mathrm{W}$ & 0 & \\
\hline \multirow{3}{*}{$\begin{array}{l}\text { 700-2000 m/s } \\
\text { (Saprolite?) }\end{array}$} & E & $5.85 \pm 3.50$ & \multirow{3}{*}{6.33} \\
\hline & NW & $11.57 \pm 5.97$ & \\
\hline & $\mathrm{W}$ & $1.57 \pm 1.97$ & \\
\hline \multirow{3}{*}{$\begin{array}{l}2000-3500 \mathrm{~m} / \mathrm{s} \\
\text { (Fractured granite?) }\end{array}$} & $\mathrm{E}$ & $11.45 \pm 6.20$ & \multirow{3}{*}{11.08} \\
\hline & NW & $12.28 \pm 8.80$ & \\
\hline & $\mathrm{W}$ & $9.50 \pm 6.30$ & \\
\hline
\end{tabular}

In Treeline's NR, the aspects with the thinnest saprolite layers are the East (5.64 \pm $2.79 \mathrm{~m})$ and Southwest $(6.02 \pm 3.67 \mathrm{~m})$ aspects; these correspond to the thickest fractured bedrock layers $(29.11 \pm 7.95 \mathrm{~m}$ for the Southwest aspect and $19.85 \pm 12.60 \mathrm{~m}$ for the East aspect).

The thickest saprolite layers are present in the Southeast $(8.13 \pm 2.67 \mathrm{~m})$ and South $(8.43 \pm 2.61 \mathrm{~m})$ aspects. However, these aspects correspond to the least thick fractured bedrock layers $(16.70 \pm 7.05 \mathrm{~m}$ for the Southeast aspect and $14.83 \pm 10.11 \mathrm{~m}$ for the South aspect).

Treeline's SR is the only location where this change in least thick, to thickest layers (and vice versa) doesn't happen. For the SR, the thinnest saprolite layer is located in the West aspect, and the thickest is located in the Northwest aspect; the same trend continues for the fractured bedrock layer. 


\subsection{Weathering depth discussion}

- $\quad$ Seismic profiles 4, 5, and 7 (figure 33) end in a Northwest facing aspect, where vegetation changes from grass and shrubs to a tree dominated area. The thickness of the saprolite layer in the NW aspect at the SR in Treeline is $11.57 \pm 5.97$ $\mathrm{m}$, the highest calculated at either Lower Weather or Treeline, and more than twice as thick as observed on any other aspect at Treeline.

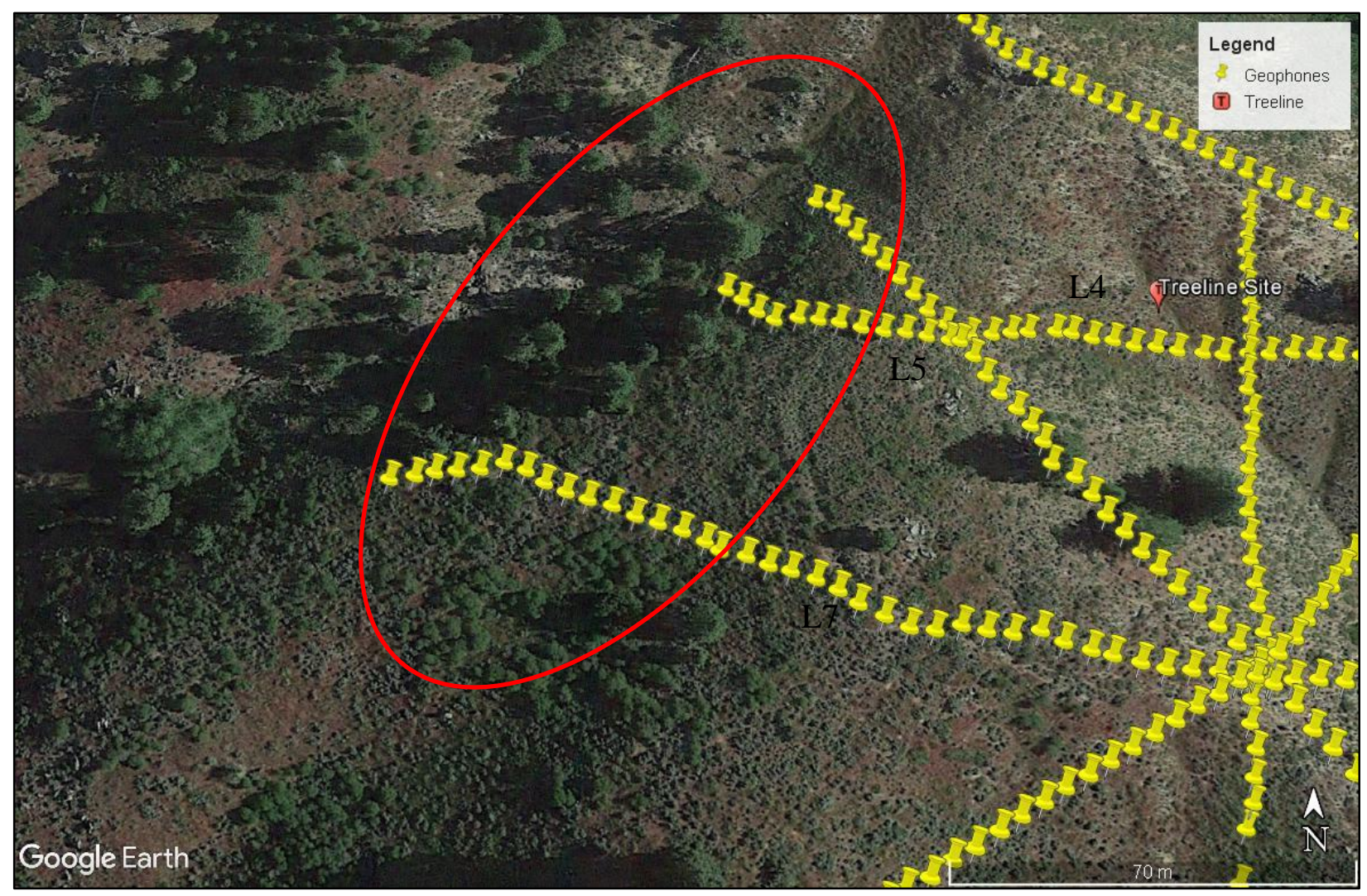

Figure 33: Zoom into forested area at Treeline.

If I was only to compare the different aspects in the SR at Treeline, I would preserve: local and regional stress, and roughly the same level of the water table. The elements that change among aspects are: aspect itself, vegetation type, solar input, and snow accumulation. 
I hypothesize there is a positive interaction of various elements that favors weathering at this specific site. There is likely more vegetation because of water availability and solar input. The increased vegetation in turn holds more moisture and the roots enhance weathering.

Kormos et al. (2014) suggests that at Treeline snow remains for longer periods of time in North facing aspects. Anderson et al. (2014) showed that forested areas hold snow for longer periods of time within the DCEW. Langston et al. (2015) present models indicating that a large sustained recharge pulse forces more water deeper into the saprolite matrix and the fractures than repeated, smaller recharge events. Therefore if there's more snow throughout the winter at the NW facing slope at Treeline, due to the vegetation and aspect, there's more weathering happening because of the possible duration of snow cover in that area. More snow research needs to be done at this specific aspect in Treeline to prove this hypothesis.

The NW aspect at Treeline has a higher tree density, than the rest of Treeline. I believe the tree roots permit meteoric fluids to penetrate deeper into the subsurface promoting weathering processes. Some studies suggest that there is a positive feedback between increase in tree density and increase in weathering (Gabet and Mudd, 2010; Ebel et al., 2015). More research needs to be done to determine exactly the main factors increasing weathering in Treeline, overall. More focused seismic profiles can be carried out in the NW aspect at Treeline.

- The model of St. Clair et al. (2015) explains that both topography and regional stress play a role in bedrock fracture distribution (Moon et al., 2017). In some cases, a "bow-tie" effect happens under ridges, meaning, there is an increase in fractures 
below ridge tops, therefore there is a decrease in $\mathrm{Vp}$ below ridge tops, this effect has been referred as "the bow-tie effect" or "mirroring effect". This can also be seen as the depth to bedrock not always following the topography, but rather it sometimes mirrors the topography.

Not all seismic profiles collected in this research allow to observe distinctly the "bow-tie effect", because I didn't capture both ridge top and ridge bottom in all my profiles. Although, we can distinctly observe the "bow-tie effect" in lines 1, 3, 4, and 6, from figures 12 and 13, and the ridge perpendicular profile in figure 8. A detailed analysis of local stress at the DCEW is needed to better understand the spatial distribution of the least compressive stress. Having a detailed analysis on stress at the DCEW will help us better predict zones of high fracturing. -In my study I found that the average thickest saprolite, and fractured bedrock layers, are present at the lowest elevation (Lower Weather) site, and the thinnest saprolite is at the Bogus Basin site (figure 34). The elevation difference between Treeline and Lower Weather is approximately $500 \mathrm{~m}$. The elevation difference between Bogus Basin and Lower Weather is approximately $800 \mathrm{~m}$. 

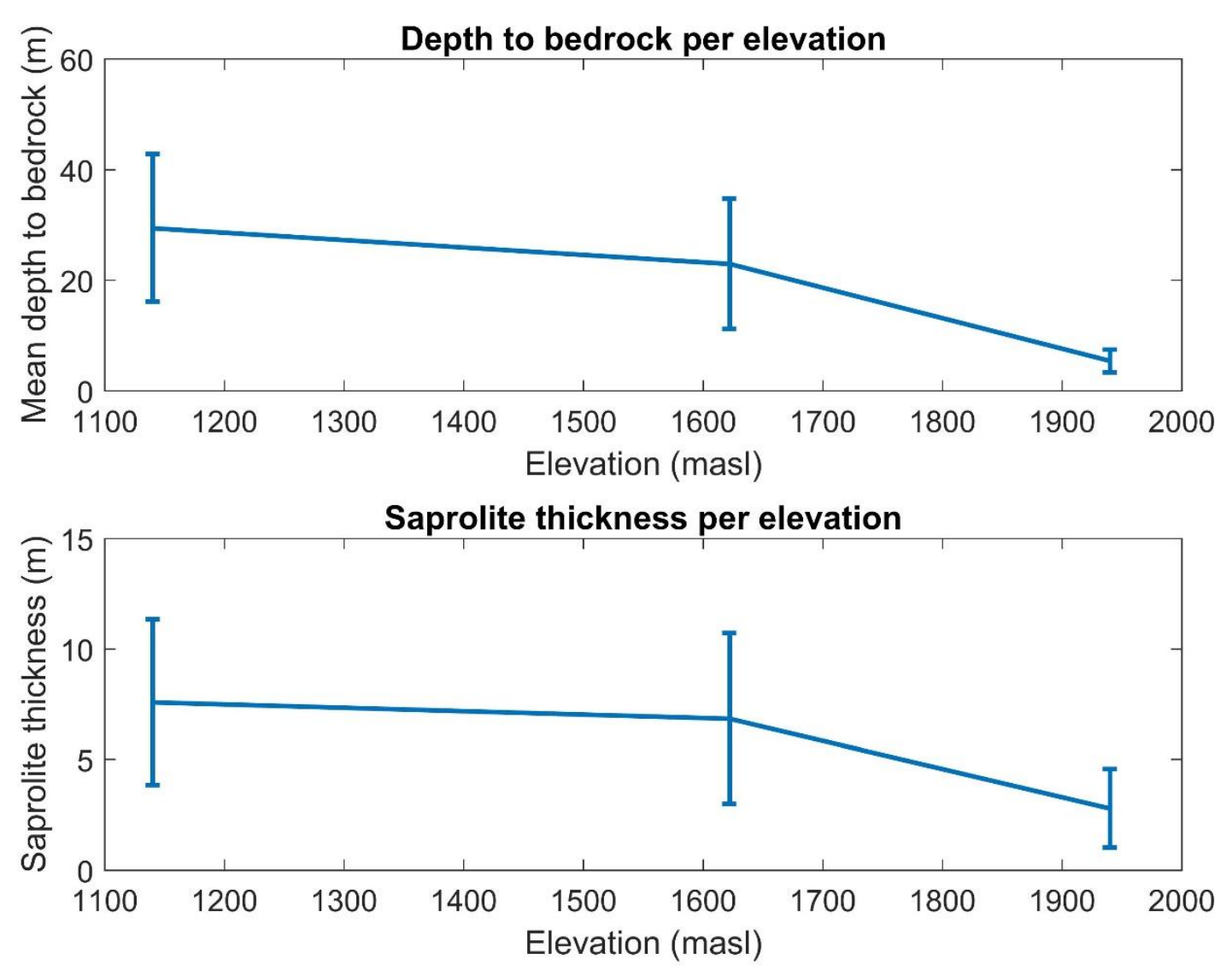

Figure 34: Depth to bedrock and saprolite thickness as a function of elevation.

The overall depth of the weathering zone decreases with increasing elevation.

The mean depth to bedrock at Lower weather is $29 \mathrm{~m}$, at Treeline $23 \mathrm{~m}$, and at Bogus Basin $5 \mathrm{~m}$.

An increase in weathering with decreasing elevations has also been observed at Johnston's Draw, Reynolds Creek Critical Zone Observatory, by Nielson (2017). As noted by Nielson, this trend is likely caused by the increasing temperature with decreasing elevations, and this is consistent with other studies (Rasmussen et al., 2010; Rech et al., 2001). 


\subsection{Weathering depth conclusions}

The calculation of depth to bedrock is velocity dependent. I assumed the granitic bedrock at my sites has a Vp of $3500 \mathrm{~m} / \mathrm{s}$ (from Olona et al., 2010). I recognize this model could be wrong, however this single value does provide a basis for interpretation of relative variations.

From the surface seismic refraction data collections I observe that depth to bedrock increases with decreasing elevation. This same pattern has been observed in the Reynolds Creek Critical Zone Observatory. It has been hypothesized that this feature could be related with increasing temperatures at lower elevations. Higher temperatures could increase reactivity in weathering processes.

Comparing the use of seismic refraction vs. ERT to delineate weathered layers, I conclude that seismic refraction is a more suitable method than ERT.

I observed a significant increase in weathering at a Northwest facing slope in Treeline. This slope has higher tree density than the rest of Treeline. Therefore, I believe that there is a positive feedback between tree roots and fractures as well as moisture delivery and solar input that promotes weathering in this specific site. Since this is a northern aspect, it most likely retains moisture better than southern aspects. This additional effect could also promote weathering at this site. 


\section{CHAPTER FIVE: CONCLUSIONS AND RECOMMENDATIONS}

I conducted a series of 2D ERT and seismic refraction surveys in the DCEW, at three different elevations: Lower Weather, Treeline, and Bogus Basin. At each site, I collected the surveys at different azimuths, with a common crossing point. I was able to determine, slow or fast velocity directions at each site, but I am not able to fully characterize the preferential fracture orientation, at any site; to do so, I need more azimuthal coverage in my experiment. I suggest to carry out full 3D seismic surveys to improve my azimuthal resolution power.

In Treeline's NR, fractures seem to mostly close at around $25 \mathrm{~m}$ depth. At the SR, fractures mostly close at around $15 \mathrm{~m}$ depth. Fractures appear to close at around $27 \mathrm{~m}$ depth, in Lower Weather. Depth to unweathered bedrock is highest at Lower Weather. It is important to mention, that due to the scales I'm working in my seismic refraction surveys, with seismic waves spanning up to tens of meters in wavelengths, I am able to resolve that most fractures are closed at the aforementioned depths. I am not able to resolve the effect of a single or very few fractures on Vp. At "closure depth" I mean fracture density is significantly lower. The fracture density "closure" depends on velocity. I assumed the fractures would close at $3500 \mathrm{~m} / \mathrm{s}$. However, I am aware this assumption could be wrong. My results show that anisotropy continues deeper than my closure depth, this indicates that fractures are still present at lower depths; I'm just not able to fully resolve them. A better rocks physics model, for the granite at the DCEW could help me improve this aspect. 
From the seismic surveys done at Treeline (figures 12and 13) I am able to identify an area of high weathering at Treeline, in a NW facing slope. The main difference between this specific area and the rest of Treeline is the type of vegetation, and aspect. Therefore I believe there is a positive feedback between vegetation type, soil moisture, solar flux, and weathering, at Treeline.

Geophysical surveys can be carried out to help characterize subsurface hydrologic parameters. When surveying in a fractured area, one has to take into account the possibility of fracture induced anisotropy. Neglecting fracture induced anisotropy can lead to erroneous interpretations of the subsurface hydrologic system.

My results suggest the presence of anisotropy at the surveyed sites. Lower Weather displayed the highest anisotropy, up to almost 30\%. I also determined anisotropy at Treeline. Bogus Basin showed little to no anisotropy. Geophysical surveys done at a mountain watershed underlain by fractured bedrock should take into account the possibility of anisotropic medium. Therefore, data collection should be planned accordingly. One single azimuth (e.g. a single 2D profile) is not sufficient to properly characterize the fractured subsurface.

There are more geophysical tools that can be used in the future to better characterize the hydrologic system at the DCEW. S-wave velocity is more sensitive to fractured media and is subject to birefringence (different polarizations traveling as different modes in the same direction with differing velocity), therefore, it could be a powerful tool to characterize the fractured system at the DCEW. I recognize that S-wave data collection is logistically more complicated than P-wave data collection. S-wave data collection was beyond the scope of this investigation. 
In the hope of upscaling the overall effect of fractures at the DCEW, a seismic interferometry survey could be carried out to characterize in a bigger scale the subsurface of the DCEW.

In order for seismic interferometry to work, we need a source of seismic noise. The road from Boise to Bogus Basin is regularly transited by vehicles. Vehicles could be a useful source of seismic noise in low frequencies. Low frequency waves are able to travel deeper into the subsurface allowing us to probe the subsurface at the watershed scale.

To do a better job in a petrophysical analysis, we need a deep knowledge of the mineralogy of the subsurface, collecting deep borehole geologic data would be especially useful. A detailed research of the stresses in the DCEW is also suggested to better predict areas of bedrock weathering. 


\section{REFERENCES}

Acker, B. (2008). Scale and heterogeneity in hydraulic properties of the fractured bedrock granitic Boise front, Boise, Idaho. (Unpublished Master's thesis). Retrieved from: Boise State University Library (Thesis GB1025.I2 H64 2008).

Aishlin, P., \& J.P. Mcnamara (2011). Bedrock infiltration and mountain block recharge accounting using chloride mass balance. Hydrological Processes. http://doi.org/10.1002/hyp.7950

Aldridge, D. F., \& D.W. Oldenburg (1993). Two-dimensional tomographic inversion with finite-difference traveltimes. Journal of Seismic Exploration, 2, 257-274.

Anderson, B. T., Mcnamara, J. P., Marshall, H. P., \& A.N. Flores (2014). Insights into the physical processes controlling correlations between snow distribution and terrain properties. Water Resources Research, 50, 1-19. http://doi.org/10.1002/2013WR013714

Anderson, R. S., Anderson, S. P., \& G.E. Tucker (2013). Rock damage and regolith transport by frost : an example of climate modulation of the geomorphology of the critical zone. Earth Surface Processes and Landforms, 38, 299-316. http://doi.org/10.1002/esp.3330

Anderson, S. P., Von Blanckenburg, F., \& A.F. White (2007). Physical and Chemical Controls on the Critical Zone. Elements, 3, 315-320.

Babcock, E. L., Bradford, J. H., \& C. Hall (2015). Cold Regions Science and Technology Electrical anisotropy in sea ice and a dual-polarization radar system to mitigate the effects of preferential attenuation in imaging sea ice. Cold Regions Science and Technology, 118, 105-111. http://doi.org/10.1016/j.coldregions.2015.06.012 
Barker, R.D. (1996). The application of electrical tomography in groundwater contamination studies: EAGE 58th Conference and Technical Exhibition Extended Abstracts, 744-747.

Befus, K. M., Sheehan, a. F., Leopold, M., Anderson, S. P., \& R.S. Anderson (2011). Seismic Constraints on Critical Zone Architecture, Boulder Creek Watershed, Front Range, Colorado. Vadose Zone Journal, 10(4), 1342. http://doi.org/10.2136/vzj2010.0108er

Berryman, J. G., \& G.M. Hoversten (2013). Modelling electrical conductivity for earth media with macroscopic fluid-filled fractures. Geophysical Prospecting, 61, 471493. http://doi.org/10.1111/j.1365-2478.2012.01135.x

Berryman, J. G. (2007). Seismic waves in rocks with fluids and fractures. Geophysical Journal International, 171, 954-974. http://doi.org/10.1111/j.1365246X.2007.03563.X

Berryman, J. G., \& Grechka, V. (2006). Random polycrystals of grains containing cracks : Model of quasistatic elastic behavior for fractured systems Random polycrystals of grains containing cracks : Model of quasistatic elastic behavior for fractured systems. Journal of Applied Physics, 100(113527).

http://doi.org/10.1063/1.2399891

Burns, D.R., Willis, M.E., \& M.N. Toksoz (2007). Fracture properties from seismic scattering. The Leading Edge.

Busby, J. P. (2000). The effectiveness of azimuthal apparent-resistivity measurements as a method for determining fracture strike orientations. Geophysical Prospecting, 48, 677-696.

Caballero-Sanz, V., Roubinet, D., Demirel, S., \& Irving, J. (2017). 2.5-D discrete-dualporosity model for simulating geoelectrical experiments in fractured rock. Geophysical Journal International, 209, 1099-1110. http://doi.org/10.1093/gji/ggx080

Crampin, S., Mcgonigle, R., \& D. Barnford (1980). Estimating crack parameters from observations of P-wave velocity anisotropy. Geophysics, 45(3). 
Crampin, S. (1985). Evaluation of anisotropy by shear-wave splitting. Geophysics, 50(1), 142-152.

Ebel, B. A., Rengers, F. K., \& G.E. Tucker (2015). Aspect-dependent soil saturation and insight into debris-flow initiation during extreme rainfall in the Colorado Front Range. Geology, 43(8), 659-662. http://doi.org/10.1130/G36741.1

Gabet, E. J., \& S.M. Mudd (2010). Bedrock erosion by root fracture and tree throw : A coupled biogeomorphic model to explore the humped soil production function and the persistence of hillslope soils. Journal of Geophysical Research, 115. http://doi.org/10.1029/2009JF001526

Gates, W. C. B., Parkinson, C. L., \& K.L. Schroeder (1994). Groundwater development in granitic terrain Bogus Basin ski resort. In Hydrogeology, Waste disposal, Science and politics proceedings.

Greenhalgh, M.S. (2008). DC Resistivity modelling and sensitivity analysis in anisotropic media. (PhD thesis) Retrieved from the University of Adelaide Library.

Greenhalgh, S. A. G., Marescot, L. M., Zhou, B. Z., Greenhalgh, M. G., \& T.W. Wiese (2009). Electric Potential and Frechet Derivatives for a Uniform Anisotropic Medium with a Tilted Axis of Symmetry. Pure and Applied Geophysics, 166, 673-699. http://doi.org/10.1007/s00024-009-0465-6

Greenhalgh, S., Wiese, T., \& L. Marescot (2010). Comparison of DC sensitivity patterns for anisotropic and isotropic media. Journal of Applied Geophysics, 70(2), 103112. http://doi.org/10.1016/j.jappgeo.2009.10.003

Habberjam, G.M., and G.E. Watkins (1967). The use of a square configuration in resistivity prospecting. Twenty-ninth meeting of the European Association of Exploration Geophysicists.

Habberjam, G.M. (1971). The effects of anisotropy on square array resistivity measurements. Thirty-third meeting of the European Association of Exploration Geophysicists.

Holbrook, W. S., Riebe, C. S., Elwaseif, M., Hayes, J. L., Basler-Reeder, K., Harry, D. L., Armen, M., Dosseto, A., Hartsough, P.C., \& J.W. Hopmans (2014). 
Geophysical constraints on deep weathering and water storage potential in the Southern Sierra Critical Zone Observatory. Earth Surface Processes and Landforms, 39(3), 366-380. http://doi.org/10.1002/esp.3502

Illman, W. A. (2006). Strong field evidence of directional permeability scale effect in fractured rock. Journal of Hydrology, 319, 227-236. http://doi.org/10.1016/j.jhydrol.2005.06.032

Keller, G.V., \& F.C. Frischknecht (1966), Galvanic resistivity methods, in Electrical methods in geophysical prospecting, International series of monographs in electromagnetic waves, vol. 10, edited by Cullen A.L, Fock, V.A., and Wait, J.R., pp. 90-91, Pergamon Press, New York.

Knight, R.J., \& A.L Endres. “An introduction to rock physics principles for near-surface geophysics."Near-Surface Geophysics. Ed. Dwain K. Butler. Tulsa, Oklahoma: Society of Exploration Geophysicists, 2005. 31-65.

Kleinfelder Inc. (1993). Summary of Phase II Hydrogeological services installation and aquifer testing. Test wells No.1, 2, and 3. Bogus Basin Ski Resort, Boise, Idaho. Hydrogeology services report. Kleinfelder Inc., Boise, Idaho (1993).

Kormos, P. R., Marks, D., Williams, C. J., Marshall, H. P., Aishlin, P., Chandler, D. G., \& J.P. McNamara (2014). Soil, snow, weather, and sub-surface storage data from a mountain catchment in the rain-snow transition zone. Earth System Science Data, 6(1), 165-173. http://doi.org/10.5194/essd-6-165-2014

Kormos, P. R., McNamara, J. P., Seyfried, M. S., Marshall, H. P., Marks, D., \& A.N. Flores (2015). Bedrock infiltration estimates from a catchment water storagebased modeling approach in the rain snow transition zone. Journal of Hydrology, 525, 231-248. http://doi.org/10.1016/j.jhydrol.2015.03.032

Langston, A. L., Tucker, G. E., Anderson, R. S., \& S.P. Anderson (2015). Evidence for climatic and hillslope-aspect controls on vadose zone hydrology and implications for saprolite weathering. Earth Surface Processes and Landforms, 40, 1254-1269. http://doi.org/10.1002/esp.3718 
Li, P., \& F. Uren (1997). Analytical Solution for the Point Source Potential in an Anisotropic 3-D Half-Space I: Two-Horizontal-Layer Case. Mathematical and Computer Modelling, 26(5), 9-27. https://doi.org/10.1016/S0895-7177(97)001556

Lynn, H., \& R.J. Michelena (2011). Practical applications of anisotropy. The Leading Edge, 30(7), 726-730.

Loke, M. H., Acworth, I., \& T. Dahlin (2003). A comparison of smooth and blocky inversion methods in 2D electrical imaging surveys. Exploration Geophysics, 34(3), 182-187.

Miller, C. R., Routh, P. S., Brosten, T. R., \& J.P. McNamara (2008). Application of timelapse ERT imaging to watershed characterization. Geophysics, 73(3), 7-17. http://doi.org/10.1190/1.2907156

Matias, M. J. S. (2002). Square array anisotropy measurements and resistivity sounding interpretation. Journal of Applied Geophysics, 49(3), 185-194. http://doi.org/10.1016/S0926-9851(01)00113-6

Moon, S., Perron, J. T., Martel, S. J., Holbrook, W. S., \& J. St. Clair (2017). A model of three-dimensional topographic stresses with implications for bedrock fractures, surface processes, and landscape evolution. Journal of Geophysical Research, 124. http://doi.org/10.1002/2016JF004155

Morey, R.M., Kovacs, A., \& G.F.N Cox (1984). Electromagnetic properties of sea ice. Cold Reg.Sci. Technol. 9 (1), 53-75.

National Research Council (2001), Basic research opportunities in earth science, National Academy Press, Washington, DC.

Nielson, T. (2017). Application of hydrogeophysical imaging in the Reynolds Creek Critical Zone Observatory. (Unpublished Master's thesis). Retrieved from: Boise State University Library

Novitsky, C.G., Holbrook, W.S., Carr, B., \& S. Pasquet (2016), Fracture orientation in the shallow critical zone from seismic anisotropy, Abstract EP43C-0969 presented at 2016 Fall Meeting, AGU, San Francisco, Calif., 11-15 Dec. 
Olona, J., Pulgar, J. A., Fernández-Viejo, G., López-Fernández, C., \& J.M. GonzálezCortina (2010). Weathering variations in a granitic massif and related geotechnical properties through seismic and electrical resistivity methods. Near Surface Geophysics, 8, 585-599. http://doi.org/10.3997/1873-0604.2010043

Parham, W.B. (2015). Spatial and temporal storage dynamics moderate the ecohydrologic significance of evapotranspiration in semi-arid mountainous terrain. (Unpublished Master's thesis). Retrieved from: Boise State University Library

Poulos, M.J. (2016) "Feedbacks among climate, soils, vegetation, and erosion drive valley asymmetry development in the mountains of central Idaho". Boise State University Theses and Dissertations.

Rasmussen, C., Dahlgren, R. A., \& R.J. Southard (2010). Basalt weathering and pedogenesis across an environmental gradient in the southern Cascade Range, California, USA. Geoderma, 154(3-4), 473-485. http://doi.org/10.1016/j.geoderma.2009.05.019

Rech, J. A., Reeves, R. W., \& D.M. Hendricks (2001). The influence of slope aspect on soil weathering processes in the Springerville volcanic field, Arizona. Catena, 43, 49-62.

Rempe, D. M., \& W.E. Dietrich (2014). A bottom-up control on fresh-bedrock topography under landscapes. Proceedings of the National Academy of Sciences of the United States of America, 111(18). http://doi.org/10.1073/pnas.1404763111

Riebe, C. S., Hahm, W. J., \& S.L. Brantley (2016). Controls on deep critical zone architecture : a historical review and four testable hypotheses. Earth Surface Processes and Landforms. http://doi.org/10.1002/esp.4052

Roubinet, D., \& Irving, J. (2014). Journal of Geophysical Research : Solid Earth Discrete-dual-porosity model for electric current flow in fractured rock. Journal of Geophysical Research: Solid Earth, 119, 767-786. http://doi.org/10.1002/2013JB010668.Abstract

Roubinet, D., Linde, N., Jougnot, D., \& Irving, J. (2016). Streaming potential modeling in fractured rock: Insights into the identification of hydraulically active fractures. 
Geophysical Research Letters, 4937-4944.

http://doi.org/10.1002/2016GL068669.Numerous

Schuster, G. T., \& A. Quintus-bosz (1993). Wavepath eikonal traveltime inversion: Theory. Geophysics, 58(9), 1314-1323.

Sondergeld, C. H., \& Rai, C. S. (1992). Laboratory observations of shear-wave propagation in anisotropic media. The Leading Edge, 11(2), 38-43.

St. Clair, J., Moon, S., Holbrook, W. S., Perron, J. T., Riebe, C. S., Martel, S. J., Carr, B., Singha, K., \& D. de B. Richter (2015). Geophysical imaging reveals topographic stress control of bedrock weathering. Science, 350(6260), 534-539.

Taylor, R. W., \& A.H. Fleming (1989). Characterizing Jointed systems by Azimuthal Resistivity Surveys. Groundwater, 26(4).

Tsvankin, I., and V. Grechka (2011), Seismology of Azimuthally Anisotropic Media and Seismic Fracture Characterization. Tulsa, Oklahoma, Society of Exploration Geophysicists.

Thomsen, L. (1986). Weak elastic anisotropy. Geophysics, 51(10), 1954-1966.

Watanabe, T., \& A. Higuchi (2015). Simultaneous measurements of elastic wave velocities and electrical conductivity in a brine-saturated granitic rock under confining pressures and their implication for interpretation of geophysical observations. Progress in Earth and Planetary Science. http://doi.org/10.1186/s40645-015-0067-0

Williams, C.J. (2005). Characterization of the spatial and temporal controls on soil moisture and streamflow generation in a semi-arid headwater catchment. (Unpublished Master's thesis). Retrieved from: Boise State University Library

Yamakawa, Y., Kosugi, K., Masaoka, N., Sumida, J., Tani, M., \& T. Mizuyama (2012). Combined geophysical methods for detecting soil thickness distribution on a weathered granitic hillslope. Geomorphology, 145-146, 56-69. http://doi.org/10.1016/j.geomorph.2011.12.035 
Yamakawa, Y., Kosugi, K., Masaoka, N., Tada, Y., \& Mizuyama, T. (2010). Use of a Combined Penetrometer - Moisture Probe Together with Geophysical Methods to Survey Hydrological Properties of a Natural Slope. Vadose Zone Journal, 9, 768779. http://doi.org/10.2136/vzj2010.0012

Yeboah-Forson, A., \& D. Whitman (2014). Electrical resistivity characterization of anisotropy in the Biscayne Aquifer. Groundwater, 52(5), 728-36. http://doi.org/10.1111/gwat.12107

Zhu, T., Zhou, J., \& J. Hao (2012). Experimental Studies on the Changes in Resistivity and Its Anisotropy Using Electrical Resistivity Tomography. International Journal of Geophysics, 2012. http://doi.org/10.1155/2012/14206 
APPENDIX 


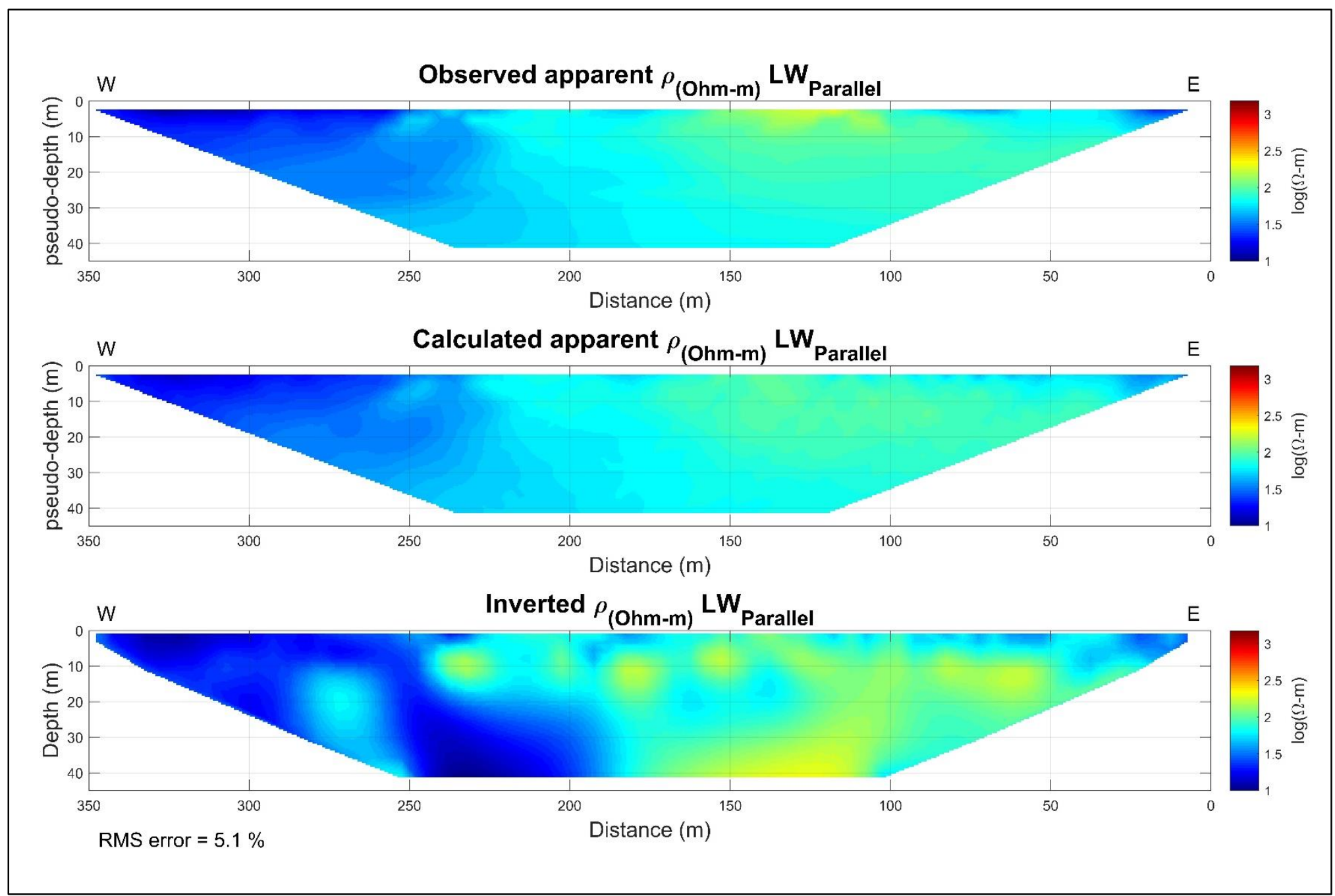

Figure 35: Observed apparent ER pseudo-section, calculated apparent ER pseudo-section, and inverted ER section, for the Lower Weather parallel ER profile. 


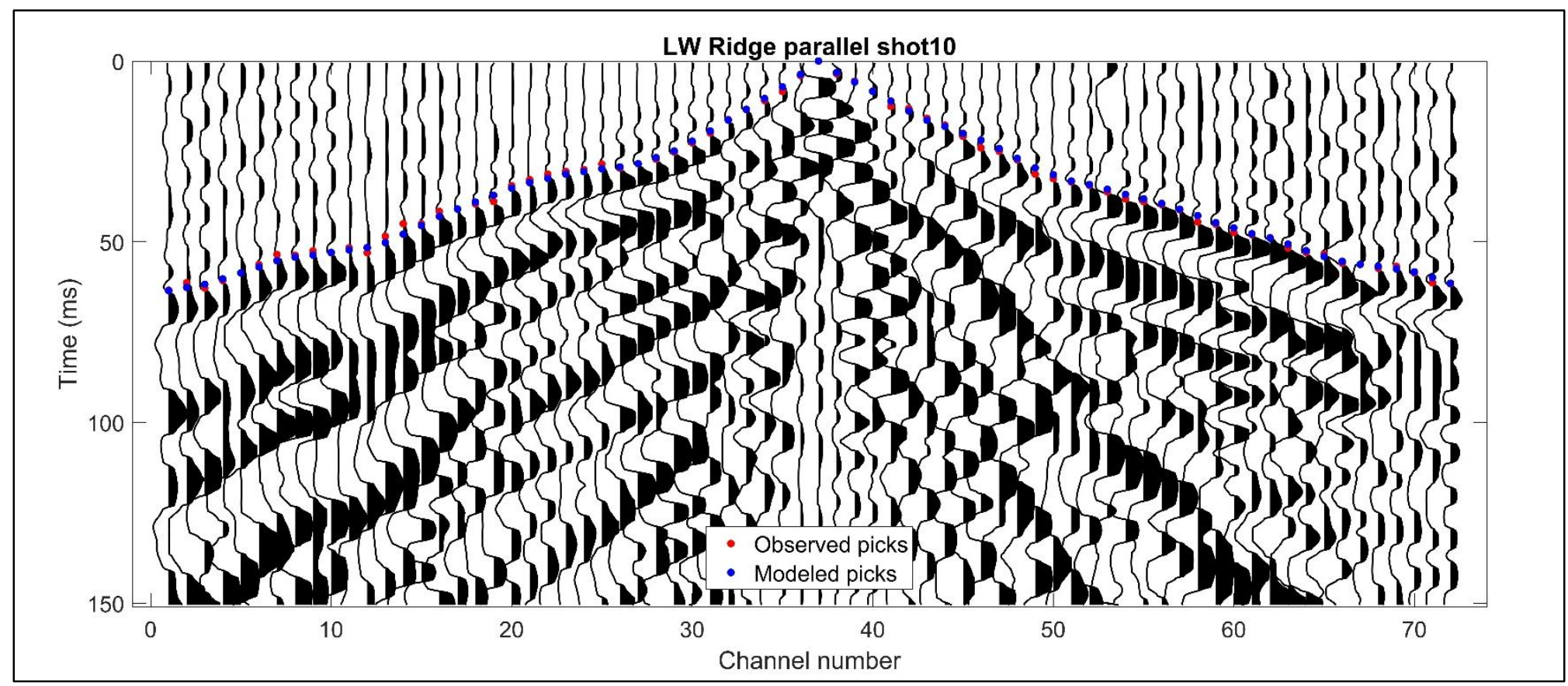

Figure 36: Example of shot-gather and first break picks for the Lower Weather ridge parallel seismic profile.

On figures 36, 38, and 39 I present seismic shot gathers with the observed and modeled time picks. I need to manually pick the first arrival (red) of the seismic wave, in order to obtain a model from a shot gather in a seismic refraction experiment. In the inversion process a first arrival time is modeled (blue) and checked aga inst the observed picks iteratively. From this process the velocity section is created. 


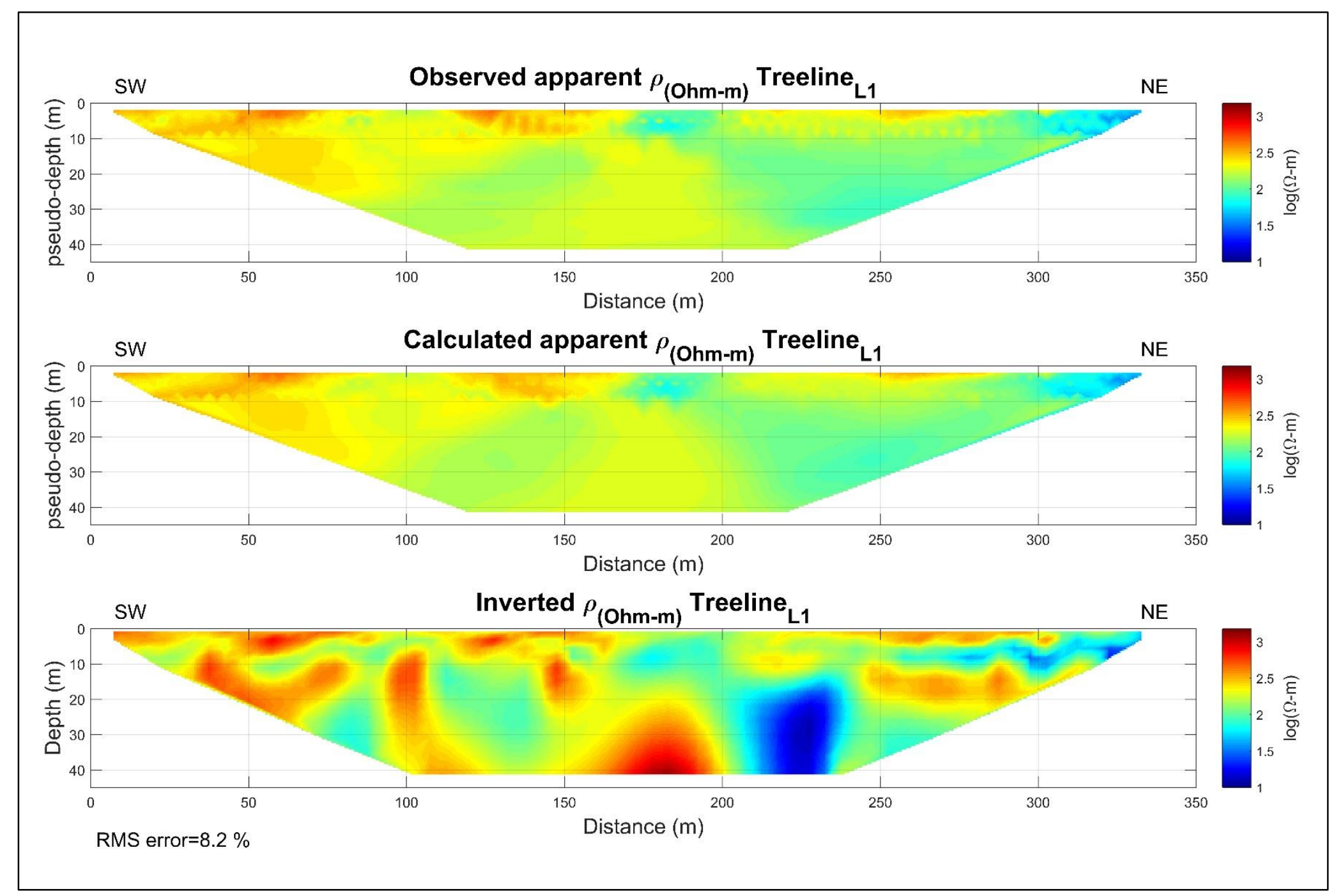

Figure 37: Observed apparent ER pseudo-section, calculated apparent ER pseudo-section, and inverted ER section, for $L 1$, at Treeline. 
On figures 35 and 37 I present the ER observed and calculated pseudo-sections. I additionally present the inverted ER section. In these three plots I show how ER data evolves from the measured to the inverted data. The RMS value shows how much the measured and modeled data differ.

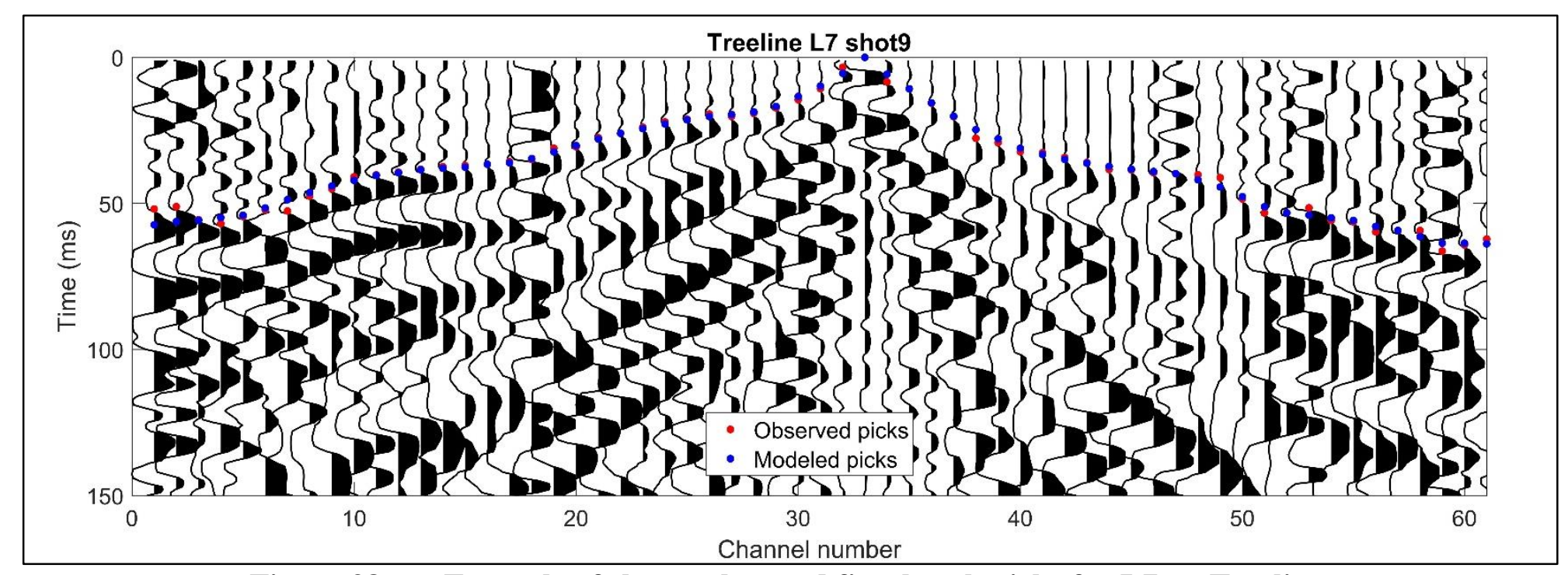

Figure 38: Example of shot-gather and first break picks for L7, at Treeline. 


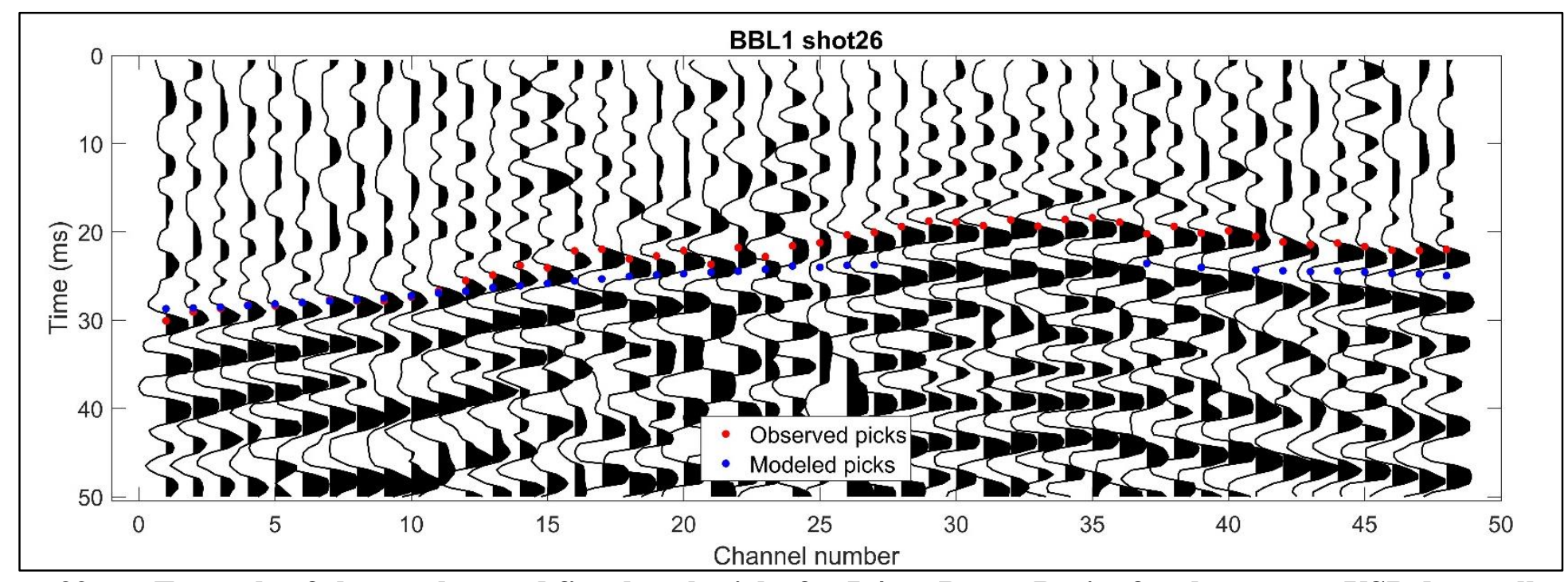

Figure 39: $\quad$ Example of shot-gather and first break picks for L4, at Bogus Basin, for the reverse VSP data collection. 